OSVALDO GOGLIANO SOBRINHO

SERVIÇO DE RESOLUÇÃO E DESCOBERTA

DE INFORMAÇÕES SOBRE OBJETOS

EM SISTEMAS BASEADOS EM RFID

São Paulo

2013 
OSVALDO GOGLIANO SOBRINHO

\section{SERVIÇO DE RESOLUÇÃO E DESCOBERTA \\ DE INFORMAÇÕES SOBRE OBJETOS \\ EM SISTEMAS BASEADOS EM RFID}

Tese apresentada à Escola Politécnica da Universidade de São Paulo para obtenção do título de Doutor em Engenharia

Área de Concentração:

Engenharia de Computação

Orientador: Prof. Livre-Docente

Carlos Eduardo Cugnasca 
Este exemplar foi revisado e corrigido em relação à versão original, sob responsabilidade única do autor e com a anuência de seu orientador.

São Paulo, 10 de outubro de 2013.

Assinatura do autor

Assinatura do orientador

FICHA CATALOGRÁFICA

Gogliano Sobrinho, Osvaldo

Serviço de resolução e descoberta de informações sobre objetos em sistemas baseados em RFID / O. Gogliano Sobrinho. -- versão corr. -- São Paulo, 2013.

$123 \mathrm{p}$.

Tese (Doutorado) - Escola Politécnica da Universidade de São Paulo. Departamento de Engenharia de Computação e Sistemas Digitais.

1. Rastreamento 2. Logística 3. Internet 4. Radiofreqüência I. Universidade de São Paulo. Escola Politécnica. Departamento de Engenharia de Computação e Sistemas Digitais II. t. 


\section{DEDICATÓRIA}

Dedico este trabalho à minha esposa e meu eterno amor, Renata Maria Marè Gogliano, pelo seu constante apoio e incentivo, por sua inabalável confiança em meu trabalho, por todos os momentos roubados de nosso convívio e pela cuidadosa revisão do textos e sugestões precisas que tornaram este trabalho possível. Sem você, nada teria acontecido... 


\section{AGRADECIMENTOS}

Aos meus pais, Dirceu e Juju, que não puderam me acompanhar até o final desta jornada, mas que a tudo observaram de um plano superior.

Ao meu orientador, Prof. Livre-Docente Carlos Eduardo Cugnasca, por seu apoio, sua sapiência e paciência....

Aos Professores do Laboratório de Automação Agrícola da Escola Politécnica da USP, Prof. Titular Antonio Mauro Saraiva, Prof. Dr. Pedro Luis Pizzigatti Corrêa e Prof. Dr. Andre Riyuiti Hirakawa pelo apoio, incentivo e sugestões.

Ao Prof. Dr. Iran José Oliveira da Silva pelo apoio e pelas valiosas sugestões.

À minha sogra, Maria Valentina de Oliveira Marè, pelos momentos de bom humor que sempre temperam as dificuldades.

À empresa Abili Tecnologia da Informação Ltda. pelo suporte material a esta pesquisa e por ser uma constante fonte de desafios.

À Cuca, que a cada minuto de falta, respondeu com horas de carinho e amor.

À Nina, Neve e Terra, que, cada uma, acompanharam esta jornada em momentos e circunstâncias diversas, mas igualmente importantes.

Ao Dr. Ede Oliveira Silva, pelo suporte nos aspectos insanos deste processo.

Ao meu colega do LAA Prof. Leonardo Barreto Campos pelas sugestões.

Aos meus colegas e professores do Laboratório de Automação Agrícola da Escola Politécnica da USP pelo incentivo, apoio e sugestões.

À Elisa. Este trabalho é dedicado também a você... 


\section{EPÍGRAFE}

"Ideas and information are important, but things matter much more."

(Kevin Ashton) 


\section{RESUMO}

Apresenta-se o resultado de uma pesquisa destinada a propor um serviço para a resolução e descoberta de informações sobre objetos. Neste contexto, entendem-se como objetos os itens de uma cadeia produtiva e, como prováveis clientes do serviço proposto, sistemas de informação destinados ao gerenciamento de logística junto às cadeias produtivas e/ou à manutenção de dados sobre a rastreabilidade das cadeias. Encontram-se no mercado diversos sistemas de informação com estas características. A conveniência da troca de informações diretas entre os membros das cadeias produtivas, motiva diversos pesquisadores a propor a criação de padrões de dados. Uma das propostas mais relevantes, apresentada pela entidade internacional GS1, envolve a especificação de uma arquitetura para estes sistemas, bem como um vocabulário de dados padronizado, a Rede EPCglobal ${ }^{\circledR}$. A utilização da tecnologia RFID permite a obtenção automática de dados, quando da passagem dos itens por leitores RFID instalados ao longo da cadeia produtiva. A utilização de um código padronizado, denominado Electronic Product Code ${ }^{\mathrm{TM}}$ (EPC) na gravação das etiquetas RFID é outra vantagem desta tecnologia. Uma das funcionalidades essenciais deste sistema consiste na possibilidade de obtenção de informações relativas a um determinado produto. Estas informações podem se encontrar não somente no produtor do item, mas em todos os membros da cadeia produtiva que tiveram acesso ao item. Esta funcionalidade é o único aspecto da rede EPCglobal ${ }^{\circledR}$ ainda não especificada pelo GS1. Por esta razão, diversos pesquisadores têm-se dedicado à elaboração de propostas. O resultado desta pesquisa é mais uma delas. A solução apresentada baseia-se no uso de redes peer-to-peer (P2P), mais especificamente do protocolo Kademlia, escolhido a partir da comparação entre os vários protocolos propostos na literatura, visando a uma melhor eficácia. A partir de uma simulação efetuada em software especialmente desenvolvido para esta finalidade, apresentam-se os detalhes da sugestão e os resultados obtidos com sua utilização.

Palavras-chave: EPC. EPCglobal ${ }^{\circledR}$. RFID. Internet das coisas. Rastreabilidade. Logística. Redes P2P. Kademlia. 


\begin{abstract}
This is the result of a survey intended to propose a resolution and discovery service of information about objects. In this context, objects are items of a production chain and, likely customers of the proposed service, are information systems intended for logistics management at the productive chains and/or maintenance of data on traceability of supply chains. This scenario fits perfectly to the paradigm of the Internet of Things, where objects of everyday use have active participation on the Internet. The convenience of direct exchange of information between the members and the supply chains motivates many researchers to propose the creation of data standards. One of the most relevant proposals, presented by the international organization GS1, involves the architecture specification for these systems, as well as a standard data vocabulary, the EPCglobal ${ }^{\circledR}$ Network. The use of RFID technology allows obtaining data, during the passage of items by RFID readers installed along the supply chain. The use of a standardized code in the recording of RFID tags, called the Electronic Product Code ${ }^{\mathrm{TM}}$ (EPC), is another advantage of this technology. One of the essential features of this system is the possibility of obtaining information relating to an individual product. This information can be found not only in item producer, but also in all members of the supply chain that had access to the item. This functionality is the only aspect of EPCglobal ${ }^{\circledR}$ not yet specified by GS1. For this reason, several researchers have been working with new suggestions. The solution presented is another proposal based on the use of an implementation of a peer-to-peer (P2P) network, using the Kademlia Protocol, chosen from the comparison between the several protocols proposed in the literature, aiming at a better effectiveness. From a simulation carried out in software specially developed for this purpose, we present the details of the suggestion and the results obtained with its use.
\end{abstract}

Keywords: EPC. EPCglobal ${ }^{\circledR}$. RFID. Internet of things. Traceability. Logistics. P2P networks. Kademlia. 


\section{LISTA DE ILUSTRAÇÕES}

Figura 1 - Modelo de uma Cadeia Produtiva ............................................................ 18

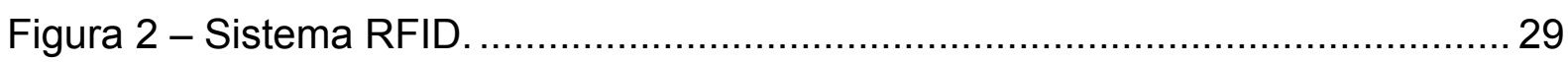

Figura 3 - Etiquetas RFID em diversas apresentações......................................... 30

Figura 4 - Aplicação da tecnologia RFID em ambiente hospitalar........................... 40

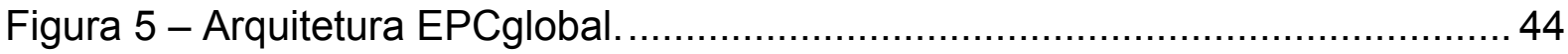

Figura 6 - Conversão de código EPC sgtin96 para sua correspondente URI. ......... 48

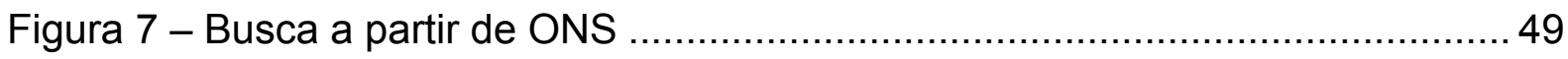

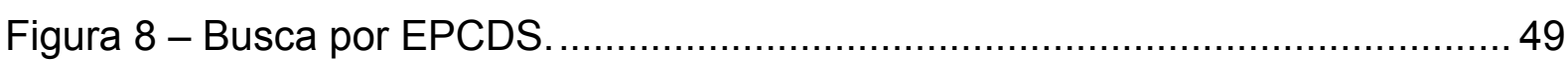

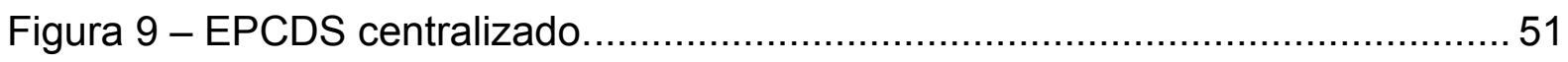

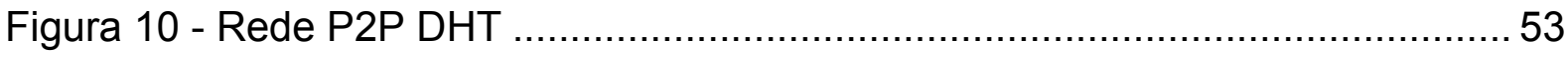

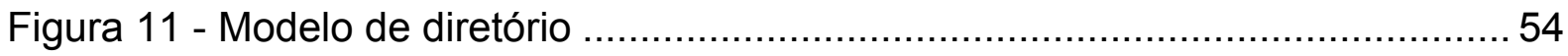

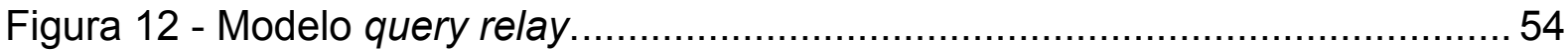

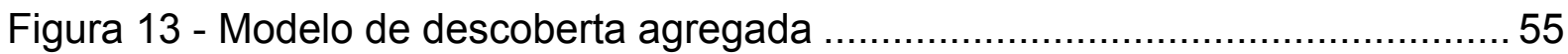

Figura 14 - Utilização da tecnologia RFID ao longo de uma cadeia produtiva......... 57

Figura 15 - Diagrama de Sequência - Exemplo de busca de eventos envolvendo

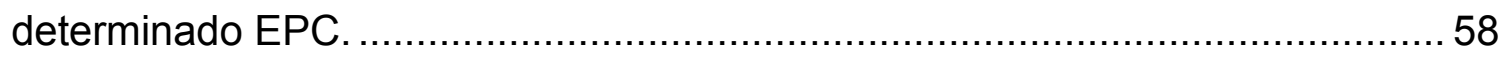

Figura 16 - A rede EPCglobal ao longo da cadeia produtiva. ................................ 59

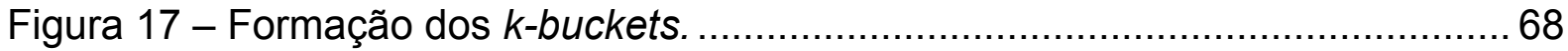

Figura 18 - Representação dos nós de uma rede Kademlia em árvore binária. ...... 69

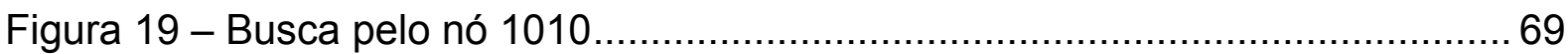

Figura 20 - Cliente de uma EPCIS baseado na rede P2P Kademlia original............ 79

Figura 21 - Exemplo de fluxo para a busca proposta....................................... 80

Figura 22 - Diagrama funcional do emulador de nó P2P Kademlia modificado. ...... 82

Figura 23 - Diagrama funcional do software de simulação...................................... 83

Figura 24 - Tela do computador realizando a simulação........................................ 83 


\section{LISTA DE TABELAS}

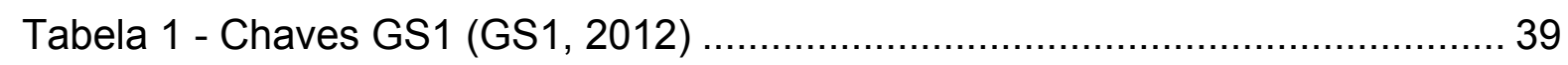

Tabela 2 - Exemplos de eventos em ambiente hospitalar.................................... 40

Tabela 3 - Código SGTIN-96 e SGTIN-198. Alocação de bits por partição ............. 37

Tabela 4 - Esquemas de Codificação e Chaves GS1 ........................................... 38

Tabela 5 - Parâmetros globais do protocolo Kademlia........................................ 70

Tabela 6 - Comparação entre redes P2P DHT ……….................................... 76

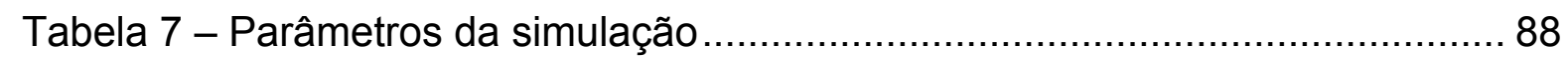

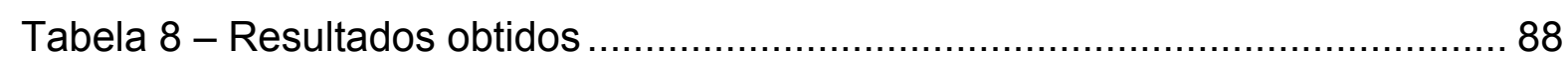




\section{LISTA DE QUADROS}

Quadro 1 - Valores correspondentes aos EPCs gerados durante a simulação e sua distribuição pela rede 100

Quadro 2 - Resultados das buscas efetuadas durante a simulação 113 


\section{LISTA DE ABREVIATURAS E SIGLAS}

\begin{tabular}{ll} 
ALE & Application Level Events \\
DDNoS & Distributed Denial of Service \\
DHT & Distributed Hash Table \\
DNS & Domain Name System \\
DoS & Denial of Service \\
EAN & European Article Number \\
EPC & Electronic Product Code \\
EPCDS & EPC Discovery Service \\
EPCIS & EPC Information System \\
GDTI & Global Document Type Identifier \\
GIAI & Global Individual Asset Identifier \\
GID & General Identifier \\
GLN & Global Location Number \\
GRAI & Global Returnable Asset Identifier \\
GSRN & Global Service Relation Number \\
GTIN & Global Trade Item Number \\
IETF & Internet Engineering Task Force \\
IOT & Internet of Things \\
IP & Internet Protocol \\
LDAP & Lightweight Directory Access Protocol \\
MIT & Massachusetts Institute of Technology \\
NAPTR & Naming Authority Pointer Record \\
ONS & Object Name Services \\
P2P & Peer-to-Peer \\
RFID & Radio Frequency Identification \\
SGTIN & Serialized Global Trade Item Number \\
SISBOV & Serviço Brasileiro de Rastreabilidade da Cadeia Produtiva de \\
& Bovinos e Bubalinos \\
SOA & Service Oriented Architecture \\
SSCC & Serial Shipping Container Code \\
TTL & Time to Live \\
\hline
\end{tabular}




$\begin{array}{ll}\text { UCC } & \text { Uniform Code Council } \\ \text { UDP } & \text { User Datagram Protocol } \\ \text { URI } & \text { Uniform Resource Identifier } \\ \text { URL } & \text { Uniform Resource Locator } \\ \text { UTC } & \text { Coordinated Universal Time } \\ \text { WWW } & \text { World Wide Web } \\ \text { XML } & \text { Extensible Markup Language } \\ \text { XOR } & \text { Exclusive OR }\end{array}$




\section{SUMÁRIO}

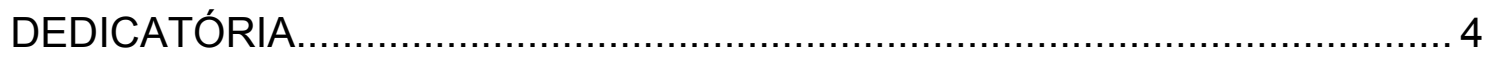

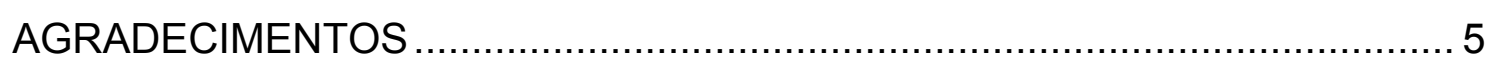

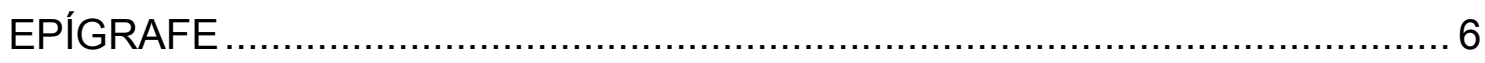

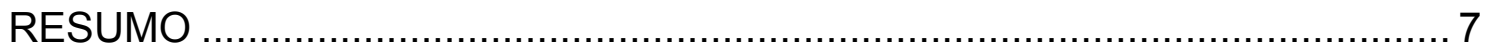

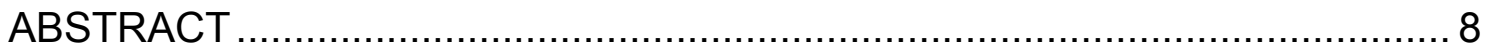

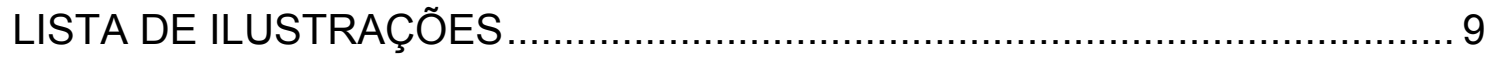

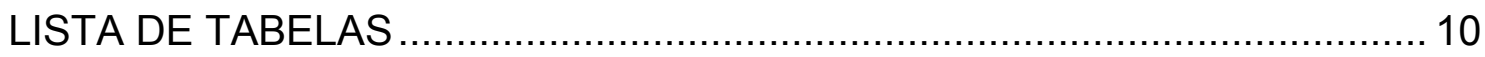

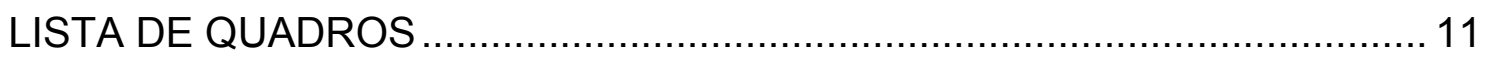

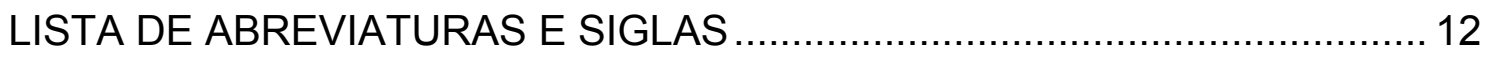

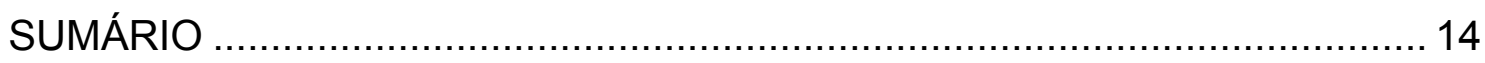

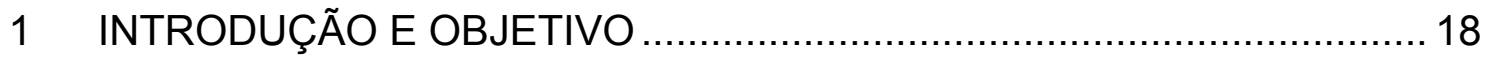

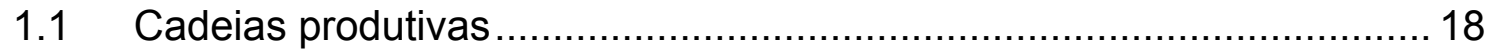

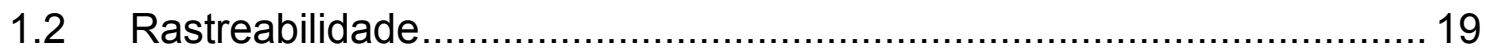

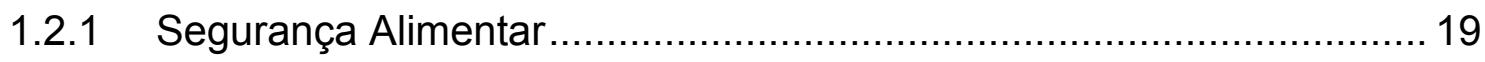

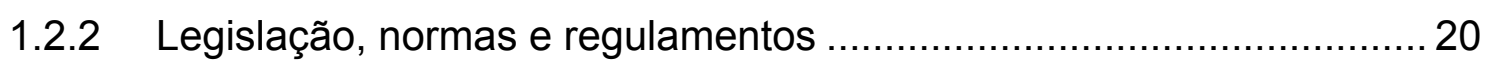

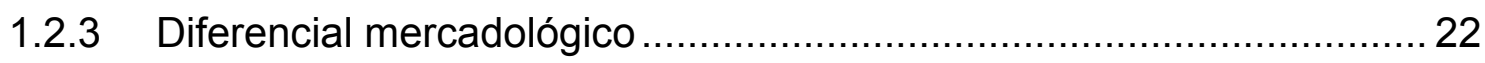

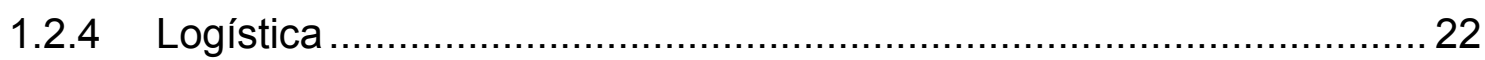

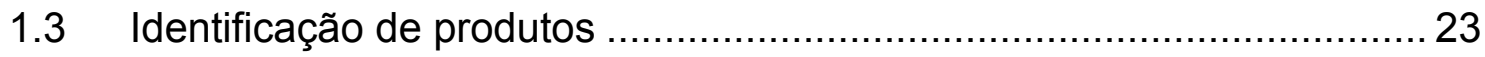

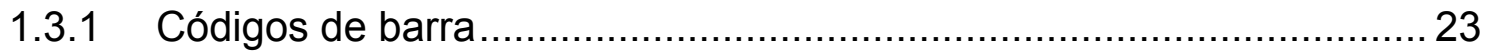

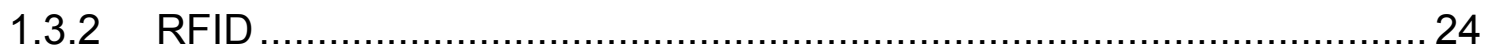

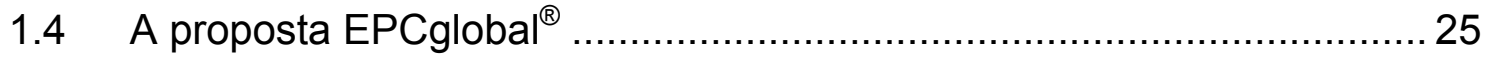

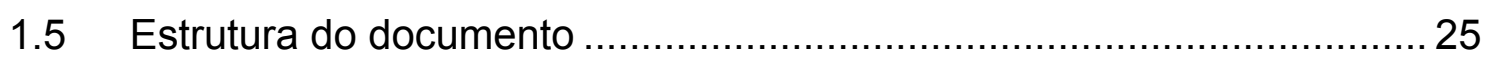

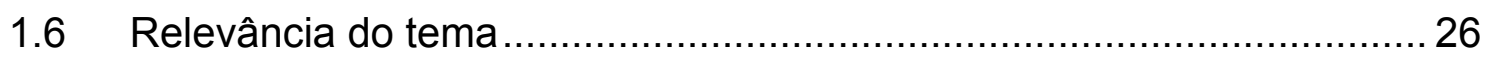

1.7 Definição do problema e hipótese assumida........................................ 27

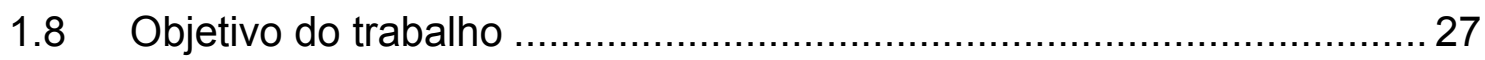

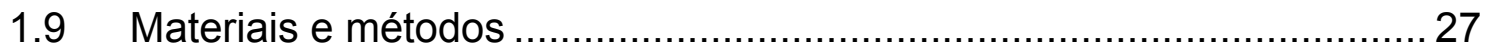

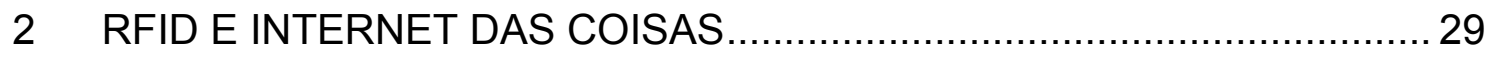

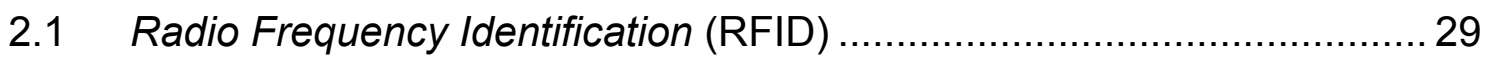

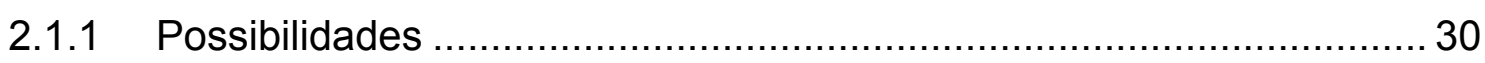

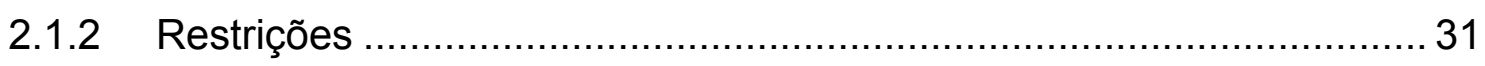

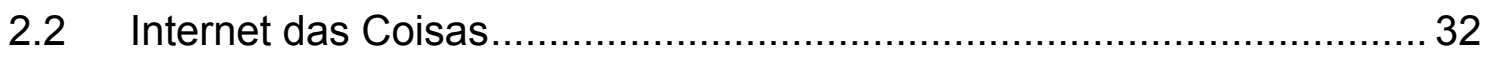




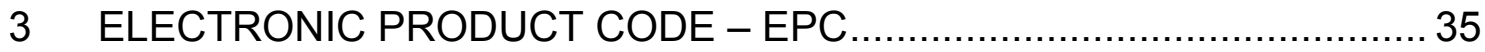

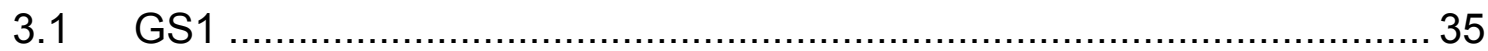

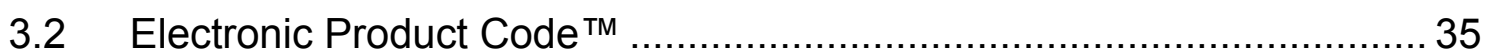

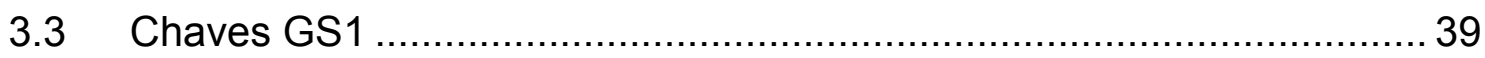

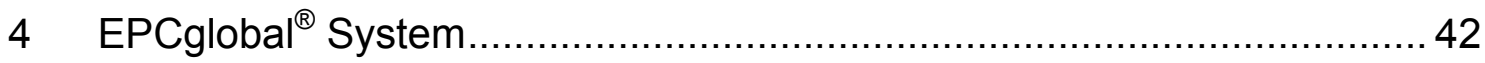

4.1 Aspectos gerais do EPCglobal ................................................... 42

4.1.1 Leitura dos códigos EPC ............................................................... 43

4.1.2 Eventos em Nível de Aplicação (Application Level Events - ALE) ...... 45

4.1.3 EPC Information System (EPCIS) ................................................. 45

4.1.4 Servidores de Nome de Objetos ........................................................ 46

4.1.5 Serviço de Descoberta de EPCs (Electronic Product Code Discovery

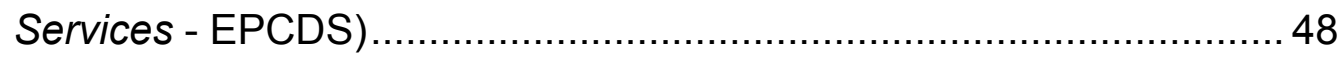

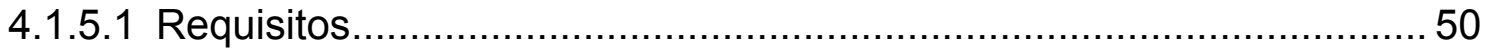

4.1.5.2 Modelos de Arquitetura para EPCDS ............................................. 51

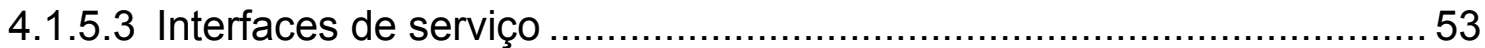

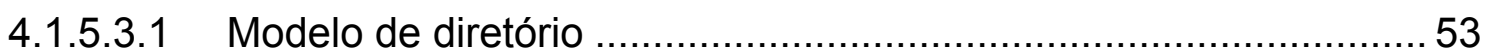

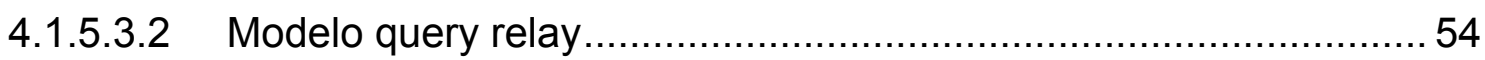

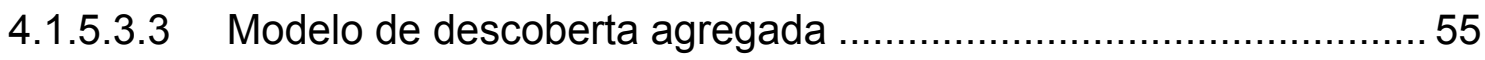

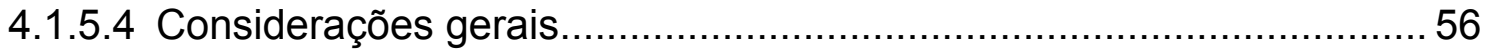

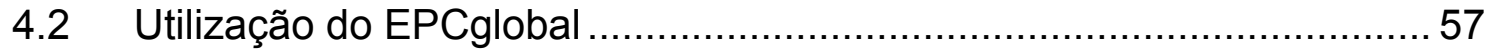

4.3 Perspectivas sobre a utilização futura do EPCglobal ............................. 59

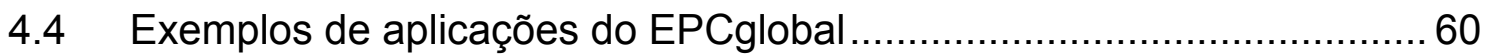

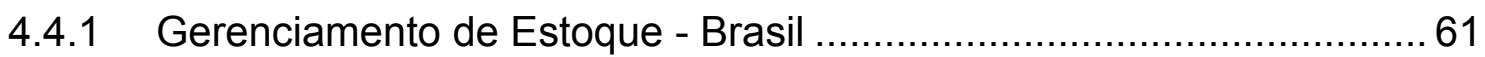

4.4.2 Rastreabilidade da cadeia vinícola - da Itália para Hong Kong........... 61

4.4.3 Rastreabilidade da Carne - Nova Zelândia ....................................... 62

5 REDES PEER-TO-PEER (P2P) - KADEMLIA ....................................63

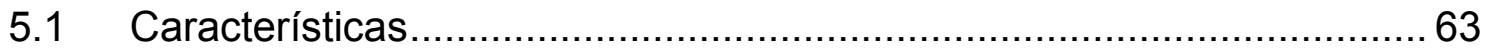

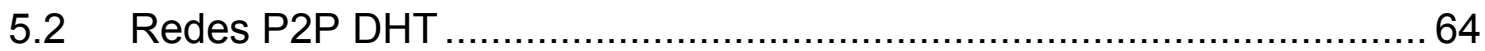

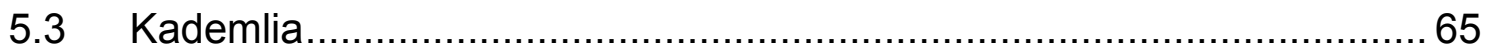

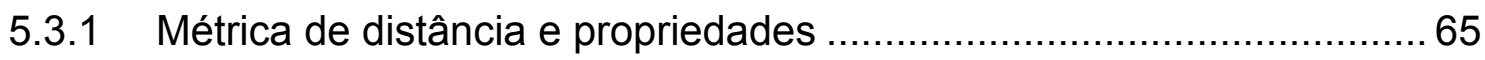

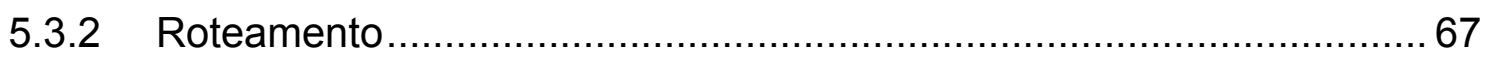

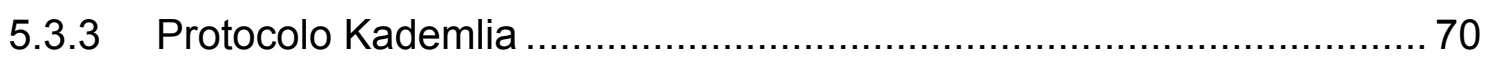

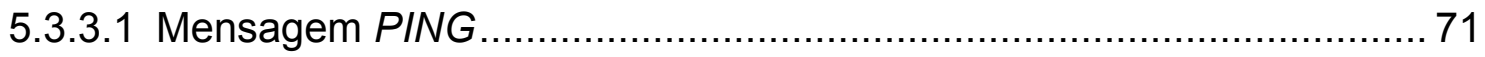

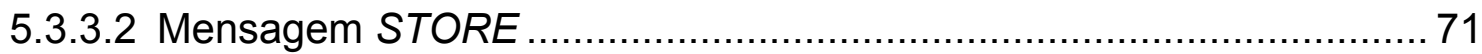




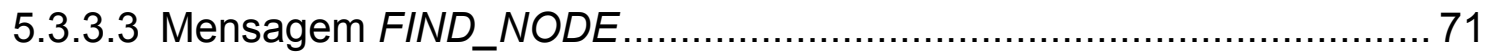

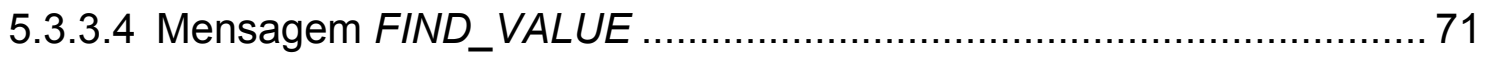

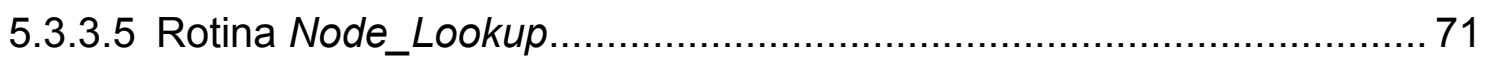

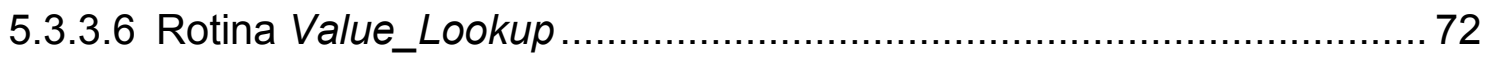

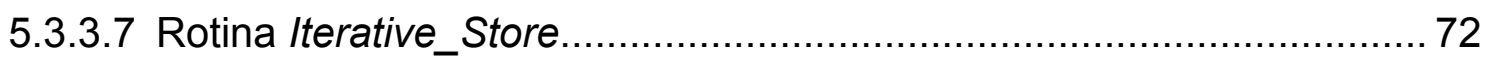

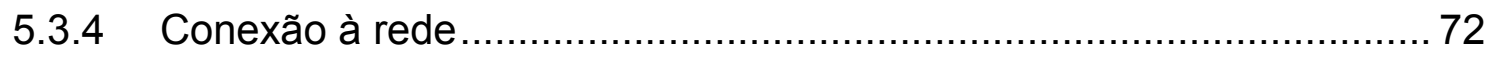

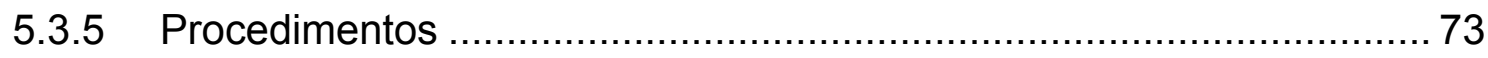

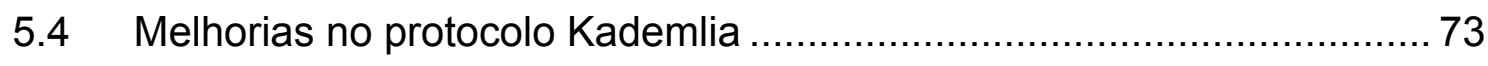

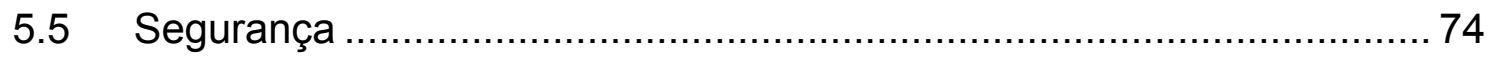

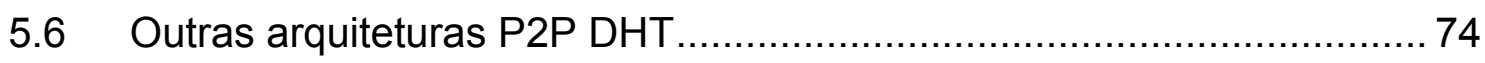

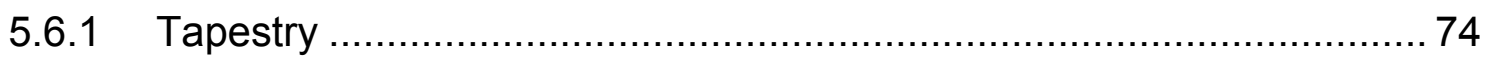

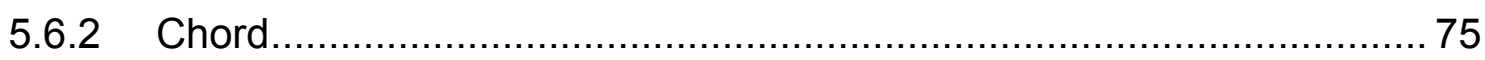

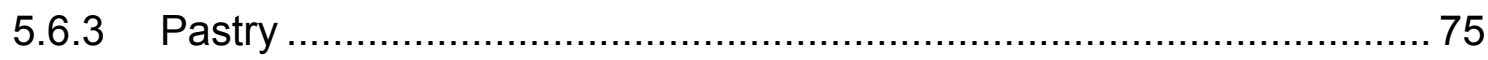

5.7 Comparação entre arquiteturas ......................................................... 76

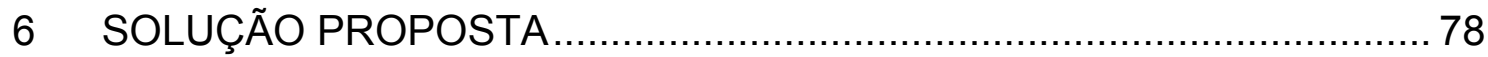

6.1 Problema não resolvido no algoritmo Kademlia .................................. 78

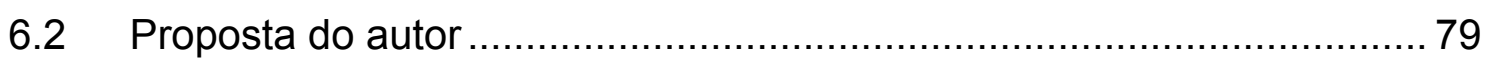

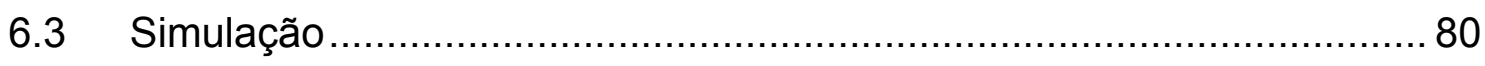

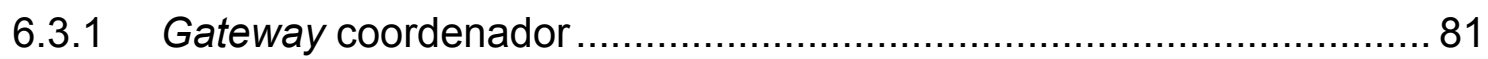

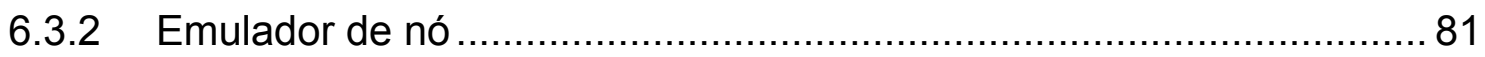

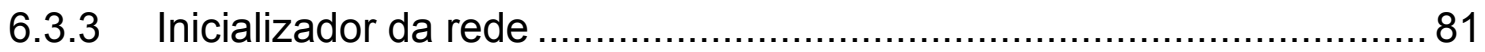

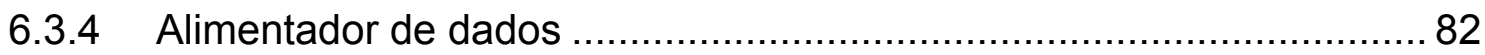

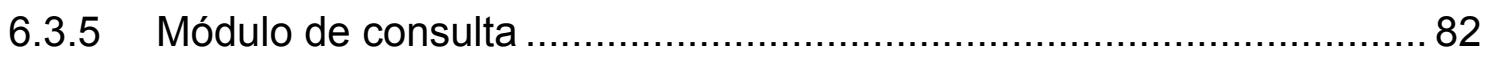

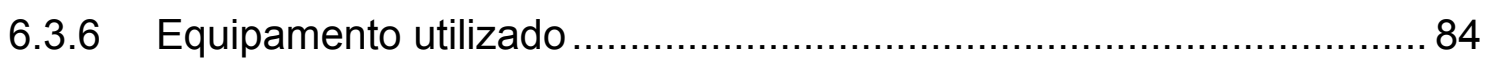

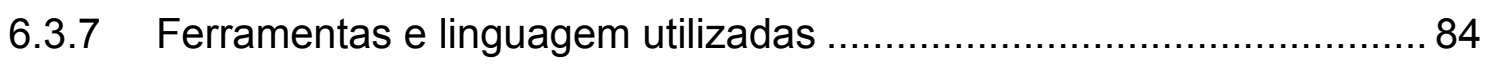

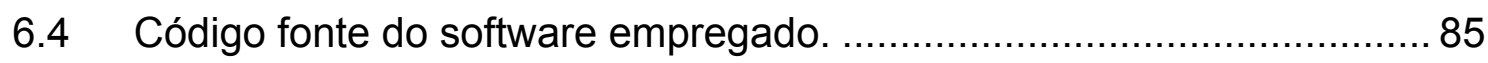

6.5 Pontos não abordados na solução proposta ………………….............. 85

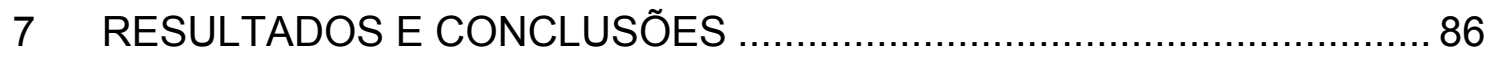

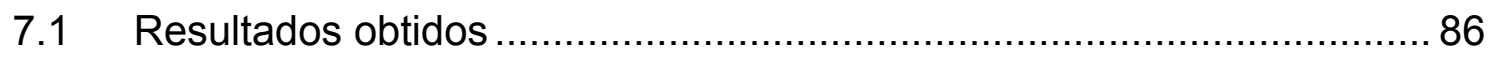

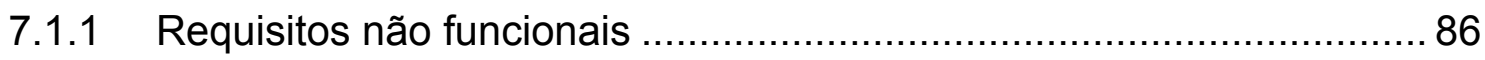

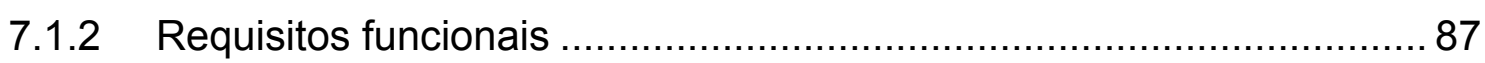

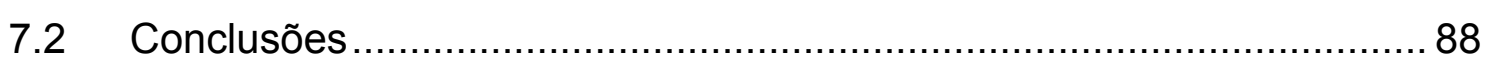

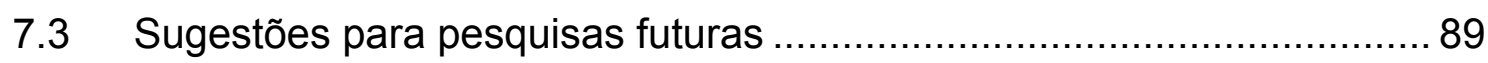

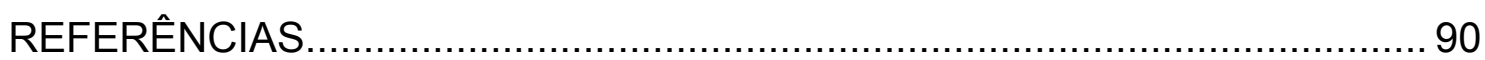


ANEXO A. Valores correspondentes aos EPCs gerados durante a simulação e sua distribuição pela rede ......................................................... 100

ANEXO B. Resultados das buscas efetuadas durante a simulação................ 113 


\section{INTRODUÇÃO E OBJETIVO}

Apresentam-se neste capítulo, os elementos que compõem o cenário de aplicação do serviço proposto bem como, a estrutura deste documento. A seguir, apresentam-se a relevância do tema abordado, a definição do problema identificado a partir da revisão bibliográfica e a hipótese gerada. Finalmente, apresenta-se o objetivo principal da pesquisa.

\subsection{Cadeias produtivas}

Considerando-se a cadeia produtiva como instrumento de visão sistêmica, supõe-se que a produção de bens pode ser representada por meio de um sistema que interconecta os diversos atores, alimentados por fluxos de insumos, capital e informação. Seu objetivo é suprir o mercado consumidor com seus produtos (GOMES DE CASTRO; LIMA; CRISTO, 2002).

Segundo os mesmos autores, este conceito surgiu no setor agrícola, dada a necessidade de considerações sobre o negócio antes e depois da propriedade agrícola. Desta forma, cadeias produtivas agropecuária englobam fornecedores de insumos básicos, as fazendas, agroindústrias e unidades de comercialização atacadista e varejista, chegando ao consumidor final. Acompanham e alimentam esta cadeia fluxos de capital, insumos e informação. Exibe-se na Figura 1, um modelo de cadeia produtiva agrícola.

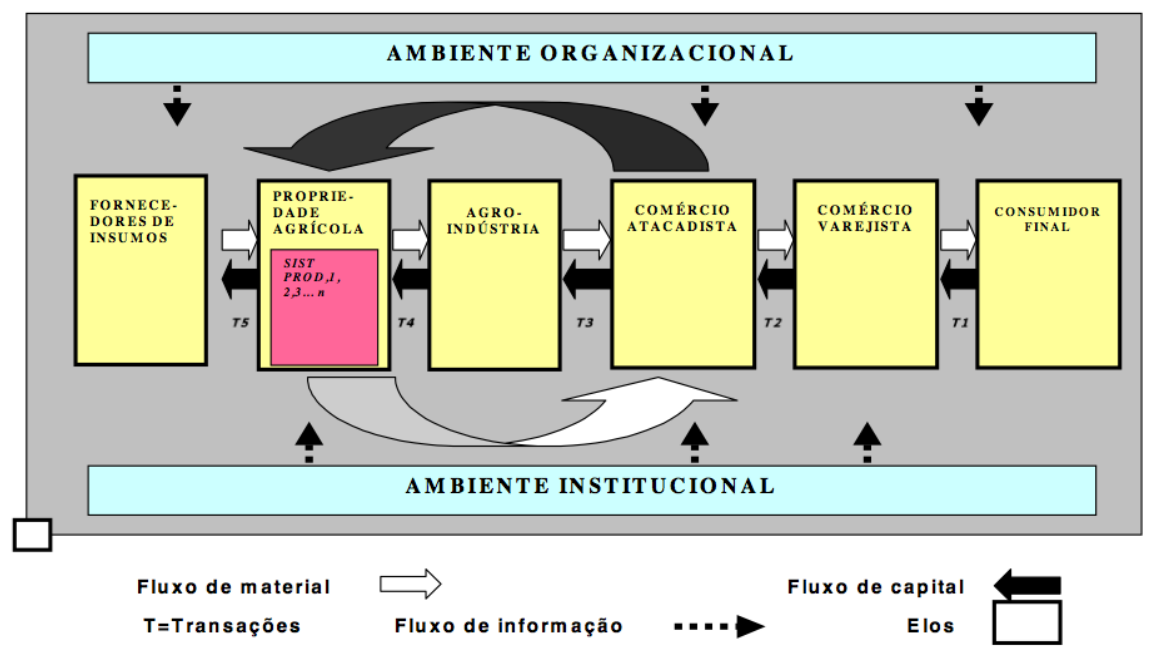

Figura 1 - Modelo de uma Cadeia Produtiva. Fonte: Gomes de Castro et. al. (2002). 


\subsection{Rastreabilidade}

A seguir, apresentam-se considerações sobre aspectos ligados à rastreabilidade nas cadeias produtivas.

Considera-se um cenário onde todos os atores participantes de determinada produtiva utilizem a tecnologia apresentada neste trabalho, o que hoje não ocorre, de um modo geral. Com os potenciais benefícios da adoção desta tecnologia, expostos ao longo deste trabalho, é razoável supor-se que isto possa ocorrer em um intervalo de tempo razoavelmente curto.

\subsubsection{Segurança Alimentar}

A crescente preocupação com a rastreabilidade de produtos alimentícios acentuou-se durante as décadas de 1980 e 1990. Eventos na Europa, como a contaminação do leite e derivados, na Bélgica, por dioxinas (BERNARD et al., 2002) e, em particular, a disseminação da Encefalopatia Espongiforme Bovina (LATOUCHE; RAINELLI; VERMERSCH, 1998), o mal da vaca louca, afetaram duramente o mercado da carne e leite.

Outras questões têm contribuído para o aumento deste interesse (MACHADO, 2000). Os consumidores têm demonstrado interesse crescente na obtenção de informações sobre os alimentos consumidos. São cada vez mais frequentes perguntas como:

- Um produto (ou insumo de alimento industrializado) foi geneticamente modificado?

- Em seu cultivo ou processamento, foram utilizados pesticidas, defensivos agrícolas, fertilizantes, fungicidas, aditivos ou outros produtos químicos?

- Em que condições foram colhidos, transportados, armazenados e processados?

- Existe a presença, no caso de produtos industrializados, de insumos de origem animal, o que os torna vedados a consumidores vegetarianos ou com restrições de ordem religiosa?

- No caso de produtos de origem animal, como estes foram criados? 


\subsubsection{Legislação, normas e regulamentos}

Em 28 de janeiro de 2002 foi promulgado o Regulamento CE) No 178/2002 do Parlamento Europeu e Conselho (2002). Em seu artigo $18^{\circ}$, definiram-se responsabilidades para todos os envolvidos na cadeia produtiva de alimentos ou produtos alimentícios comercializados dentro da ou para a comunidade europeia. A adoção destas medidas tornou-se obrigatória a partir de $1^{\circ}$ de janeiro de 2005.

A norma ABNT ISO 22000 (2006) também trata da rastreabilidade aplicada a organizações produtoras de alimentos, em seu item 7.9:

A organização deve estabelecer e aplicar um sistema de rastreabilidade que permita a identificação de lotes de produtos e sua relação com lotes de matérias-primas, processamento e registros de liberação.

O sistema de rastreabilidade deve ser capaz de identificar o material recebido de fornecedores diretos e a rota inicial de distribuição do produto final.

Os registros de rastreabilidade devem ser mantidos por um período definido para a avaliação do sistema, de modo a permitir o tratamento adequado de produtos potencialmente inseguros $e$ no eventual recolhimento do produto. Os registros devem estar de acordo com os requisitos estatutários e regulamentares e requisitos de clientes e podem, por exemplo, ser baseados na identificação do lote do produto final.

O mesmo Regulamento define rastreabilidade como:

a capacidade de detectar a origem e de seguir o rasto de um género alimentício, de um alimento para animais, de um animal produtor de géneros alimentícios ou de uma substância, destinados a ser incorporados em géneros alimentícios ou em alimentos para animais, ou com probabilidades de o ser, ao longo de todas as fases da produção, transformação e distribuição.

Além da questão comercial, é importante ressaltar que esta exigência legal decorre de uma justa preocupação com a questão da segurança alimentar.

A rastreabilidade das cadeias atende a requisitos de outras áreas, como logística e metrologia.

Segundo a norma ISO ABNT 9000:2005 (2005), rastreabilidade é a "capacidade de recuperar o histórico, a aplicação ou a localização daquilo que está sendo considerado". Em sua Nota 1, apresenta-se claramente a preocupação com questões ligadas à logística:

Ao considerar um produto, a rastreabilidade pode estar relacionada com: a origem dos materiais e as peças; o histórico do processamento; e a distribuição e localização do produto depois da entrega. 
O Bureau Internacional de Pesos e Medidas (2008) trata a questão de maneira adequada a seu domínio, trazendo a definição de rastreabilidade metrológica como sendo:

a propriedade de um resultado de medição em que o resultado pode ser relacionado com uma referência por meio de uma cadeia ininterrupta e documentada de calibrações, cada qual contribuindo para a incerteza da medida.

No âmbito da América do Sul, não se menciona o termo rastreabilidade na Portaria Mercosul GMC, n 80/96 (1996), em seu anexo "Regulamento Técnico sobre as condições Higiênico-Sanitárias e de Boas Práticas de Fabricação para Estabelecimentos Elaboradores / Industrializadores de Alimentos", referendada no Brasil pela Portaria 368 de 1997 (1997) do Ministério da Agricultura, Pecuária e Abastecimento.

A iniciativa brasileira mais conhecida na área, o antigo Serviço Brasileiro de Rastreabilidade da Cadeia Produtiva de Bovinos e Bubalinos (SISBOV), atualmente denominado Sistema de Identificação Individual de Bovinos e Búfalos, tem como objetivo

registrar e identificar o rebanho bovino e bubalino do território nacional possibilitando o rastreamento do animal desde o nascimento até o abate, disponibilizando relatórios de apoio à tomada de decisão quanto à qualidade do rebanho nacional e importado.

Em Janeiro de 2013 sua revisão foi submetida à consulta pública, com o objetivo de adequá-lo à nova legislação instaurada pela Lei 12.097/2009 (2009). Esta lei refere-se especificamente à rastreabilidade das cadeias produtivas das carnes de bovinos e de búfalos. São dignos de destaque os seguintes aspectos:

- Os produtores têm um prazo de dois anos para a adoção das medidas apresentadas (Art. $3^{\circ}$, parágrafo único);

- Os dados de rastreabilidade deverão ser mantidos por um período de 5 anos $\left(\right.$ Art $\left.^{\circ} .3^{\circ}\right)$;

- Para identificação do produtor, o Art. $4^{\circ}$ determina o uso de "marca a fogo, tatuagem ou outra forma permanente e auditável de marcação dos animais";

- O Art. $5^{\circ}$, parágrafo 3 , determina que "será dispensado o uso de marca a fogo, tatuagem ou outra forma de marcação permanente quando for utilizado sistema de identificação dos animais por dispositivo 
eletrônico"; esta abertura permite a utilização de outras tecnologias como a RFID;

- Finalmente, a Lei especifica que a manutenção dos dados de rastreabilidade deverão ser feitas por meio eletrônico (Art. $4^{\circ}$, Item $\mathrm{V}$, parágrafo 2).

\subsubsection{Diferencial mercadológico}

Especialmente importantes para a indústria alimentícia são as questões do valor agregado a seus produtos aos olhos do público consumidor e dos subsídios fornecidos para a fundamentação de solicitações de indicações geográficas (indicação de procedência e denominação de origem), concedidas pelo Instituto Nacional da Propriedade Industrial (INPI) (2000).

A solicitação destas concessões ao INPI, pode ser significativamente fortalecida quando uma política de rastreabilidade é adotada, seguida da coleta e fornecimento de dados adequados. No Brasil, considera-se estratégico o valor agregado aos produtos por estas indicações, principalmente com a proximidade dos grandes eventos previstos a partir de 2014 ..

Em Abril de 2012, foi lançada a terceira edição do Catálogo de Indicações Geográficas Brasileiras (GIESBRECHT, 2011) que apresenta 14 indicações geográficas no país até 2011.

No mercado internacional, o efeito destas indicações foi objeto de estudo de Dimara e Skuras (2003).

\subsubsection{Logística}

Uma das grandes preocupações da logística é a análise de tempos ao longo das cadeias produtivas. Conceitos como operação just-in-time, compressão do ciclo de tempo, redução de custos associados ao tempo são preocupações sempre presentes em análises de logística (DAUGHERTY; PITTMAN, 1995).

As dificuldades na gestão da cadeia produtiva decorrem das inúmeras instalações e organizações que a compõem, com objetivos distintos e, muitas vezes, opostos, da exigência do emparelhamento de suprimento e demanda, e da 
imposição de novos problemas criados ao longo do tempo, que não apresentam histórico conhecido para tomada de decisões e desenvolvimento de soluções (SIMCHI-LEVI; KAMINSKY; SIMCHI-LEVI, 2003).

Um dos fatores que impactam a produtividade da cadeia produtiva é o tempo de permanência de um item nos vários estágios. As unidades de negócio envolvidas na cadeia produtiva devem trabalhar de forma sincronizada, mantendo contínuos a velocidade e o fluxo de movimentação do item, minimizando os tempos de permanência (BOWERSOX; CLOSS; COOPER, 2006).

A avaliação do tempo de permanência pode ser problemática por depender de registros de movimentação, usualmente, de um grande número de itens. A coleta automática destes tempos, por meio de sistemas de informação pode contribuir significativamente para esta análise e, consequentemente para a gestão da logística.

No Capítulo 4 deste trabalho, apresenta-se a arquitetura de sistemas de informação que podem levar à obtenção automática destes dados.

\subsection{Identificação de produtos}

As exigências do gerenciamento das cadeias produtivas impõem a capacidade de identificar produtos e lotes de maneira unívoca.

Sob o ponto de vista da rastreabilidade, o Regulamento (CE) No178/2002 (2002) especifica em seu Artigo 18 : "Todos os alimentos colocados no mercado devem ser adequadamente etiquetados e identificados, com o objetivo de facilitar a sua rastreabilidade".

A Norma NBR ISO 22000 traz em seu item 7.9: "O sistema de rastreabilidade deve ser capaz de identificar o material recebido de fornecedores diretos e a rota inicial de distribuição do produto final".

\subsubsection{Códigos de barra}

Código de barras é uma representação gráfica, linear ou bidimensional, que corresponde a um valor ou conjunto de dados numéricos ou alfanuméricos.

A história dos códigos de barra, tais como conhecidos hoje, iniciou-se em 1948 por meio de Bernard Silver e Normal Joseph Woodland. A partir da idéia de 
utilizar o código Morse, estendendo pontos e traços em uma dimensão, a primeira proposta utilizava uma tinta especial que brilhava sob luz ultravioleta. A tecnologia tornou-se madura na década de 1960 e sua utilização comercial começou na década seguinte. Mais exatamente, em 26 de Junho de 1974 o primeiro produto comercializado com um código de barras foi uma caixa de chicletes (que hoje faz parte do acervo do Institituto Smithsoniano em Washington D.C.) em um supermercado na cidade de Troy, Ohio (SEIDEMAN, 2011).

Os dados destinam-se à identificação de produtos, pessoas, unidades logísticas, dentre outros, e são capturados a partir de scanners ou coletores de códigos de barras.

Ao longo das últimas décadas, o surgimento de inúmeros padrões para impressão e leitura destes códigos (GS1 BRASIL, 2012) . A popularização desta tecnologia permite a automação significativa no manuseio de itens manufaturados. Por outro lado, a existência de padrões distintos leva à necessidade de múltiplos tipos de leitores e adaptação de softwares.

\subsubsection{RFID}

Radio Frequency Identification (RFID) é um processo de identificação de objetos ou pessoas, baseado em aproximação eletromagnética. Envolve a aplicação de etiquetas (tags) nos objetos a serem identificados, e leitores para a obtenção das informações ali registradas.

Em relação aos códigos de barras, as etiquetas RFID apresentam inúmeras vantagens como capacidade para armazenamento de maior densidade de informação, habilidade para comunicação bidirecional (tags ativas e passivas), e comunicação sem a necessidade de aproximação ótica (WHITE et al., 2007).

A partir da década de 1990, esta tecnologia vem sendo amplamente aplicada em diversos domínios, levantando questões sobre normas, segurança, privacidade e ética. Possui importante papel como suporte à logística em cadeias produtivas, justamente pela capacidade de identificar e rastrear a informação em todas as suas etapas (Zhu et al., 2012). 


\subsection{A proposta EPCglobal ${ }^{\circledR}$}

A existência de uma multiplicidade de padrões para sistemas de codificação, conforme exposto no item 1.3.1 dificulta a integração de informações entre parceiros de uma cadeia produtiva.

O GS1, entidade internacional sem fins lucrativos com membros afiliados em mais de 100 países dedica-se ao desenvolvimento e implementação de padrões e soluções que em sua visão, incrementem a eficiência e visibilidade das cadeias de suprimentos e demanda ao redor do mundo, e entre setores" (GS1, 2010b). Uma de suas iniciativas foi a criação do EPCglobal ${ }^{\circledR}$ System (daqui por diante denominado EPCglobal), cujo propósito é "dar suporte à adoção universal do Electronic Product Code (EPC) e de padrões correlatos que permitem a visibilidade de informações ao longo das cadeias produtivas, de maneira pronta e efetiva em termos de custo" (GS1, 2008b).

Estes padrões permitem não apenas a globalização de uso dos códigos EPC, mas também a troca de informações entre parceiros de negócios, além de viabilizar a criação de um mercado de soluções em sistemas de informação, já que os padrões definem apenas interfaces e vocabulários de dados, deixando suas possíveis implementações a cargo dos usuários.

\subsection{Estrutura do documento}

Este documento segue, em sua apresentação, a ordem em que a pesquisa foi realizada.

No Capítulo 2 apresentam-se com maior profundidade a tecnologia RFID e o conceito de Internet das Coisas.

No Capítulo 3 segue-se a mesma linha do anterior, mas referindo-se ao EPC.

No Capítulo 4 apresentam-se os aspectos do EPCglobal, detalhando-se em sua arquitetura os serviços Object name services (ONS) e EPC Discovery Service (EPCDS). A seguir, descreve-se e exemplifica-se a sua utilização.

No Capítulo 5 descreve-se a rede Peer-to-peer (P2P), base da arquitetura proposta, e o software Kademlia utilizado na pesquisa.

No Capítulo 6 apresentam-se as etapas do método de pesquisa adotado, que 
possibilitaram o desenvolvimento do serviço proposto.

No Capítulo 7 apresentam-se os resultados alcançados e as conclusões. Ao final, sugestões de pesquisas futuras correlatas.

No Anexo A apresentam-se os valores correspondentes aos EPCs gerados durante a simulação e sua distribuição pela rede

No Anexo B apresentam-se os resultados das buscas efetuadas durante a simulação.

\subsection{Relevância do tema}

A importância do tema apresentado reside não apenas no fato da proposta ser uma contribuição ao único elemento da rede EPCglobal, ainda não especificado pelo GS1. A relevância intrínseca da rede EPCglobal agrega valor à pesquisa em questão.

A possibilidade de obtenção, de maneira automatizada e em grandes volumes, de informações relevantes para a rastreabilidade e logística das cadeias produtivas, aliada às interfaces previstas na rede para interação com Sistemas de Informação diversos, conferem à rede EPCglobal potencial significativo para a resolução das dificuldades hoje encontradas para gerenciamento e controle das cadeias produtivas.

Em particular, o uso de serviços EPCDS é vital para o sucesso da rede EPCglobal, pois somente ele torna possível a localização de informações em nível de produto (considerando-se produtor, modelo e número de série). Como sua definição encontra-se aberta pelo GS1, qualquer discussão e contribuição de qualidade à sua futura implementação é bem vinda.

A rede EPCglobal tem sido internacionalmente pesquisada em diversas cadeias produtivas, com vários exemplos de implementações (THAKUR et al., 2011) (THIESSE et al., 2009), inclusive no Brasil, a exemplo do projeto piloto em 2005, envolvendo as empresas Companhia Brasileira de Distribuição do Grupo Pão de Açúcar, Accenture, Procter \& Gamble e Gilette (ACCENTURE, 2005) e a implantação em supermercado no Brasil relatada por Dalfovo e Hostins (2010).

Resta salientar que o EPCglobal constitui-se em um dos primeiros casos de arquitetura de sistemas que contempla um número considerável de características 
propostas no que hoje se denomina a "Internet das Coisas" (Internet of Things IoT).

\subsection{Definição do problema e hipótese assumida}

A partir da revisão bibliográfica realizada, identificou-se o seguinte problema: a especificação da arquitetura EPCglobal, não apresenta uma solução para um de seus mais importantes módulos, aquele que permite a busca de informações sobre objetos ao longo das cadeias produtivas a partir de seu código EPC, denominado EPC Discovery Service (EPCDS). A definição de uma proposta adequada para este serviço é um problema a ser enfrentado pela comunidade científica.

A hipótese assumida pelo autor foi a viabilidade da especificação para este serviço por meio da utilização de redes do tipo peer-to-peer (P2P). Nesta hipótese, têm-se como variáveis independentes o algoritmo básico da rede P2P bem como as contribuições propostas. Como variáveis dependentes têm-se o desempenho (velocidade de retorno das informações) e eficácia (capacidade de localizar todas as informações disponíveis) da solução, passíveis de medição por simulação da solução proposta.

\subsection{Objetivo do trabalho}

O objetivo deste trabalho é apresentar uma proposta de serviço de resolução e descoberta de informações sobre objetos em redes EPCglobal (EPCDS), a partir da análise de alternativas para a arquitetura de redes $\mathrm{P} 2 \mathrm{P}$, com a escolha de uma arquitetura básica a ser utilizada, e com a devida contribuição do autor para que se chegue às características de desempenho e eficácia aceitáveis, conforme tratamento mais adiante neste documento.

\subsection{Materiais e métodos}

A condução da pesquisa passou pelas seguintes fases:

- Revisão bibliográfica 
- Estudo aprofundado da proposta EPCglobal ${ }^{\circledR}$

- Estudo sobre redes peer to peer

- Estudo sobre protocolos para redes peer to peer

- Elaboração da proposta

- Desenvolvimento do software de simulação

- Realização da simulação

- Avaliação dos resultados. 


\section{RFID E INTERNET DAS COISAS}

\subsection{Radio Frequency Identification (RFID)}

O uso de sistemas baseados na tecnologia de identificação por radiofrequência (RFID), embora proposto há várias décadas (LANDT, 2005), intensificou-se somente nos últimos anos, devido aos avanços da tecnologia que permitiram uma diminuição significativa de custos e a produção de dispositivos de menor tamanho.

Simplificadamente, um sistema envolvendo o uso da tecnologia RFID é constituído por etiquetas (tags) RFID, leitores e sistemas de captura de dados (Figura 2).

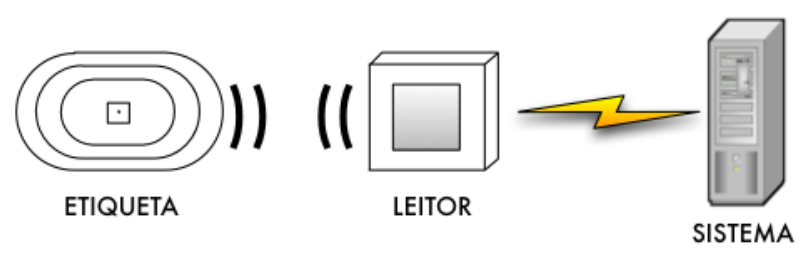

Figura 2 - Sistema RFID.

Dividem-se as etiquetas RFID em dois grandes grupos: ativas ou passivas. Nas etiquetas passivas (sem alimentação própria), um campo magnético proveniente do leitor induz na antena um diferencial de potencial que alimenta o circuito de transmissão que irradia um código pré-gravado (acoplamento indutivo). As etiquetas ativas dispõem de alimentação própria e transmitem seu código ao detectar o campo eletromagnético do leitor (acoplamento por propagação) (LANDT, 2005; ROBERTS, 2006; ZHU; MUKHOPADHYAY; KURATA, 2012).

Outras classificações envolvem o tamanho do pacote de dados pré-gravado, a possibilidade de receber novos dados após sua fabricação, a faixa de radiofrequência utilizada na transmissão ou o seu protocolo (GS1, 2008a). Uma discussão detalhada sobre as diferenças em cada categoria foge ao escopo deste trabalho, já que um maior entendimento sobre esta classificação não é necessário para a análise deste texto.

Fisicamente, as etiquetas podem se apresentar sob diversas formas como cartões, selos adesivos, dentre outras (Figura 3 ). 


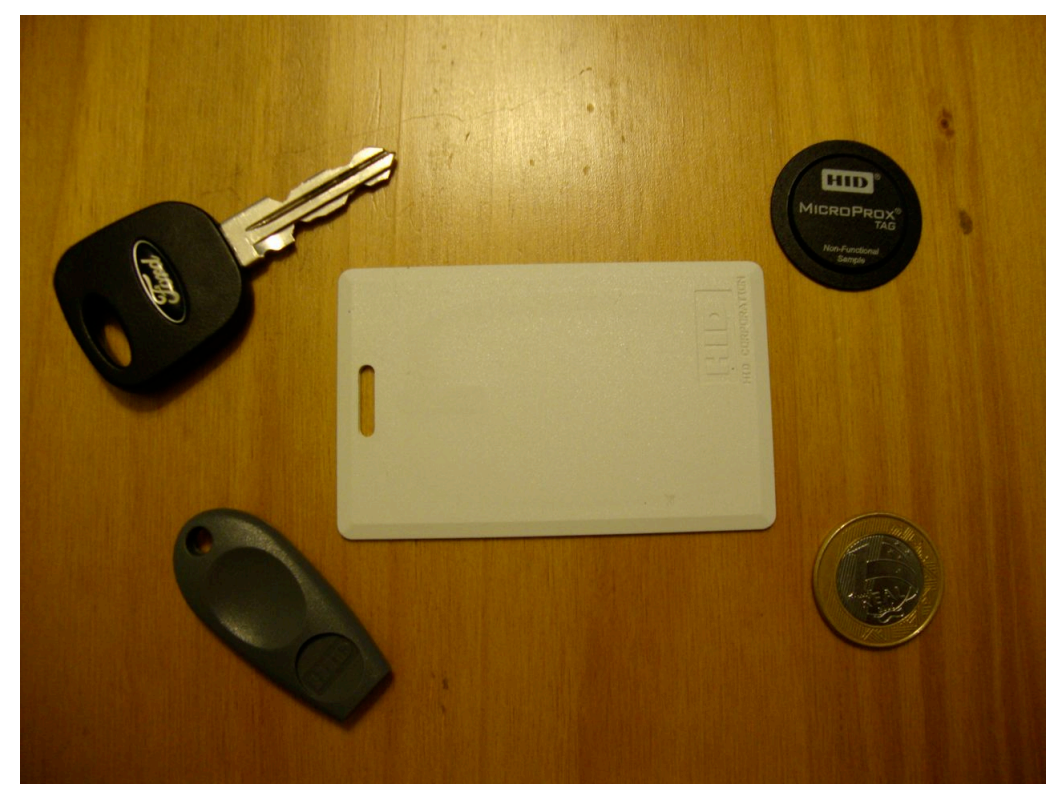

Figura 3 - Etiquetas RFID em diversas apresentações.

\subsubsection{Possibilidades}

Segundo Roberts (2006), o uso de sistemas RFID apresenta diversas características desejáveis:

- Leitura sem contato físico ou visual;

- Possibilidade de leitura em ambientes adversos;

- Possibilidade de leitura simultânea de um grande número de etiquetas, dado o curto tempo de resposta;

- Possibilidade de acoplamento de sensores que forneçam informações sobre o estado do produto ao qual à etiqueta está aplicada.

Para quantificar o crescimento deste mercado, apresentam-se os dados a seguir: a previsão de vendas de etiquetas RFID era de 3,98 bilhões de unidades em 2012, contra uma venda de 2,93 bilhões em 2011 (IDTECHEX, 2012). Segundo a mesma fonte, no início de 2012, a venda cumulativa de etiquetas ao longo dos últimos 65 anos foi de 15,1 bilhões de unidades, sendo que $20 \%$ deste número correspondem a vendas efetuadas somente em 2011.

Sob o ponto de vista desta pesquisa, a capacidade de alta velocidade de leitura bem como a possibilidade de inserção de códigos individuais nas etiquetas, tornam esta tecnologia adequada para utilização em cadeias produtivas, seja do 
ponto de vista da logística como da rastreabilidade.

Em logística, os eventos de passagem de itens por leitores RFID distribuídos ao longo da cadeia produtiva, permitem seu acompanhamento em todo o ciclo, inclusive com o cálculo de tempo de permanência entre os vários estágios.

O código inserido na etiqueta RFID permite a identificação do produtor, da categoria do item e até de um número de série único. Esta capacidade é essencial para a rastreabilidade, na qual a possibilidade de identificação unívoca de cada item faz-se necessária.

\subsubsection{Restrições}

Além das restrições físicas, tais como, impossibilidade de leitura em determinadas situações (por exemplo, etiquetas RFID inseridas em invólucros metálicos que atenuam o sinal de radiofrequência), a introdução de novas tecnologias, a despeito de quaisquer vantagens obtidas, usualmente encontra resistências de toda ordem.

Uma das utilizações que pode trazer grande benefício ao consumidor, e que é citada como exemplo de vantagem em inúmeros trabalhos (DALFOVO; HOSTINS, 2010) (WU et al., 2011), é no comércio varejista, o que permite grande agilidade no processo de fechamento da conta: em um supermercado é possível capturar todos os códigos de produtos colocados em um carrinho, sem a necessidade de retirá-los, tornando o cálculo do valor a ser pago quase que instantâneo. Um recente estudo de Trocchia e Ainscough (2012) sobre o comportamento de consumidores norteamericanos quanto ao uso de sistemas RFID em ambientes comerciais de varejo mostra alguns resultados curiosos:

- Consumidores não querem ser "rastreados" além dos limites da loja, independentemente de qualquer incentivo oferecido para tal;

- Compensação financeira não motiva os consumidores a participarem em programas RFID, a não ser que já estejam pré-dispostos a fazê-lo;

- Um caixa "ultra-rápido" não é capaz de induzir os consumidores a utilizá-lo, a não ser que já estejam pré-dispostos a fazê-lo;

- Homens tem maior probabilidade de achar programas RFID interessantes do que as mulheres; 
- A resistência a participar em soluções RFID cresce com a idade.

\subsection{Internet das Coisas}

O termo Internet das Coisas (Internet of Things - loT) designa um novo paradigma que trata da possibilidade de integração ativa e direta à Internet de objetos do uso cotidiano. Para muitos este conceito é altamente abstrato e de difícil compreensão. Dúvidas sobre o por que desta integração, como ela seria possível e qual sua utilidade são colocações frequentes. Na questão do por que, convém citar o trabalho de Ashton (2009), um dos pesquisadores pioneiros nesta área e, possivelmente, o criador do termo Internet das Coisas:

Hoje, computadores e, portanto, a Internet, são quase que inteiramente dependentes de seres humanos para informação. Praticamente todos os quase 50 petabytes (um petabyte $=1024$ terabytes) de dados disponíveis na Internet foram capturados em primeiro lugar por seres humanos, por digitação, pelo aperto em uma tecla de gravação, pela tomada de uma fotografia digital ou o escaneamento de código de barras. Os diagramas convencionais da Internet incluem servidores, roteadores e outros equipamentos, mas deixam de lado os mais importantes e numerosos roteadores: as pessoas. O problema é que pessoas apresentam limites para tempo, atenção e exatidão, portanto não são bons executores do papel de capturar dados sobre objetos do mundo real ${ }^{1}$.

Na visão de Ashton, o fato da tecnologia da informação ser tão baseada em dados coletados por pessoas, traz como consequência o fato de que os computadores e a Internet trazem mais informações sobre ideias do que sobre coisas. Para quem julga isto desejável, o autor contesta:

Somos físicos e nosso meio ambiente também o é. Nossa economia, sociedade e sobrevivência não são baseados em ideias ou informação, mas sim em coisas. Não se comem bits, nem se pode usá-los como combustível para aquecimento ou em tanques de combustível. Ideias e informação são importantes, mas coisas são muito mais.

Finalmente, apresenta sua visão do que seria uma situação ideal:

Se tivéssemos computadores que conhecessem tudo sobre as coisas, usando dados por eles coletados, sem qualquer ajuda nossa, seríamos capazes de rastrear e contar todas as coisas, e reduzir grandemente 0

\footnotetext{
${ }^{1}$ Tradução nossa
} 
desperdício, perdas e custos. Saberíamos quando as coisas precisassem ser substituídas, reparadas e se estão ou não dentro da validade.

Nem todos concordam com este pensamento. Uma rápida busca na Internet revela a ação de membros de diversas comunidades, que expressam abertamente suas objeções (CASPIAN, 2012a; CASPIAN, 2012b; SPYCHIPS, 2012). Em sua grande maioria, estas restrições estão ligadas aos conceitos de individualidade, privacidade e segurança e são reflexos das resistências já mencionadas à tecnologia RFID.

O potencial de transformação associado ao conceito de loT é tão grande que, em 2008, o Conselho Nacional de Inteligência dos Estados Unidos da América classificou a Internet das Coisas com uma das seis "tecnologias civis disruptivas" com capacidade de causar "impactos potenciais nos interesses dos Estados Unidos até 2025" (NATIONAL INTELLIGENCE COUNCIL, 2008).

Sem tomar partido na discussão filosófica que envolve esta questão, vale ressaltar que, para o usuário, a presença ubíqua de objetos "inteligentes" capazes de consultar, monitorar, informar e/ou atuar, pode trazer benefícios tanto no âmbito doméstico como no trabalho. Na área empresarial, além do potencial de criação de novas funcionalidades para produtos existentes, as vantagens decorrentes da automação de atividades ligadas à rastreabilidade e à logística das cadeias produtivas são marcantes.

Por outro lado, questões envolvendo segurança e privacidade demandam solução. Na visão de Atzori et al. (2010) , a Internet das Coisas apresenta alto grau de vulnerabilidade a ataques, pois:

- os objetos permanecem na maior parte do tempo sem a atenção dos usuários, facilitando ataques pela demora em sua constatação;

- as comunicações, na maioria sem fio, facilitam tentativas de interceptação e/ou injeção de dados;

- a necessidade de baixo consumo de energia, que leva a uma baixa capacidade computacional, torna difícil a implantação de esquemas voltados à segurança nos objetos.

A implantação de estruturas computacionais que tragam suporte aos conceitos da Internet das Coisas constitui-se em uma das áreas de pesquisa mais ativas no momento (ATZORI; IERA; MORABITO, 2010; WEBER, 2010).

Finalmente, é importante ressaltar que a funcionalidade da Internet das 
Coisas, nos moldes em que é proposta, que inclui a atribuição de um endereço Internet Protocol (IP) a cada objeto, permitiria, em tese, a obtenção das informações sobre sua passagem ao longo da cadeia produtiva, o que é de grande interesse para as áreas de rastreabilidade e logística.

Uma das propostas em uso que contempla diversos aspectos da loT e que, em diversos aspectos, encontra-se em um estágio de maturação considerável, é o Sistema EPCglobal ${ }^{\circledR}$ (GS1, 2010a). 


\section{ELECTRONIC PRODUCT CODE - EPC}

\section{$3.1 \quad$ GS1}

GS1 é uma entidade internacional, sem fins lucrativos, com membros afiliados em mais de 100 países, criadora do chamado GS1 System.

O GS1 System teve origem nos Estados Unidos da América em 1973 pela ação do Uniform Product Code Council, conhecido até 2005 como Uniform Code Council (UCC) e, desde então, como GS1 US. Originalmente, o UCC adotou um código de identificação numérico de doze dígitos, que transformado em códigos de barra, incorporaram-se aos produtos a partir de 1974 (GS1, 2013). Posteriormente, em 1977, criou-se na Europa a European Article Numbering Association, conhecida como EAN International. Esta entidade desenvolveu uma extensão do código UCC para aplicação fora da América do Norte, utilizando treze dígitos. A partir de 2005, a EAN International transformou-se no atual GS1. Deste então, tem-se trabalhado para a unificação dos padrões de códigos numéricos, por meio da criação de padrões GS1.

\subsection{Electronic Product Code ${ }^{\mathrm{TM}}$}

A possibilidade de se atribuir a cada produto um código único, gravado em uma etiqueta de baixo custo, rápida e facilmente registrável por hardware relativamente barato, tem grande potencial de auxílio em um dos desafios clássicos da logística que é o do registro e análise do fluxo de partes e produtos ao longo das cadeias produtivas (MCFARLANE; SHEFFI, 2003). A automação deste processo evita problemas ocasionados por operações manuais que podem levar ao registro incorreto, à perda ou adulteração de informações. Estes registros são também essenciais para a manutenção de informações sobre a rastreabilidade nas cadeias produtivas, hoje tão valorizadas e exigidas por diversos países.

$\mathrm{Na}$ década de 1970, a adoção dos códigos de barra impressos lidos por scanners resolveu este problema apenas parcialmente, porque em termos de velocidade de leitura, esta solução deixa muito a desejar quando comparada às possibilidades oferecidas pela tecnologia RFID (WHITE et al., 2007). 
Em 1999, o Auto-ID Lab do MIT iniciou uma série de pesquisas visando à criação de padrões que viabilizassem a utilização em larga escala da tecnologia RFID. Esta pesquisa já considerava o conceito de integração ativa à Internet de objetos de uso cotidiano, identificados por etiquetas RFID, a ideia básica do que hoje se denomina Internet das Coisas (Internet of Things - loT).

A adoção em larga escala de sistemas RFID permitiria a automação do fluxo de informações ao longo das cadeias produtivas, condição desejável para incremento da eficiência, produtividade e administração, além de simplificar outras atividades como a manutenção de registros de rastreabilidade ao longo das cadeias (THIESSE; MICHAHELLES, 2006).

Um dos resultados mais importantes foi a proposição de um esquema de codificação numérica que, além de englobar os padrões mais utilizados nos códigos de barra da época - o americano UCC e o europeu EAN - fosse também extensível a futuros esquemas de numeração que viessem a ser criados. Esta proposta gerou $O$ que hoje é conhecido como Electronic Product Code TM (EPC) (BROCK, 2001).

Com o término das pesquisas em 2003, a administração desta tecnologia foi transferida à EPCGlobal ${ }^{\circledR}$ Inc, hoje integrada ao GS1. A partir de então, projetos nela baseados, propostos tanto por grandes empresas como IBM (GLOBAL COMMERCE INITIATIVE, 2005), Oracle (SMIERS; GRIFFIOEN, 2006), dentre outras, bem como iniciativas de software livre (RODUNER; FLOERKEMEIER, 2012), têm surgido sistematicamente.

A utilização de códigos mais longos oferecida pelo EPC, possibilita a inclusão de números de série únicos em produtos industrializados. Desta forma, produtos idênticos de um mesmo fabricante podem ter códigos EPC distintos. Esta unicidade de identificação atende a um dos requisitos de rastreabilidade impostos pela Comunidade Europeia aos participantes das cadeias produtivas de produtos alimentícios, por meio do Regulamento 178/2002 (2002).

A proposta de código do Auto-ID Lab, em 2001 (BROCK, 2001) empregava códigos de 64 e 96 bits para a codificação EPC, com espaço para cabeçalho de 8 bits.

$\mathrm{Na}$ definição de um dos pesquisadores e diretores do Auto-ID Center (BROCK; CUMMINS, 2003): 
"O Electronic Product Code ${ }^{\mathrm{TM}}$ é um esquema de numeração idealizado para identificar de maneira unívoca qualquer objeto. Foi criado para enumerar todos os objetos, bem como acomodar todos os esquemas de numeração correntes e futuros. Tão importante quanto isso, o EPC foi criado para permitir a conexão entre objetos físicos e as redes de computadores, de maneira a servir como uma eficiente referência de informações."

O EPC apresenta um cabeçalho que identifica a categoria do código. A cada Chave GS1 corresponde uma formatação de EPC. Quando aplicada a produtos, a chave GTIN (Global Trade Item Number) não possui espaço para a inclusão de números de série. Criou-se então uma extensão do código que o transforma no chamado SGTIN (Serial Global Trade Item Number). Atualmente duas variantes de códigos SGTIN coexistem: o sgtin-96 e o sgtin-198 com 96 e 198 bits, respectivamente.

Apresentam-se na Tabela 1, a alocação de bits para cada categoria.

Tabela 1 - Código SGTIN-96 e SGTIN-198. Alocação de bits por partição

\begin{tabular}{ccccccc}
\hline Padrão & Cabeçalho & Filtro & Partição & $\begin{array}{c}\text { Prefixo } \\
\text { Companhia }\end{array}$ & $\begin{array}{c}\text { Número de } \\
\text { referência } \\
\text { do item }\end{array}$ & $\begin{array}{c}\text { Número de } \\
\text { série }\end{array}$ \\
\hline sgtin-96 & 8 & 3 & 3 & $20-40$ & $24-4$ & 38 \\
\hline sgtin-198 & 8 & 3 & 3 & $20-40$ & $24-4$ & 140 \\
\hline
\end{tabular}

Observa-se que no padrão sgtin-96, o espaço reservado de 38 bits permite a existência de até 274.877.906.943 números de série distintos, para produtos de uma mesma categoria e produtor. No caso do sgtin-198, seus 140 bits permitem a existência de até $2^{140}$ números de série distintos.

Outros esquemas de codificação surgiram. Sua identificação continua sendo feita pelo conteúdo do cabeçalho do EPC. Na versão 1.6 de 2011 (GS1, 2011), outros esquemas de codificação encontram-se definidos (Tabela 2). 
Tabela 2 - Esquemas de Codificação e Chaves GS1

\begin{tabular}{ccc}
\hline Chave GS1 & Codificação & Uso típico \\
\hline SGTIN & sgtin-96 & Produtos \\
sgtin-198 & Contêineres e unidades em paletes \\
SScc-96 & sgln-96 & Localização \\
GLN & sgln-195 & geográfica \\
GIAI & giai-96 & Ativo fixo \\
& giai-202 & \\
GDTI & gdti-96 & Documentos \\
GSRN & gdti-113 & Relações de serviço \\
GRAI & grn-96 & Elemento retornável ou reutilizável \\
GID & grai-170 & gid-96
\end{tabular}

Criaram-se também outras codificações reservadas para o Departamento de Defesa dos Estados Unidos bem como para a Indústria Aeroespacial e de Defesa Aérea americanas.

Tal como nas definições iniciais de 2001, cada novo esquema aloca partições variadas com números de bits pré-definidos, para que se possam mapear neste código as informações necessárias.

Cada esquema associado a uma chave GS1 permite a utilização de códigos EPC para cada elemento associado a estas chaves.

Esta possibilidade de associação é essencial, pois permite o uso de códigos EPC no esquema existente de codificação proposto pelo GS1.

A gravação de um número que obedeça a estas codificações em uma etiqueta RFID gera um EPC, passível de leitura em grande volume e alta velocidade por equipamentos de hardware específicos, os leitores RFID. Dá-se a este processo o nome de comissionamento. 


\subsection{Chaves GS1}

Um dos objetivos da criação de padrões pelo GS1 foi a proposição de esquemas de numeração e codificação com validade universal para fabricantes, produtos, partes, ativos, documentos, relações de serviço e demais elementos das cadeias produtivas. Tais esquemas são conhecidos como Chaves GS1 (GS1 Keys) (GS1, 2012).

Seguindo os princípios do GS1, um dos requisitos da arquitetura EPCglobal é a identificação única de objetos, lotes, locais, documentos, ativos e quaisquer outras entidades que devam ser rastreáveis (GS1, 2008b), por códigos numéricos que possam ser associados às Chaves GS1. Apresentam-se na Tabela 3 algumas das principais Chaves GS1. A cada uma delas corresponde um determinado formato de código e as regras para sua devida aplicação.

Tabela 3 - Chaves GS1 (GS1, 2012)

\begin{tabular}{|c|c|c|}
\hline Chave GS1 & Padrão & Aplicação \\
\hline GTIN & Global Trade Item Number & $\begin{array}{l}\text { Produtos, itens } \\
\text { comercializáveis }\end{array}$ \\
\hline SSCC & Serial Shipping Container Code & $\begin{array}{l}\text { Contêineres, tambores, } \\
\text { caixas e outros meios para } \\
\text { transporte agregado }\end{array}$ \\
\hline GLN & Global Location Number & Localizações geográficas \\
\hline GIAI & Global Individual Asset Identifier & Ativos fixos \\
\hline GID & General Identifier & Genérica \\
\hline GDTI & Global Document Type Identifier & Documentos em geral \\
\hline GRAI & Global Returnable Asset Identifier & $\begin{array}{l}\text { Materiais reutilizáveis para } \\
\text { transporte de itens }\end{array}$ \\
\hline GSRN & Global Service Relation Number & Relações de serviço \\
\hline
\end{tabular}

Pode-se compreender mais facilmente a utilização prática destes padrões com o auxílio da Figura 4 e da Tabela 4, adaptadas de (GS1, 2010a). 


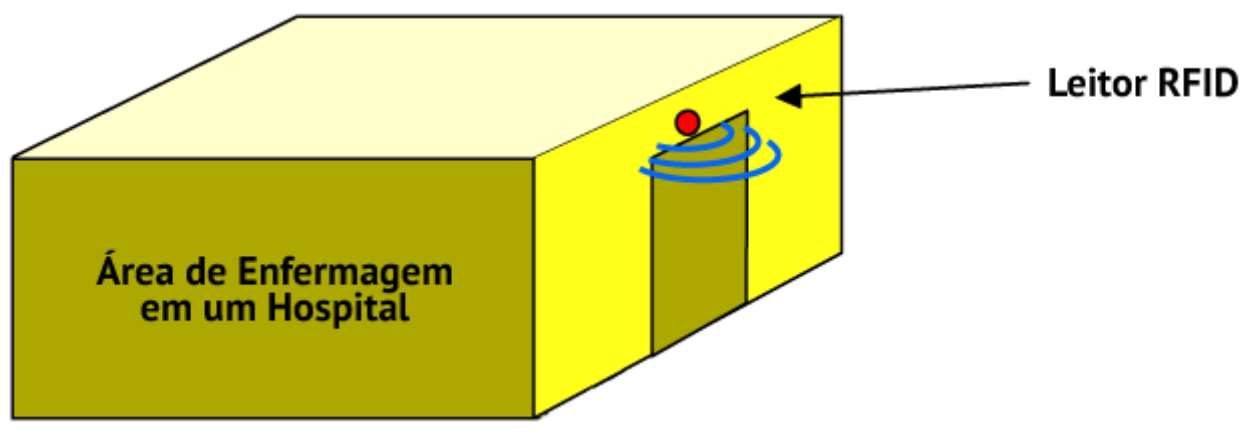

Figura 4 - Aplicação da tecnologia RFID em ambiente hospitalar. Adaptado de (GS1, 2010a).

Observam-se na Tabela 4 os dados de sete eventos capturados pelo leitor RFID na porta da área de enfermagem. Durante a passagem de produtos (seringas), funcionários (enfermeiras), itens de ativo fixo (bomba de infusão), itens de transporte retornáveis (carrinho) e até documentos (ficha de paciente), todos contendo etiquetas EPC. O horário do evento e o sentido (entrada ou saída) são automaticamente registrados.

Tabela 4 - Exemplos de eventos em ambiente hospitalar

Adaptado de (GS1, 2010a)

\begin{tabular}{|c|c|c|c|}
\hline Horário & $\begin{array}{l}\text { Entrada } \\
\text { /Saída }\end{array}$ & EPC & Comentário \\
\hline $08: 23$ & $E$ & urn:epc:id:sgtin:0614141.012345.62852 & Seringa $10 \mathrm{~cm}^{3} \# 62852$ (produto) \\
\hline 08:52 & $E$ & urn:epc:id:sgtin:0614141.012345.2528 & $\begin{array}{l}\text { Carrinho de transporte \#2528 } \\
\text { (transporte retornável) }\end{array}$ \\
\hline 08:59 & $E$ & urn:epc:id:sgtin:0614141.012345.1542 & Seringa $10 \mathrm{~cm}^{3} \# 1542$ (produto) \\
\hline 09:02 & S & urn:epc:id:giai:0614141.17320508 & Bomba de infusão \#52 (ativo) \\
\hline 09:32 & $E$ & urn:epc:id:gsrn:0614141.0000010253 & $\begin{array}{l}\text { Enfermeira Maria (relação de } \\
\text { serviço) }\end{array}$ \\
\hline 09:42 & S & urn:epc:id:gsrn:0614141.0000010253 & $\begin{array}{l}\text { Enfermeira Maria (relação de } \\
\text { serviço) }\end{array}$ \\
\hline 09:52 & $E$ & urn:epc:id:gdti:0614141.00001.1618034 & $\begin{array}{l}\text { Ficha médica do paciente João } \\
\text { (documento) }\end{array}$ \\
\hline
\end{tabular}

Observam-se ainda os códigos EPC apresentados em sua forma Uniform Resource Identifier (URI). Os códigos EPC podem ser representados em diversos formatos, sendo a forma URI (WORLD WIDE WEB CONSORTIUM, 2001) a mais utilizada em textos por seu fácil entendimento pelo leitor. Maiores detalhes sobre 
outras formas de representação encontram-se em (GS1, 2011). A apresentação detalhada destas formas foge ao escopo deste trabalho e não é necessária para a compreensão deste documento. 


\section{EPCglobal $^{\circledR}$ System}

Apresentam-se a seguir, as características do EPCglobal.

\subsection{Aspectos gerais do EPCglobal}

Inicialmente, é importante ressaltar que o EPCglobal não é um produto de software ou hardware. Trata-se de uma arquitetura de referência para sistemas de informação. Define um vocabulário comum eXtensible Markup Language (XML) (WORLD WIDE WEB CONSORTIUM, 2007a) para troca de informações. Para os diversos componentes de sua arquitetura, estão bem definidas as funcionalidades $\mathrm{e}$ interfaces a serem oferecidas para os demais módulos internos, ou aplicativos externos. Tratando-se de um padrão, está a cargo dos usuários a implementação de sistemas de informação (softwares) aderentes à especificação.

Também é importante ressaltar que o uso do EPCglobal não implica no armazenamento de dados das empresas em um único "repositório global de dados". $\mathrm{Na}$ realidade, cada membro da cadeia mantém seu próprio repositório de dados em seu EPCIS local e define sua política de compartilhamento de informações.

O repositório de dados atende a uma das principais funcionalidades proporcionadas pelo EPCglobal, sendo alimentado por eventos relativos a informações normalmente obtidas durante a passagem de itens codificados por leitores RFID ao longo da cadeia produtiva.

A arquitetura do EPCglobal permite a utilização de leitores ópticos de códigos de barra. Embora os atuais códigos de barra bidimensionais permitam a utilização de códigos numéricos extensos (GAO; PRAKASH; JAGATESAN, 2007), boa parte da funcionalidade do EPCglobal decorre de sua capacidade de processamento de um grande número de informações, com elevada velocidade de aquisição de dados. Por esta razão, as aplicações práticas do EPCglobal desenvolvem-se naturalmente com o uso de etiquetas EPC RFID. Desta forma, deste ponto em diante, considerase neste texto apenas a tecnologia RFID para utilização no EPCglobal.

Outro ponto de destaque é a utilização de vocabulário XML padronizado, que permite a troca de informações entre módulos do sistema e parceiros externos. Destaca-se ainda a possibilidade de se obterem informações sobre o fabricante dos 
produtos e todos os eventos automaticamente registrados ao longo da cadeia, por leitores RFID. A possibilidade deste intercâmbio de informações é a base do grande benefício a ser obtido com a utilização do EPCglobal, pelas entidades participantes das cadeias produtivas. Por outro lado, este benefício somente ocorre, em seu potencial máximo, quando todos os integrantes de uma cadeia produtiva utilizam sistemas deste padrão.

Apresenta-se na Figura 5 a arquitetura básica da arquitetura EPCglobal e, a seguir, considerações sobre seus diversos componentes.

\subsubsection{Leitura dos códigos EPC}

A aquisição de dados ocorre durante a passagem física de itens contendo etiquetas EPC ao longo de leitores RFID localizados em pontos significativos da cadeia produtiva. A existência de um número considerável de alternativas para leitores RFID oferecidos por diversos fabricantes, torna necessária a utilização de um middleware adequado para a uniformização de operações.

Os códigos obtidos pelos leitores RFID chegam à camada imediatamente superior, conhecida como Application Level Events (ALE). 


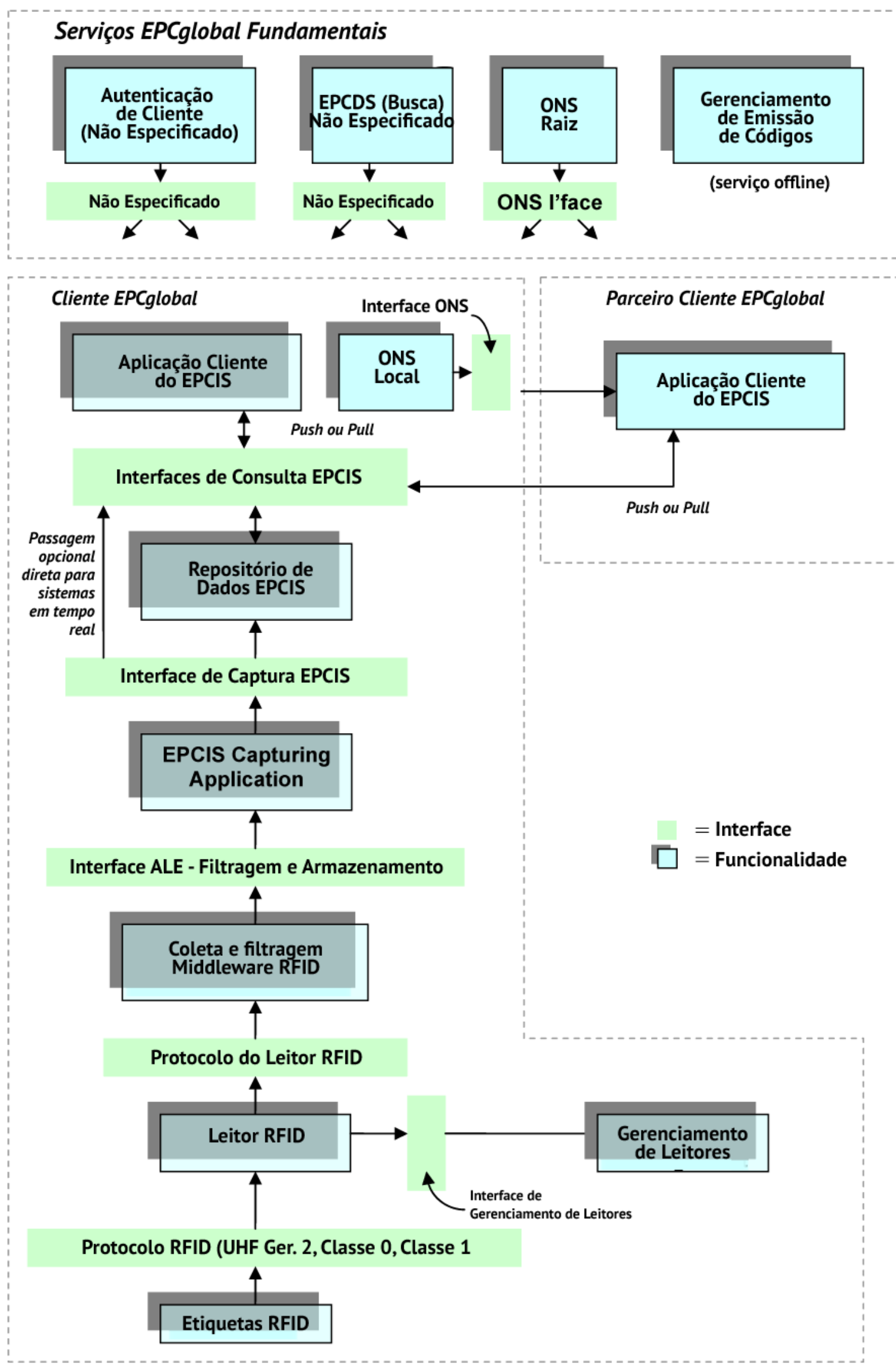

Figura 5 - Arquitetura EPCglobal. Adaptada de (GS1, 2013). 


\subsubsection{Eventos em Nível de Aplicação (Application Level Events - ALE)}

Esta camada situa-se entre os leitores RFID e os sistemas EPCIS. Trata-se de um middleware encarregado de fornecer suporte à utilização de leitores RFID de diversos fabricantes e gerenciar sua utilização. A camada realiza uma filtragem dos dados obtidos que resolve dois problemas: a eventual repetição da leitura de códigos e o encaminhamento de apenas uma ou determinadas categorias de EPC. Por exemplo, pode-se desejar apenas a leitura de EPCs do tipo SSCC (aplicáveis a caixas, contêineres, etc), descartando-se a leitura dos códigos do SGTIN (aplicáveis a produtos individuais) possivelmente recebidos.

Esta camada também gerencia a variedade de equipamentos de leitura RFID, possivelmente produzidos por diferentes fabricantes, e registra sua distribuição física ao longo da cadeia.

Desta forma, implementa-se um conceito de leitores virtuais, independentes do hardware utilizado, apresentando um formato padronizado para os dados obtidos e filtrados, para serem processados pelas camadas superiores do sistema (BARCHETTI et al., 2009).

As leituras obtidas correspondem a eventos, ligados ao registro da passagem de itens, em determinado local, em data e horário específicos e atendendo a uma finalidade.

Estes eventos procuram informar sobre quatro questões básicas: o que, onde, quando e por que. Por exemplo, em 27/07/2012, às 13:42 UTC+3, os itens EPC1, EPC2, ... EPCn, foram registrados na doca $n^{\circ} 1$ do armazém $n^{\circ} 2$ no momento de sua expedição ao distribuidor.

A camada ALE encaminha os dados resultantes (por meio de um documento denominado ECReport) à aplicação no nível acima, o sistema EPCIS (JAKKHUPAN; ARCHINT; Y., 2011).

\subsubsection{EPC Information System (EPCIS)}

A manutenção do repositório de eventos e o atendimento a consultas e 
requisições para armazenamento de dados são as principais funcionalidades do EPCIS. A existência deste repositório permite o compartilhamento de informações entre os membros da cadeia produtiva e seus parceiros de negócio, envolvendo os diversos processos que ocorrem ao longo da cadeia.

Nesta camada, o módulo de captura recebe e registra as informações provenientes do nível ALE, codificadas em vocabulário XML padronizado (EPCGLOBAL INC., 2007).

Cada usuário é responsável pela guarda de suas informações em seu próprio EPCIS. A disponibilidade e política de compartilhamento destas informações com parceiros de negócios e/ou com o público consumidor são decisões das empresas, que podem disponibilizá-las em maior ou menor grau, cabendo a cada uma a identificação e autorização de seus parceiros de negócio da cadeia produtiva no sistema.

Para servir a sistemas de informação internos ou de parceiros de negócios, existe a Interface de Consulta (Query Interface) que atende a requisições por meio de conexões, de acordo com os preceitos de uma Arquitetura Orientada a Serviços (Service-Oriented Architecture - SOA) (ERL, T., 2004).

O EPCglobal especifica, como possibilidades para troca de mensagens, por meio de web services, os protocolos:

- $\quad$ HTTP (WORLD WIDE WEB CONSORTIUM, 1999)

- HTTPS (INTERNET ENGINEERING TASK FORCE, 2000)

- HTTPISOAP (WORLD WIDE WEB CONSORTIUM, 2007b)

- $\quad$ AS2 (INTERNET ENGINEERING TASK FORCE, 2005)

A partir do vocabulário XML padronizado, as diversas interfaces dos sistemas EPCIS podem trocar mensagens, o que permite a implementação de toda a funcionalidade prevista para este serviço.

\subsubsection{Servidores de Nome de Objetos}

De maneira similar aos servidores de nomes da Internet (Domain Name System - DNS), que fornecem ponteiros relacionando domínios e endereços do Internet Protocol (IP), os servidores de nomes de objetos (Object Name Services ONS) fornecem ponteiros relacionando produtos identificados por códigos EPC aos 
responsáveis pelo comissionamento de seus códigos, usualmente seus produtores, e a seu sistema EPCDS.

A implementação deste serviço ocorre a partir da própria estrutura existente nos atuais servidores DNS, na qual ponteiros do tipo Naming Authority Pointer Record (NAPTR) são utilizados para correlacionar códigos EPC e o endereço do EPCIS do responsável pelo comissionamento, por meio do campo Regexp dos ponteiros NAPTR. Existem diversos documentos da Internet Engineering Task Force (IETF) relativos à especificação dos serviços DNS. Podem-se acessar todos eles por meio do web site do IETF (INTERNET ENGINEERING TASK FORCE, 2013).

Cada fabricante produz uma versão local do ONS contendo informações detalhadas sobre seus próprios códigos. Tal como ocorre com os servidores DNS, forma-se uma estrutura de servidores ONS em árvore, a partir de um servidor raiz (atualmente mantido pela empresa Verisign) para a resolução de códigos EPC.

Como exemplo do processo de consulta, apresenta-se na Figura 6 o conteúdo de um código EPC do tipo sgtin96 distribuído ao longo de seus 96 bits.

O primeiro passo consiste em converter o código numérico para uma URI, conforme especificação em GS1 (2011) .

Em seguida, transforma-se a URI em uma URL a ser consultada no serviço DNS. Inicialmente retiram-se da URI os termos urn:epc:id, invertem-se os campos e adiciona-se ao final da cadeia o domínio do servidor ONS raiz, onspec.com.

\section{URI: $\quad$ urn:epc:id:sgtin:4012345.734.2}

\section{URL: 2.734.4012345.sgtin.onsepc.com}

A URL resultante é consultada no serviço DNS com a requisição de registro do tipo NAPTR. Obtém-se como resultado, a URL do serviço EPCIS da entidade responsável pelo comissionamento da EPC. Por se tratar de um serviço DNS puro, outros servidores ONS podem ser anexados por delegação.

O modelo proposto para o serviço ONS tem sido frequentemente criticado por pesquisadores, devido aos potenciais riscos decorrentes à sua vinculação à arquitetura do serviço DNS. Os riscos herdados por esta vinculação incluem a negação de serviço (Distributed Denial of Service - DDNoS), contaminação de cache (cache poisoning), a dependência de funcionamento de alguns servidores chave que 
podem estar desabilitados além de outras considerações (FABIAN; GÜNTHER; SPIEKERMANN, 2010; ABU-AMARA et al., 2011; CHOPRA et al., 2009; SHRESTHA et al., 2010).

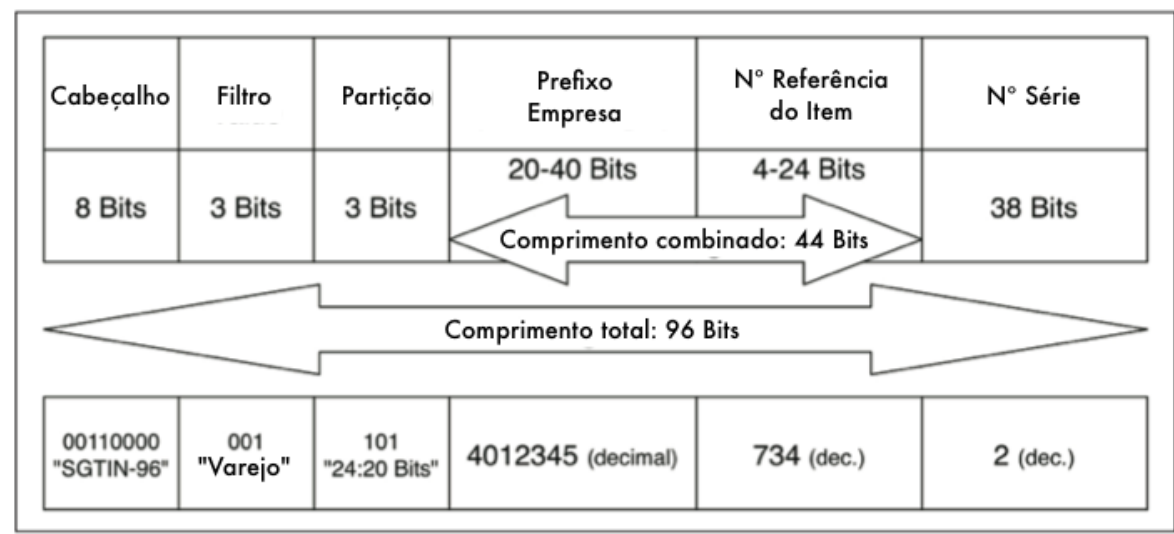

urn:epc:id:sgtin:PrefixoEmpresa.NReferencialtem.NSerie

urn:epc:id:sgtin:4012345.734.2

Figura 6 - Conversão de código EPC sgtin96 para sua correspondente URI. Adaptado de (FABIAN; GÜNTHER, 2009).

\subsubsection{Serviço de Descoberta de EPCs (Electronic Product Code Discovery Services - EPCDS)}

A obtenção de informações sobre o fabricante de determinado produto pode ser complementada por informações relativas à movimentação deste produto ao longo de toda a cadeia produtiva. No entanto, durante seu ciclo de vida, os itens identificados por códigos EPC normalmente passam por diversos membros da cadeia produtiva. Por exemplo, após seu comissionamento, um produto manufaturado é enviado a um distribuidor local que pode exportá-lo para uma empresa em outro país que, por sua vez, pode revendê-lo a um comerciante varejista. Não basta, portanto, conhecer o endereço do sistema EPCIS do responsável pelo comissionamento. É importante o conhecimento dos endereços de todos os EPCIS que mantenham informações sobre o código.

A princípio, a utilização do serviço ONS seria suficiente para a localização dos 
demais EPCIS envolvidos. Basta que se procure no EPCIS original o registro do evento de saída do código, e o endereço do EPCIS de destino. Este processo pode ser repetido até a obtenção do EPCIS final, conforme mostra a Figura 7.

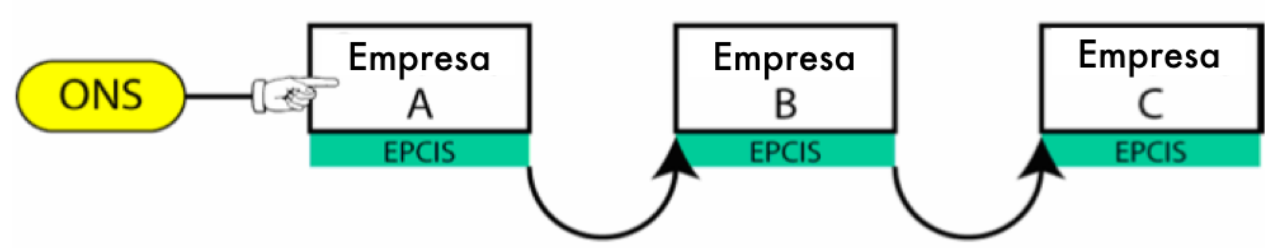

Figura 7 - Busca a partir de ONS. Adaptado de (CANTERO et al., 2008).

Na prática, esta solução mostra-se inconveniente, pois o não funcionamento de um dos servidores EPCIS impediria a obtenção dos dados nos servidores seguintes (CANTERO et al., 2008). Além do mais, não se pode garantir que o endereço de um EPCIS na cadeia esteja registrado no EPCIS imediatamente anterior.

Faz-se necessária uma solução mais robusta, escalonável e eficiente para a obtenção destas informações. A proposta para atender a estes requisitos leva aos serviços EPCDS.

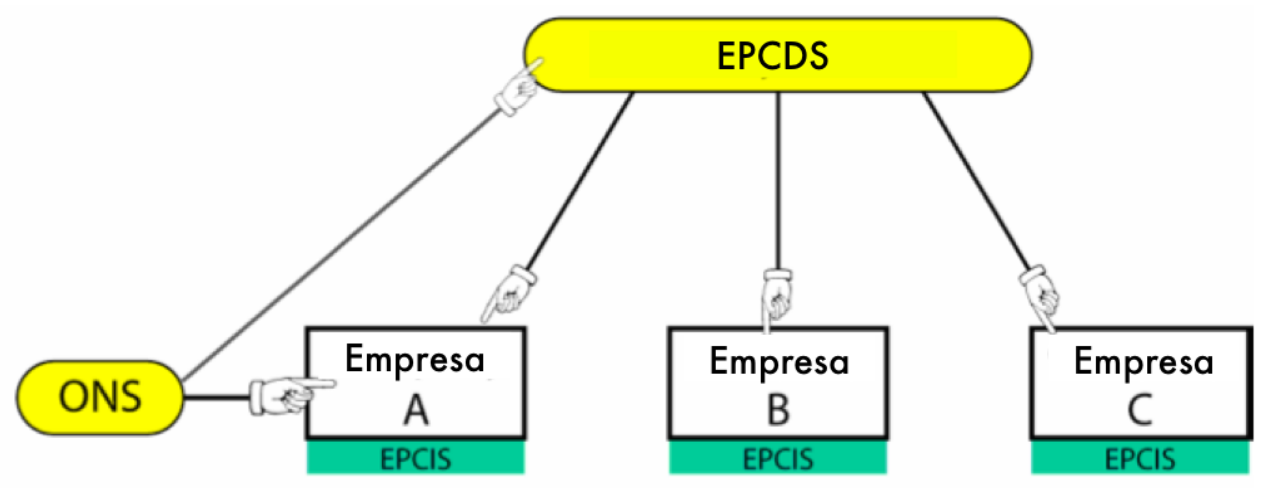

Figura 8 - Busca por EPCDS. Adaptado de (CANTERO et al., 2008)

Serviços EPCDS funcionam como intermediários no EPCglobal, de maneira análoga aos serviços de busca na World Wide Web (WWW) (MULLER et al., 2010). Seu uso simplifica a troca de informações entre parceiros em cadeias produtivas e permitem a descoberta de parceiros desconhecidos que, em algum momento, tiveram acesso a determinado produto.

Ao contrário dos serviços de busca da WWW, abertos ao público em geral, o acesso aos sistemas EPCDS pode especificar políticas de autenticação e 
autorização rígida, pois as informações que podem ser obtidas são, em muitas circunstâncias, absolutamente confidenciais.

\subsubsection{Requisitos}

Evdokimov et al. (2010) apresentam oito requisitos que consideram fundamentais para sistemas EPCDS, a saber:

1) Suporte a esquemas de identificação de códigos flexíveis: previsto para a criação futura de esquemas de codificação diversos.

2) Permissão de publicação: um provedor de informações deve poder fornecer ao EPCDS informações sobre os EPCs para os quais esteja autorizado a fazê-lo, incluindo endereços de EPCIS.

3) Publicação múltipla: diversos participantes independentes da cadeia (porém autorizados), devem ser capazes de fornecer dados.

4) Consulta a EPC: após consulta sobre determinado EPC, o serviço deve fornecer, a clientes autorizados, uma lista com os EPCIS contendo dados relativos ao código consultado.

5) Atualização: participantes da cadeia autorizados devem poder atualizar informações previamente gravadas no serviço.

6) Cancelamento: participantes da cadeia autorizados devem poder cancelar informações previamente gravadas no serviço. Documentos gravados devem possuir indicação de tempo de validade (time-to-live - TTL), com o objetivo de automatizar o trabalho de deleção e reduzir o espaço de armazenamento.

7) Endereços em nível de referência: se o EPC estiver estruturado como número de referência do item e número de série, o serviço deve ser capaz de aceitar consultas contendo apenas a informação de referência do item.

8) Endereços contendo número de série: se o EPC estiver estruturado como número de referência do item e número de série, o serviço deve ser capaz de aceitar consultas contendo a informação total, incluindo o número de referência do item e seu número de série. 


\subsubsection{Modelos de Arquitetura para EPCDS}

Para apresentar o caminho que leva à proposta desta pesquisa, faz-se necessária uma breve discussão sobre as arquiteturas que vêm sendo utilizadas em propostas oriundas da comunidade acadêmica.

Cada EPCDS oferece possibilidade de conexão a sistemas externos (EPCIS ou não). Esta interface atende a dois tipos de solicitação:

- publicação de novos dados sobre códigos EPC, gerados por EPCIS;

- consultas sobre informações envolvendo um determinado EPC.

Quanto à sua arquitetura, observa-se que este tópico é objeto de pesquisa recente de diversos autores (ABU-AMARA et al., 2011; GROVER; BERGHEL, 2011; WU; LIN; ZHANG, 2009; URDANETA; PIERRE; STEEN, 2011; LORENZ et al., 2011). Basicamente, destacam-se duas propostas:

- implementação centralizada;

- implementação distribuída.

O modelo centralizado é bem representado pela Figura 9. O ponto de acesso ao EPCDS é único e o repositório pode ser único ou baseado em uma estrutura hierárquica utilizando tecnologias como o Lightweight Directory Access Protocol (LDAP). Seu inconveniente é a existência de um ponto único de falha, o que torna o sistema susceptível a ataques e traz também problemas de escalabilidade, já que um único ponto de acesso deve coordenar todas as atividades.

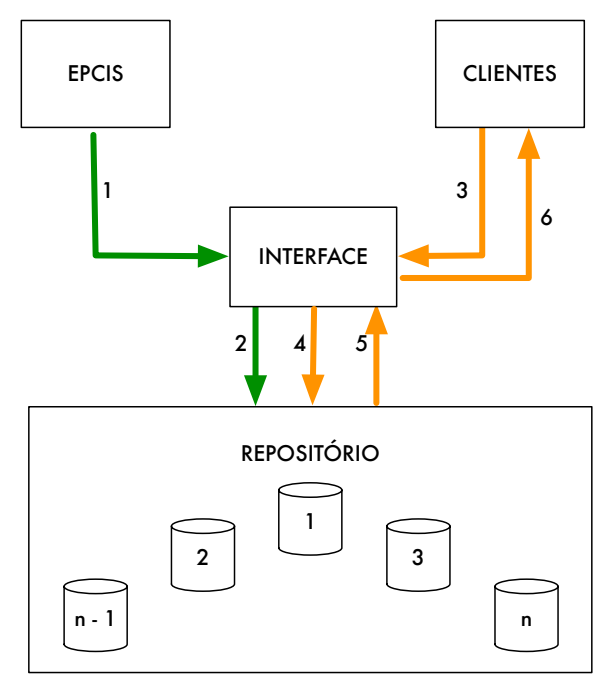

Figura 9 - EPCDS centralizado. 
Apresenta-se como alternativa, o modelo com implementação distribuída, em particular, com a utilização de redes $\mathrm{P} 2 \mathrm{P}$.

Neste modelo, além da inexistência de um ponto único de falha, as informações relacionando códigos EPC e respectivos EPCIS encontram-se distribuídas entre os diversos nós da rede, dividindo o trabalho de processamento e o tamanho das implementações locais.

Para redes P2P, empregam-se usualmente arquiteturas do tipo Distributed Hash Table (DHT) (URDANETA; PIERRE; STEEN, 2011) nas quais de atribui a cada nó participante da rede uma chave de identificação, usualmente de 160 bits, gerada por uma função criptográfica como a SHA1 (INTERNET ENGINEERING TASK FORCE, 2001). O algoritmo de roteamento da rede é capaz de realizar um mapeamento do tipo:

$$
\text { chave } \Rightarrow \text { dado }
$$

No EPCDS, a chave normalmente é o resultado da função de hash aplicada ao código EPC a ser descoberto. Como dado, tem-se o endereço do servidor que contém informações sobre o EPC procurado (IP do nó e sua porta).

Apresenta-se na Figura 10, a arquitetura básica de uma rede P2P do tipo DHT. Quando o EPCIS em um dos participantes da cadeia detecta a existência de informações sobre um novo EPC, dados correspondentes são publicados em alguns nós locais da rede P2P (fluxos $0 \mathrm{a}-0 \mathrm{c}$ ). Insere-se nestes nós um par de dados:

$$
(\text { chave }=h(E P C), \text { valor }=\text { EPCIS.endereco })
$$

onde $h$ denota uma função criptográfica adequada, como a SHA1. Aplicativos clientes, internos à cadeia (fluxo 2) ou externos (fluxo 3) que busquem informações sobre determinado EPC, podem utilizar o mecanismo de resolução da interface DHT da rede por meio de seu nó peer local e obter o endereço dos EPCIS relevantes.

Diversos modelos para a geração da infraestrutura DHT, distribuição de informações entre nós e busca de informações têm sido pesquisados e propostos. Destacam-se o Pastry (ROWSTRON; DRUSCHEL, 2001), Chord (STOICA et al., 2003) e Kademlia (MAYMOUNKOV; MAZIĖRES, 2002a). 


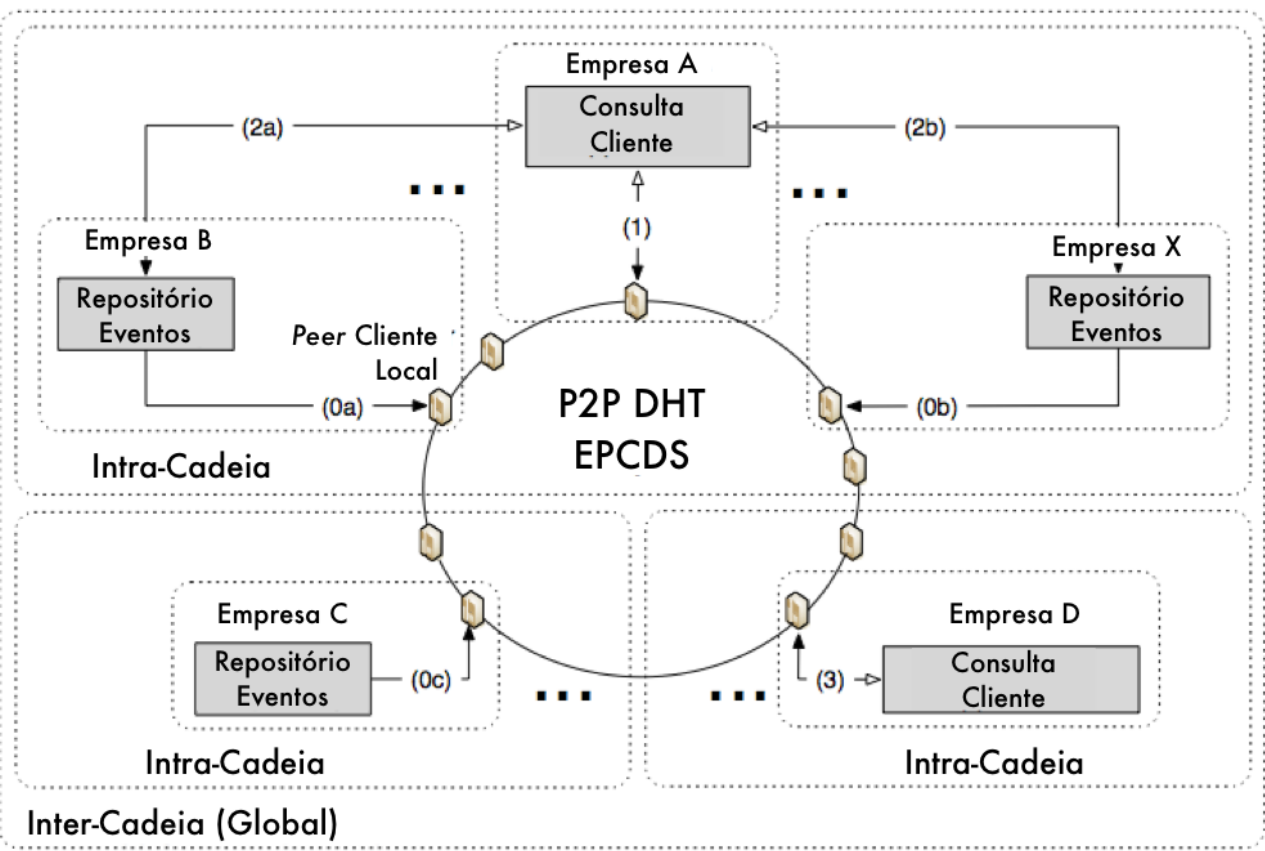

Figura 10 - Rede P2P DHT. Adaptado de (EVDOKIMOV et al., 2010).

\subsubsection{Interfaces de serviço}

Em relação à interface do serviço, têm-se apresentado vários modelos de implementação, conforme relatos de (EVDOKIMOV et al., 2010; KYWE et al., 2012; MULLER et al., 2010).

Destacam-se nas propostas três modelos:

- modelo de diretório;

- modelo query relay;

- modelo de descoberta agregada.

\subsection{Modelo de diretório}

O EPCDS mantém um diretório contendo códigos EPC e respectivos endereços de EPCIS. O fluxo de informações é direto entre os módulos (Figura 11):

1. EPCIS publica informações sobre EPCs;

2. Aplicativo cliente busca informações sobre um determinado EPC;

3. EPCDS retorna a lista de EPCISs relevantes;

4. Aplicativo cliente solicita a cada EPCIS as informações sobre o EPC;

5. EPCIS retorna as informações. 


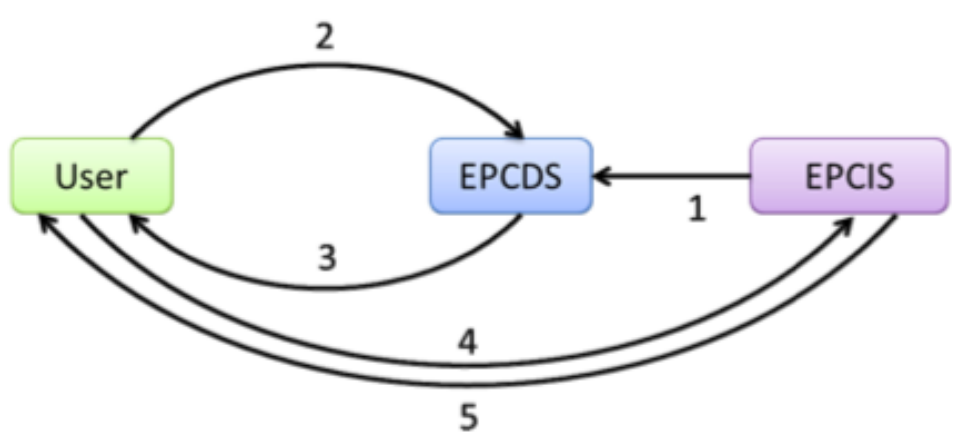

Figura 11 - Modelo de diretório. Fonte: (KYWE et al., 2012).

No modelo diretório, a implantação de mecanismos de segurança não é intrínseca ao modelo e deve ser criada pelo implementador.

O usuário recebe a lista de EPCIS relevantes que é, em princípio, uma informação sigilosa. Se o EPCDS for encarregado de verificar a credencial do cliente, a sobrecarga de trabalho será considerável, pois seria necessária a manutenção local de informações de acesso para cada EPCIS. Portanto, esta solução não atende o requisito não funcional de escalabilidade e segurança.

\subsection{Modelo query relay}

O EPCDS passa diretamente a consulta recebida do cliente ao EPCIS, juntamente com as informações de autenticação. Desta forma o EPCIS responde diretamente ao cliente, se suas credenciais de autenticação forem aceitas, simplificando o fluxo de informações (Figura 12):

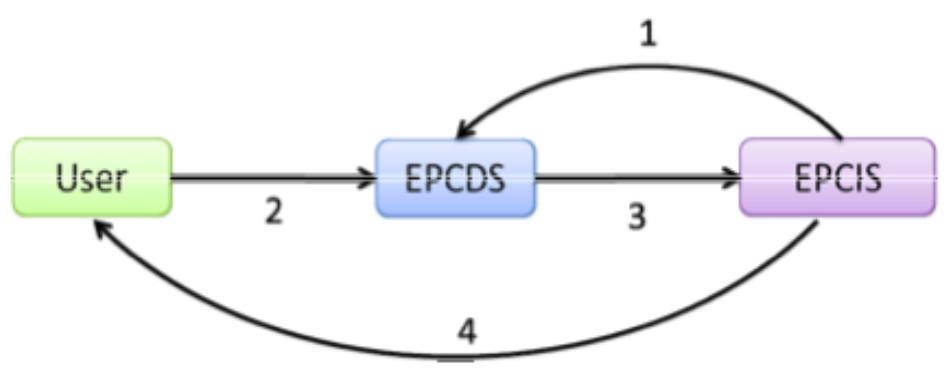

Figura 12 - Modelo query relay. Fonte: (KYWE et al., 2012).

1. EPCIS publica informações sobre EPCs;

2. Aplicativo cliente busca informações sobre um determinado EPC; 
3. EPCDS envia a consulta aos EPCISs relevantes;

4. EPCIS retornam as informações ao cliente, se a autenticação permitir.

No modelo de query relay o problema apontado no modelo de diretório não ocorre, pois a credencial de identificação do cliente é passada diretamente à EPCIS, que atende ou não à consulta em função de seu conteúdo. Como a passagem das informações é direta, o modelo leva a implementações com boa escalabilidade. No entanto, outro problema ocorre: como nem todos os EPCIS podem estar ativos no momento da consulta e outros podem não respondê-la, o cliente nunca sabe se o número de respostas recebidas é definitivo.

\subsection{Modelo de descoberta agregada}

Neste modelo (Figura 13), o EPCDS consulta diretamente os EPCIS relevantes e retorna as informações obtidas diretamente ao cliente, simplificando sua programação:

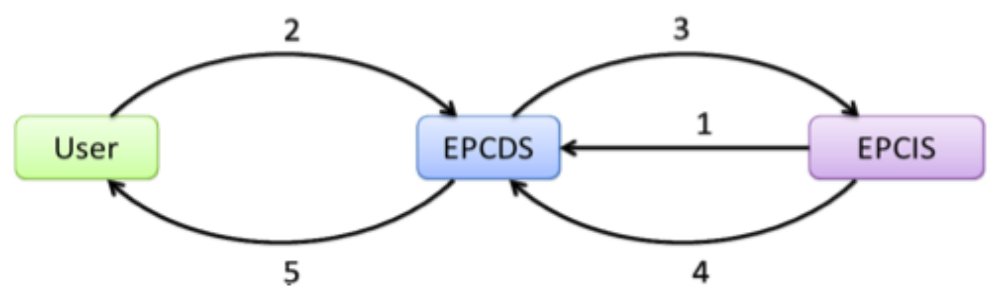

Figura 13 - Modelo de descoberta agregada. Fonte: (KYWE et al., 2012).

1. EPCIS publica informações sobre EPCs;

2. Aplicativo cliente busca informações sobre um determinado EPC;

3. EPCDS consulta os EPCIS relevantes;

4. Cada EPCIS retorna suas informações, que são agregadas no EPCDS;

5. EPCDS retorna as informações finais obtidas.

O modelo de descoberta agregada é o que exige menos esforço de programação para o aplicativo cliente. Feita a consulta, uma única resposta do EPCDS contém todas as informações obtidas. No entanto, é a que leva à maior complexidade do EPCDS que fica responsável por repassar a consulta para cada EPCIS relevante, agregar as respostas recebidas e retorná-las em uma única mensagem ao cliente. Por este motivo, a escalabilidade de soluções baseadas neste modelo é problemática. 


\subsubsection{Considerações gerais}

O objetivo dos sistemas EPCDS é fornecer um conjunto de ponteiros para todos os envolvidos em eventos ao longo da cadeia produtiva, dado um código EPC buscado. Para isso, durante o recebimento de um produto identificado por um EPC, o evento de sua entrada no ambiente local deve ser registrado em um EPCIS. Podese registrar este evento no EPCDS do responsável pelo comissionamento do item (que pode ser obtido por meio de uma requisição ao ONS). Este registro pode ser permitido apenas quando gerado por um parceiro de negócios autenticado e autorizado. Este procedimento tem sido contestado por um grande número de pesquisadores por deixar o acesso às informações dependentes da operação de um único EPCDS (EVDOKIMOV et al., 2010; FABIAN; GUNTHER, 2007; KÜRSCHNER et al., 2008).

Percebe-se que o acesso à informação sobre a movimentação, presença e quantidade de determinados insumos em instalações físicas de participantes da cadeia pode representar riscos a estas empresas. Estes riscos transcendem a rede EPCglobal e incluem diversas outras possibilidades de ataque envolvendo a leitura não autorizada e/ou alteração de etiquetas RFID (GROVER; BERGHEL, 2011).

Para evitar-se o problema da dependência de alguns poucos servidores para a continuidade do serviço, o uso de redes peer-to-peer tem sido objeto de estudos de diversos pesquisadores (ABU-AMARA et al., 2011; CHOPRA et al., 2009; FABIAN, 2009; LIU; WANG; HU, 2011; SHRESTHA et al., 2010). O uso de redes peer-to-peer distribui as informações sobre códigos EPC e sistemas EPCIS por diversos sistemas integrantes da rede. Esta distribuição permite a obtenção destes dados, mesmo quando um ou mais sistemas estejam fora de operação.

Ao contrário dos demais elementos da arquitetura do EPCglobal, até o momento da finalização deste texto (abril de 2013), o GS1 ainda não forneceu uma especificação para a implementação do serviço de EPCDS.

Atualmente, o desenvolvimento e proposição de soluções para EPCDSs é a área de pesquisa mais ativa no universo do EPCglobal, em particular, os aspectos de segurança envolvidos em seu uso (FABIAN, 2009; FABIAN; GÜNTHER; SPIEKERMANN, 2010). 


\subsection{Utilização do EPCglobal}

Apresenta-se na Figura 14 uma visão geral da utilização da tecnologia RFID ao longo de uma cadeia produtiva. No exemplo exposto, tem-se um fabricante, um distribuidor e um revendedor final.

Representam-se, na coluna da esquerda, processos típicos da cadeia produtiva e na coluna da direita as informações obtidas por meio da coleta automática de informações, a partir da leitura de etiquetas RFID durante a passagem dos itens ao longo de diversos pontos da cadeia.

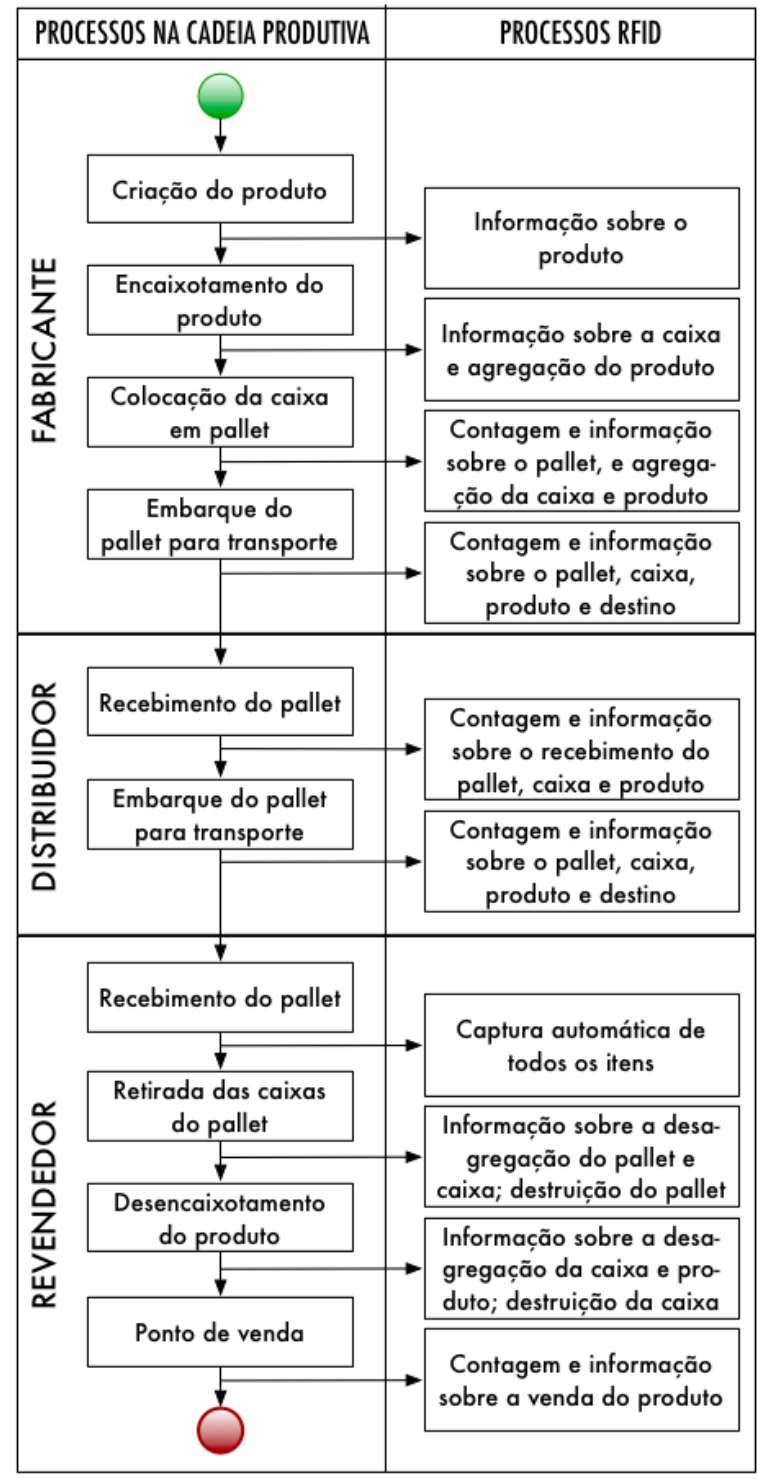

Figura 14 - Utilização da tecnologia RFID ao longo de uma cadeia produtiva. Adaptado de (JAKKHUPAN; ARCHINT; Y., 2011). 
Todos os eventos de leitura das etiquetas são capturados pelo middleware da camada ALE, sendo devidamente filtrados e tratados para encaminhamento ao EPCIS local.

Os eventos, registrados nos EPCIS dos membros da cadeia, poderão ser consultados por usuários autorizados, por meio dos serviços ONS e EPCDS. A obtenção deste histórico de eventos é informação essencial para a manutenção de registros de rastreabilidade e logística envolvidos.

Realiza-se a pesquisa por esta informação por meio de um processo dividido em etapas. Apresenta-se na Figura 15 o Diagrama de Sequência que modela um dos possíveis modos desta operação.

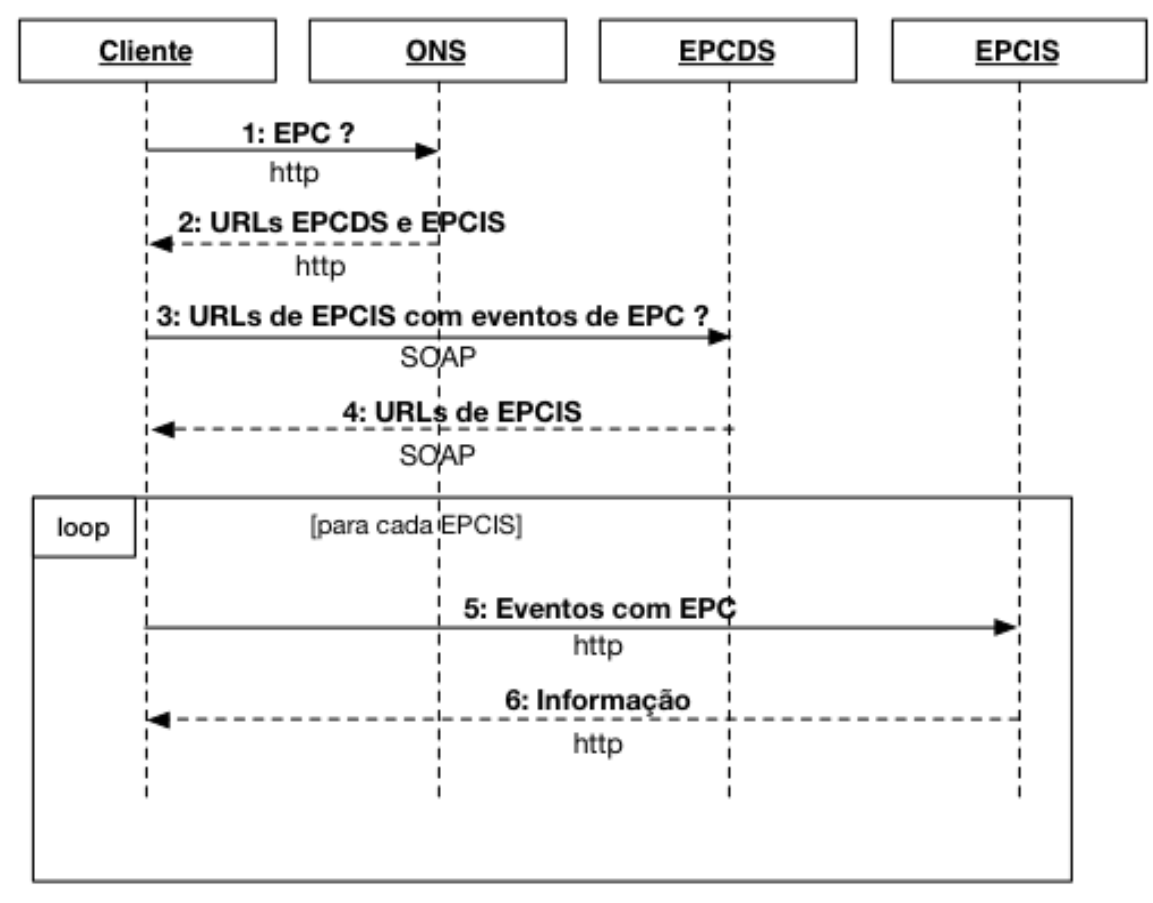

Figura 15 - Diagrama de Sequência - Exemplo de busca de eventos envolvendo determinado EPC.

$\mathrm{Na}$ primeira fase, o aplicativo cliente consulta o serviço ONS sobre determinado EPC. Por meio de uma conexão $h t t p$, obtém informações sobre a URL do serviço EPCIS do responsável pelo comissionamento da EPC e seu serviço EPCDS.

$\mathrm{Na}$ segunda fase, por meio de uma conexão SOAP, o cliente consulta o serviço EPCDS na busca de todos os eventos envolvendo o EPC em questão, recebendo uma relação com as URLs dos diversos EPCISs envolvidos.

Finalmente, na terceira fase, cada EPCIS é consultado, fornecendo as informações registradas em seu repositório de dados. 
Neste processo, a exigência de autenticação e a autorização do cliente são verificadas pelos serviços envolvidos.

Apresenta-se na Figura 16 um exemplo da distribuição dos diversos sistemas de informação componentes do EPCglobal ao longo de uma cadeia produtiva. A mesma figura permite apreciar o auxílio prestado pela rede em questões de rastreabilidade e logística, e representa-se uma cadeia simples, formada por um fabricante, um distribuidor e um revendedor final. Todos utilizam a tecnologia RFID e possuem sistemas EPCIS e ONS locais. Os serviços de ONS, conseguem identificar todos os eventos relacionados a cada item, identificado por seu EPC.

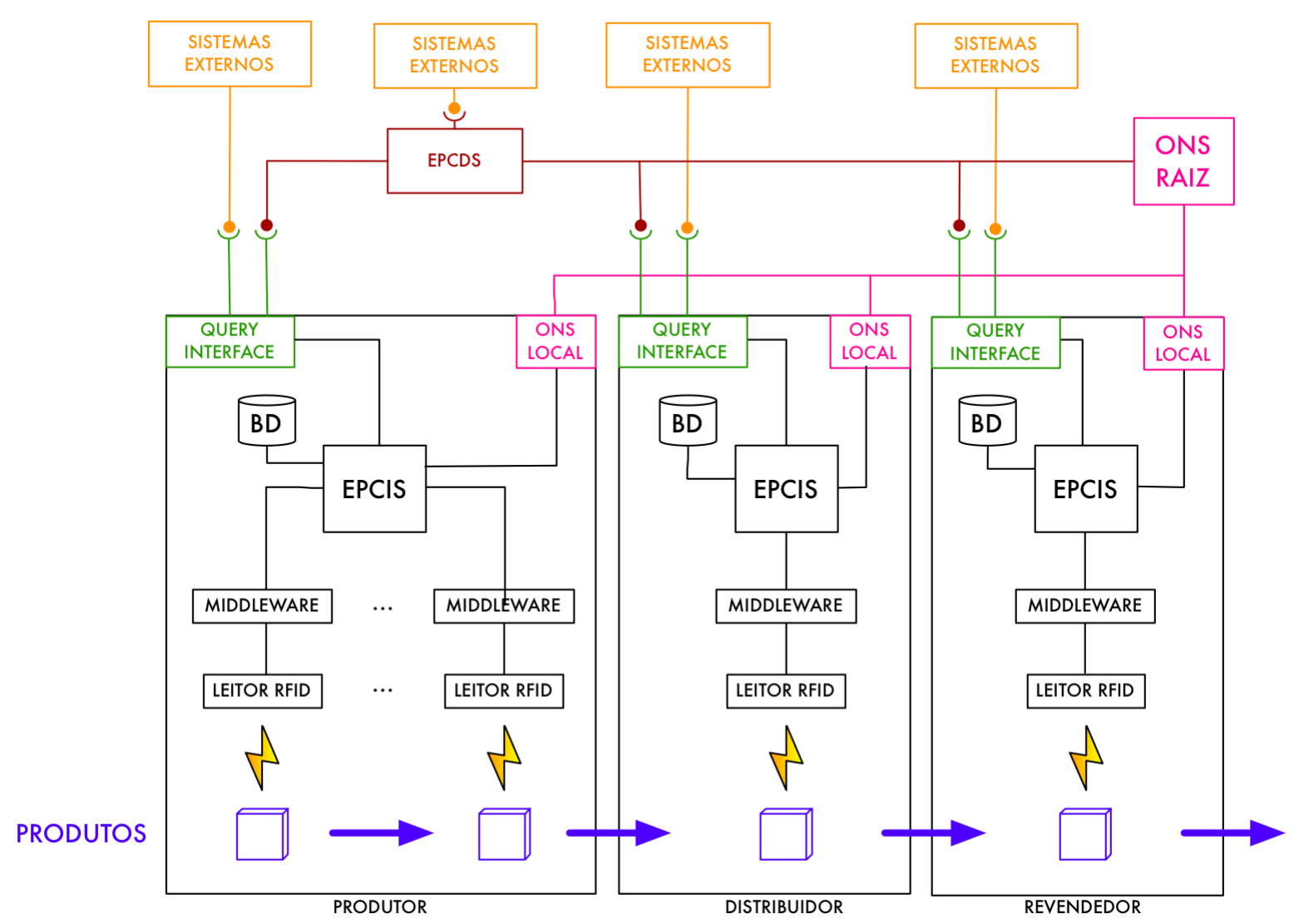

Figura 16 - A rede EPCglobal ao longo da cadeia produtiva.

\subsection{Perspectivas sobre a utilização futura do EPCglobal}

O uso amplo do EPCglobal oferece solução para problemas de rastreabilidade, logísticos e administrativos ao longo das cadeias produtivas.

Seus aspectos mais maduros envolvem o middleware para leitura, a Camada de Eventos de Aplicação (ALE) e os sistemas EPCIS. 
Como toda nova tecnologia, existem barreiras a serem superadas, dos pontos de vista técnico, econômico e cultural.

Sob o aspecto técnico, as principais dificuldades encontram-se na geração de soluções que atendam os requisitos de segurança de dados dos usuários e qualidade e disponibilidade do serviço EPCDS.

Do ponto de vista econômico, durante muitos anos o custo individual das etiquetas RFID foi um limitador. Com o passar do tempo estes custos vêm caindo significativamente, como consequência do aumento da produção. Os custos dos leitores RFID e antenas ainda são significativos, porém a necessidade de um número relativamente baixo de unidades em cada instalação física, de certa forma, ameniza este aspecto. O mesmo não se aplica, no entanto, à questão do software envolvido, incluindo o middleware da camada ALE. O custo de desenvolvimento e implantação de sistemas de informação aderentes ao EPCglobal pode ser expressivo.

Finalmente, sob o ponto de vista cultural, existem ainda diversas barreiras a serem vencidas. Além das dificuldades que estão sempre ligadas à utilização de novas tecnologias, a natureza aberta e cooperativa do EPCglobal que, em termos técnicos, é uma vantagem, torna-se de início um obstáculo, à medida que o potencial completo de utilização da rede somente será alcançado quando todos os envolvidos na cadeia produtiva o utilizarem plenamente.

No contexto da Internet das Coisas, a arquitetura EPCglobal permite a implantação de alguns de seus conceitos, como a participação ativa de objetos na rede, com o registro de informações colhidas ao longo de sua vida útil e a existência de serviços de resolução de objetos. Trata-se, provavelmente, da mais completa implementação prática envolvendo conceitos propostos neste paradigma.

Embora somente o futuro possa trazer a resposta sobre o sucesso e utilização ampla do EPCglobal, o potencial de funcionalidade embutido em seu conceito é significativo, o que tem motivado um grande número de pesquisadores a buscarem soluções aos problemas que ainda persistem.

\subsection{Exemplos de aplicações do EPCglobal}

Apresentam-se a seguir, alguns exemplos de aplicação do EPCglobal. 


\subsubsection{Gerenciamento de Estoque - Brasil}

Segundo o GS1, a loja de roupas Memove é a primeira cadeia de varejo no Brasil a adotar a tecnologia EPC/RFID, do fabricante ao consumidor final (GS1, 2012).

Cada item de vestimenta recebe, na fábrica, uma etiqueta GS1 EPC UHF Gen 2 costurada à peça. Comissionam-se as etiquetas com um SGTIN, número único que identifica cada item. Estas etiquetas são lidas em vários pontos ao longo da cadeia: no recebimento dos produtos nos centros de distribuição; no seu armazenamento; no envio dos itens aos pontos de venda; nos caixas de auto atendimento (check-out). Como resultado, a empresa sabe exatamente que itens estão em que lugar, a qualquer momento, e os estoques são atualizados automaticamente. Segundo relato do GS1, o processo de recebimento dos itens após a implantação do EPC/RFID está 300\% mais rápido, e o check-out, $60 \%$.

\subsubsection{Rastreabilidade da cadeia vinícola - da Itália para Hong Kong}

Em 2010, Hong Kong tornou-se o maior importador de vinho do mundo, com a significativa cifra de US\$850 milhões. Por sua vez, a Itália, como um dos maiores produtores de vinho, vem intensificando atividades comerciais ao redor do mundo, o que demanda uma operação eficiente ao longo de toda a cadeia (GS1, 2011).

Neste cenário, as representações do GS1 nos dois países se uniram para desenvolver uma solução de rastreamento das remessas de vinho, da vinícola na Itália, ao armazém em Hong Kong. No produtor e distribuidor Azienda Agricola Le Macchiole, cada garrafa recebe uma etiqueta EPC/RFID associada a um SGTIN. As garrafas identificadas são embaladas em caixas e estas, em paletes, que recebem etiquetas EPC/RFID associadas a um SSCC. Por meio de leitores EPC/RFID, podem-se obter informações relevantes aos estoques e movimentação da carga a partir da vinícola. Estas informações alimentam a rede EPCIS no GS1 Itália, indicando que os paletes estão prontos para envio ao porto. No recebimento em Hong Kong, os responsáveis verificam a conformidade da carga por meio de leitores RFID. Uma vez aprovada, a carga é destinada aos distribuidores e, após, às lojas. Todos estes eventos são registrados no GS1 Hong Kong por software compatível 
com o EPCglobal.

\subsubsection{Rastreabilidade da Carne - Nova Zelândia}

Por meio de trabalho conjunto do GS1 Nova Zelândia e do GS1 Hong Kong, confirmou-se que a rede EPCglobal pode ser utilizada eficazmente como sistema de rastreabilidade da carne, do ambiente rural até o varejo (GS1, 2010). Avaliaram-se as seguintes etapas da cadeia: identificação de cada animal na fazenda por meio de SGTIN (comissionamento); embarque do animal no caminhão (carga); chegada do animal na área de processamento (recepção); animal na área de abate (transformação); identificação de cada carcaça na câmara frigorífica por meio de um SSCC (comissionamento); carcaça na área de desossa (transformação); pedaços de carne embalados em caixas, sendo cada uma identificada por um SGTIN (comissionamento); carga das caixas em contêineres de transporte (transporte); chegada das caixas no varejo (recepção).

Todos os dados das etiquetas foram capturados e gravados com sucesso e transmitidos em formato XML para o servidor do GS1 Hong Kong, utilizando-se middleware EPC. Transmitiram-se os dados em lotes e não em tempo real, o que não comprometeu a rastreabilidade, visto que cada identificação EPC utilizada na cadeia pode ser consultada e reportada por meio do EPCIS. 


\section{REDES PEER-TO-PEER (P2P) - KADEMLIA}

Dado o número considerável de propostas para EPCDS baseadas na utilização de redes P2P, apresentam-se neste capítulo considerações básicas sobre as arquiteturas usuais nestas redes. Em particular, enfatiza-se o protocolo Kademlia, proposto por Maymounkov e Mazières (2002) também empregado em diversos trabalhos, e que é a base da proposta do autor.

\subsection{Características}

Segundo Androutsellis-Theotokis (2002), as redes P2P caracterizam-se pelo acesso e troca de informações diretamente nos computadores da rede, daqui por diante denominados nós, com um mínimo de coordenação central, o que contrasta com o modelo cliente-servidor tradicional. Em particular, redes P2P destinadas ao compartilhamento de arquivos entre usuários popularizaram-se consideravelmente ao longo dos últimos anos.

As redes P2P diferenciam-se do conceito de grid computing, no qual o contato direto entre computadores e ausência de coordenação central também estão presentes, porém com o objetivo de compartilhar recursos para a resolução de problemas computacionalmente complexos (BAKER; BUYYA; LAFORENZA, 2002).

A presença ou não de coordenação, bem como seu grau de importância constitui outro critério de classificação. Androutsellis-Theotokis define:

- Redes puramente descentralizadas: nas quais todos os nós participantes realizam as mesmas tarefas, atuando como clientes e servidores; como exemplo, tem-se a proposta original da rede Gnutella (CREEDON et al., 2003);

- Redes parcialmente descentralizadas: neste modelo alguns nós exercem um papel diferenciado, apresentando, por exemplo, índices de arquivos para nós locais; a criação destes nós varia conforme o protocolo empregado e, devido à sua configuração dinâmica, não constituem pontos únicos de falha capazes de tornar a rede inoperante; como exemplos de redes deste modelo, têm-se as redes Kazaa e a versão 2 da Gnutella; 
- Redes híbridas descentralizadas: neste modelo existe um servidor encarregado de registrar o conteúdo dos nós participantes, na forma de metadados; embora a transferência de informações ocorra diretamente nó a nó, o contato inicial com um servidor que identifica os computadores que disponibilizam o recurso buscado é obrigatório; desta forma este servidor constitui um ponto único de falha, capaz de tornar toda a rede inoperante. A extinta rede Napster é um exemplo deste modelo (CROSSE et al., 2003).

- Redes híbridas centralizadas: neste modelo, o servidor central também encarrega-se das transferências entre nós; por apresentar uma arquitetura do modelo cliente-servidor, não se deve classificá-la como P2P.

Boa parte das críticas de pesquisadores (BARCHETTI et al., 2009; FABIAN; GÜNTHER, 2009; JAKKHUPAN; ARCHINT; Y., 2011) ao modelo de ONS proposto pelo GS1 reside em sua dependência do serviço DNS e a consequente existência de pontos únicos de falha. Assim, as propostas mais recentes para sistemas ONS e EPCDS baseiam-se na utilização de redes P2P puramente descentralizadas, em particular da arquitetura conhecida como Tabelas Hash Distribuídas (Distributed Hast Table - DHT).

\subsection{Redes P2P DHT}

Considere-se um conjunto de dados a compartilhar, por exemplo, endereços de sistemas EPCIS (endereço IP e porta) contendo eventos relativos à passagem de códigos EPC ao longo de uma cadeia produtiva. A cada conjunto pode-se associar uma chave de busca gerada por uma função hash aplicada ao seu conteúdo. Desta maneira, pode-se construir uma tabela formada pelas chaves e endereços de sistemas EPCIS que possuem dados sobre o código.

Nas redes P2P DHT ocorre a distribuição de uma tabela acima entre os nós participantes, o que leva arquiteturas do tipo puramente ou parcialmente descentralizadas.

Para esta função, emprega-se usualmente o algoritmo SHA-1 (INTERNET ENGINEERING TASK FORCE, 2001) que leva a uma distribuição uniforme de 
chaves, com tamanho fixo (160 bits), seja qual for a distribuição dos códigos do domínio (CAl et al., 2003).

Armazenando-se esta tabela em um servidor, é viável a implantação de um serviço EPCDS, formado por uma rede P2P híbrida descentralizada. A existência de um ponto único de falha além de questões ligadas a desempenho e escalabilidade do serviço levam à busca de outras alternativas. Buscam-se frequentemente soluções que se enquadrem nos modelos puramente ou parcialmente descentralizados.

\subsection{Kademlia}

A rede Kademlia é formada por nós caracterizados como um par constituído por um conjunto de dados (valor) e uma chave de identificação, obtida pela aplicação de uma função hash (usualmente a SHA-1) ao valor. Cada nó armazena um conjunto formado pela chave de identificação, o endereço IP do nó e sua porta.

A distribuição uniforme das chaves, característica da aplicação da SHA-1 é um requisito importante das redes Kademlia, para que não se chegue a uma tabela de roteamento desbalanceada. $O$ roteamento de mensagens baseia-se na distância lógica entre nós.

\subsubsection{Métrica de distância e propriedades}

Nas redes Kademlia, entradas da tabela DHT formados por pares <chave, valor> são distribuídos e armazenados em nós, cujas chaves de identificação apresentam maior grau de "proximidade" entre a chave do par e do nó. Como métrica desta distância, utiliza-se a operação ou-exclusivo (eXclusive-OR - XOR) aplicada entre as chaves. Assim, dados dois nós A e B, com distância $d$ entre eles, tem-se:

$$
\begin{aligned}
& A=\{\text { chave } 1, \text { valor } 1\} \\
& B=\{\text { chave } 2, \text { valor } 2\} \\
& d=\text { chave } 1 \oplus \text { chave } 2
\end{aligned}
$$


O uso da operação XOR para cálculo da distância entre nós, além de ser computacionalmente simples, é uma opção válida para cálculo de distância como demonstra o trabalho de Maymounkov e Mazières (2002):

- a distância entre um nó e ele próprio é sempre zero:

$$
d(x, x)=x \oplus x=0
$$

- a distância entre dois nós distintos é sempre maior que zero:

$$
\forall x \neq y: d(x, y)=x \oplus y>0
$$

- verifica-se a simetria:

$$
\forall x, y: d(x, y)=d(y, x)
$$

- verifica-se a propriedade triangular:

$$
d(x, y)+d(y, z) \geq d(x, z)
$$

já que:

$$
d(x, y) \oplus d(y, z)=d(x, z)
$$

e:

$$
\forall a \geq 0, b \geq 0, a+b \geq a \oplus b
$$

Outra característica da métrica XOR é seu aspecto unidirecional; dados um nó $x$ e uma distância $\Delta$, existe um e somente um nó $y$ distante $\Delta$ de $x$ :

$$
\forall x, \Delta \exists ! y \mid d(x, y)=\Delta
$$

Esta propriedade é importante pois qualquer busca por uma chave de identificação converge para uma mesma sequência, qualquer que seja o nó inicial.

O tempo de recuperação de um nó a partir de sua chave de identificação é da ordem de:

$$
T_{n} \in O(\log (n))
$$

Foge ao escopo deste trabalho tecer considerações sobre a demonstração formal desta propriedade, o que encontra-se no item 3 do trabalho de Maymounkov e Mazières (2002). 


\subsubsection{Roteamento}

Daqui por diante, considera-se o caso usual de chaves de identificação contendo 160 bits de informação, salvo citação expressa em contrário. Considera-se também uma representação bigendian das chaves de identificação (bits menos significativos à direita e com menor índice).

Para cada bit entre $0 \leq i<160$, pode-se manter uma lista contendo os endereços dos nós situados a uma distância compreendida entre $2^{i}$ e $2^{i+1}$ do nó corrente. Maymounkov e Mazières atribuem a estas listas a denominação de $k$ buckets. Têm-se, portanto, até 160 k-buckets por nó. Esta denominação tem origem na capacidade de armazenar até 20 valores, sugerida pelos autores para estas listas: $k=20$. A determinação deste valor, denominado fator de replicação, tem como fundamento a ideia de que em menos de uma hora a probabilidade de um conjunto de $k$ nós se desconectarem da rede é muito baixa. $O$ trabalho original não detalha o processo de escolha deste valor.

O preenchimento da tabela de roteamento de cada nó ocorre durante a recepção de mensagens de outros nós da rede. Na recepção de qualquer mensagem, cada nó $x$ insere o endereço do nó remetente $E_{y}=\{I P$, porta $\}$ em seu $k$-bucket devido (de índice $i$ ), calculado em função da distância entre os nós $d(x, y)$ :

$$
\forall i, 0 \leq i<160: k-\text { bucket }_{i}=\left\{E_{y} \mid 2^{i} \leq d(x, y)<2^{i+1}\right\}
$$

Decorre que o índice do k-bucket é dado por:

$$
i=\lfloor\log (d)\rfloor
$$

À medida que cresce o valor de $i$, cresce o número de candidatos a serem armazenados no respectivo $k$-bucket. Para $i=1$, apenas um nó pode ser armazenado: aquele cuja identificação difere do nó corrente apenas no bit menos significativo. Para o k-bucket com maior índice, pode-se armazenar a metade dos valores disponíveis - aqueles cuja identificação diferem do nó corrente no bit mais significativo.

Embora seja possível a reserva inicial de espaço para os 160 k-buckets de um nó, parte-se usualmente de um único $k$-bucket que se divide à medida que a tabela de roteamento cresce.

Inicialmente, poucas informações fazem parte da tabela de roteamento e 
emprega-se apenas um único k-bucket. À medida que novas informações chegam, atinge-se seu limite de $k$ informações.

Neste momento, se a faixa de valores do $k$-bucket totalmente preenchido contiver a chave do próprio nó, divide-se o k-bucket em dois. Caso contrário, descarta-se o novo valor. Feita a divisão, distribui-se o conteúdo, ficando no primeiro os códigos com bit mais significativo igual a um e os demais no segundo. Repete-se a tentativa de inserção.

Com a chegada de mais informações, cada $k$-bucket divide-se em dois (b, $c$ e d) ao atingir seu limite, conforme a figura Figura 17.

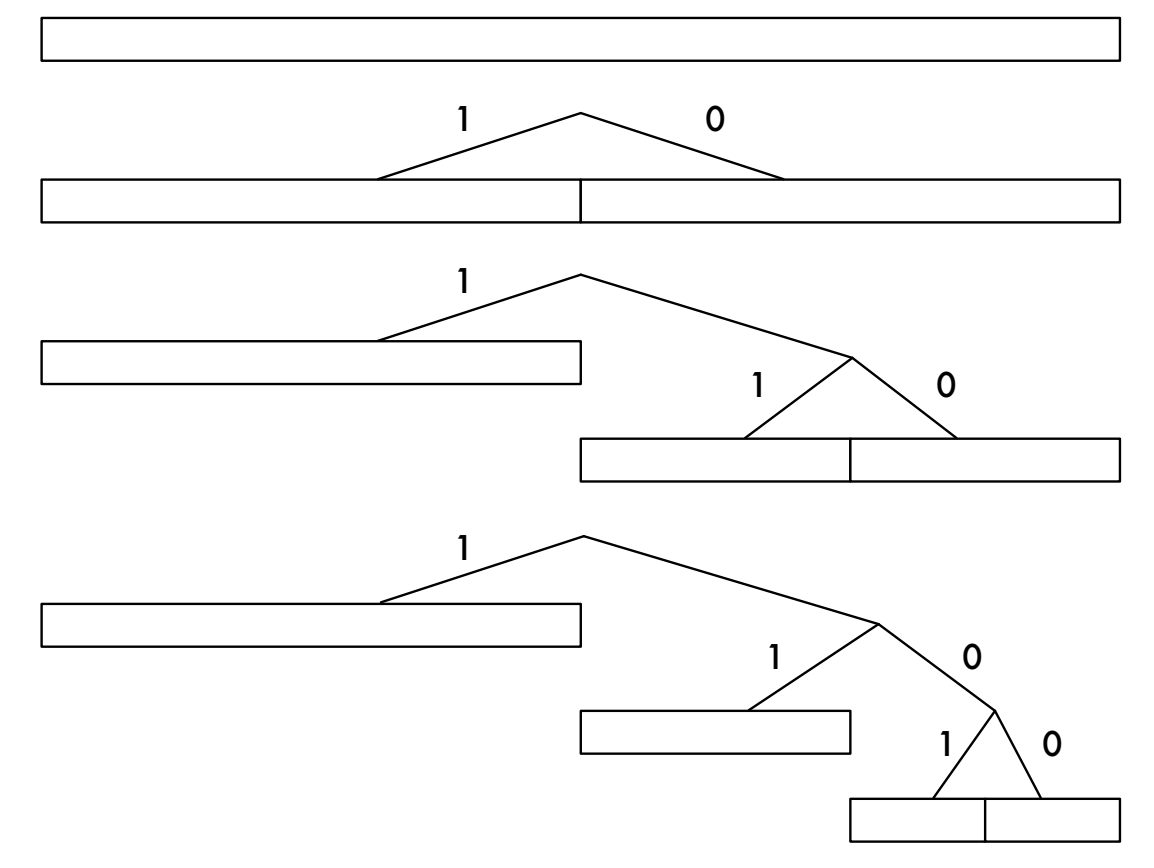

(a)

(b)

(c)

(d)

Figura 17 - Formação dos $k$-buckets.

A procura de um nó a partir de sua chave de identificação leva a uma busca iterativa por nós cada vez mais próximos ao objetivo. Podem-se representar as chaves de identificação dos nós em uma árvore binária, onde os nós são as folhas. O caminho até eles representa o código binário da chave. Observa-se, na Figura 18, o nó 0111, representado por um círculo branco, em uma rede formada com chaves de identificação de 4 bits. 


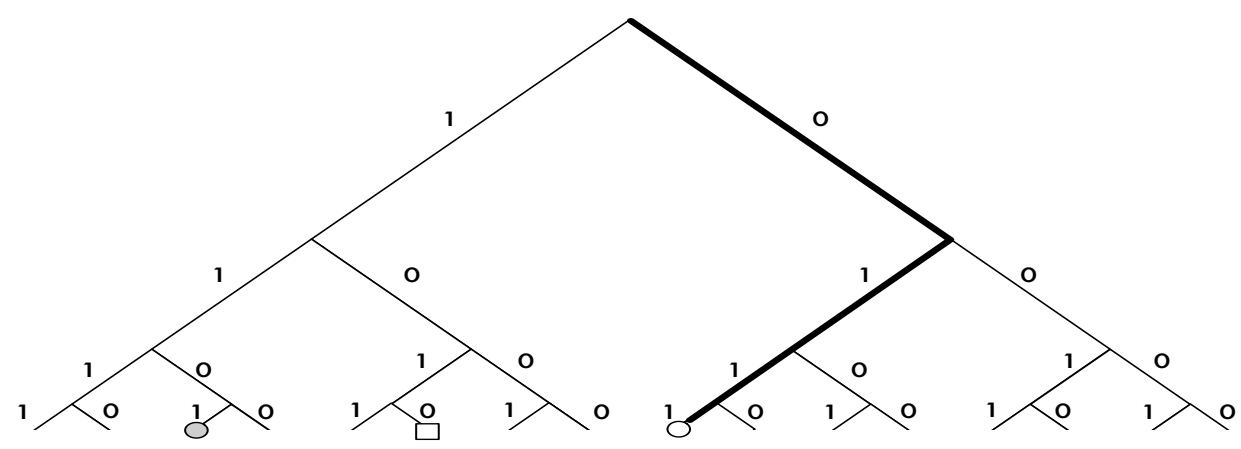

Figura 18 - Representação dos nós de uma rede Kademlia em árvore binária.

$\mathrm{Na}$ busca por outro nó, procura-se, iterativamente, o nó cuja chave de identificação seja igual à distância entre o nó corrente e o buscado. Este procedimento conduz, à cada iteração, a sub-árvores contendo a chave buscada com tamanhos menores, o que acaba por levar ao nó procurado.

Observa-se na Figura 19 a busca do nó 1010, a partir do nó 0111. A cada iteração, a sub-árvore considerada tem sua altura reduzida em uma unidade. Em três iterações, chega-se ao nó buscado. Na Figura, elementos ovais cinzas, em tons progressivamente escuros, demarcam a evolução das sub-árvores. $O$ exemplo ilustra a propriedade apresentada em (13) pois, em uma rede com $n=8$ elementos, chegou-se ao nó desejado em um número de passos não superior a $\log (8)=3$.

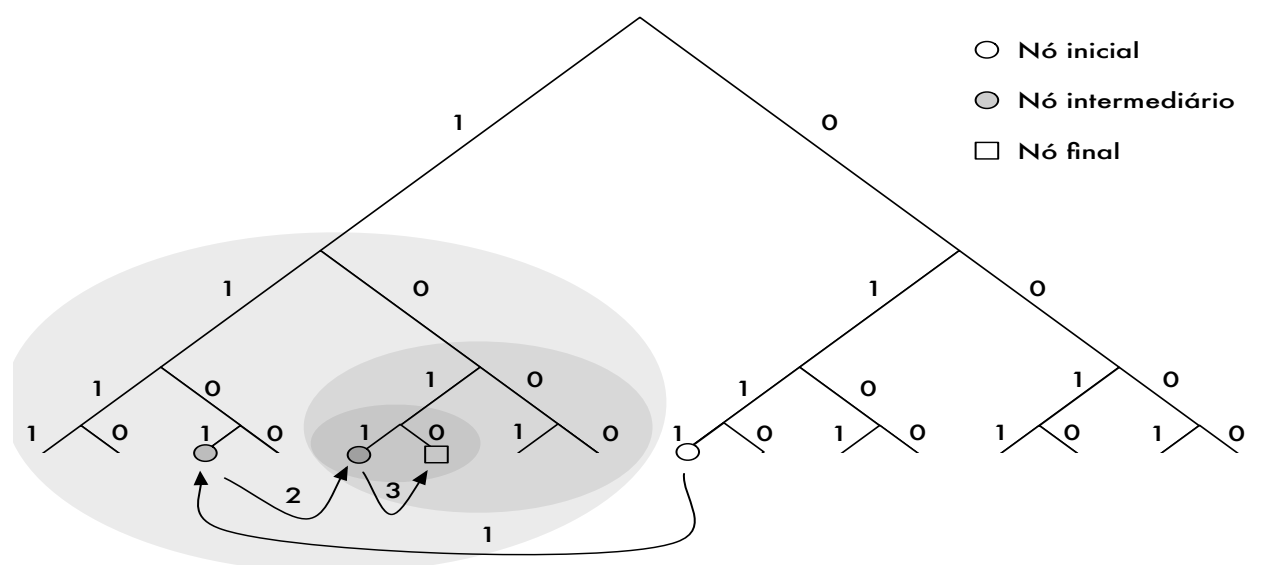




\subsubsection{Protocolo Kademlia}

A implementação do protocolo Kademlia envolve a utilização de quatro tipos de mensagem: PING, FIND_VALUE, FIND_NODE e STORE. Efetuam-se todas as trocas de mensagens por meio do protocolo User Datagram Protocol (UDP).

Além das mensagens básicas, definem-se três rotinas iterativas: Node_lookup, Value_lookup, e iterativeStore (THE XLATTICE PROJECT, 2010).

A implementação do protocolo envolve a definição de alguns parâmetros globais, apresentados na Tabela 5. Os valores na coluna da direita são sugeridos por Maymounkov e Mazières.

Tabela 5 - Parâmetros globais do protocolo Kademlia

\begin{tabular}{llc}
\hline Parâmetro & Significado & $\begin{array}{c}\text { Valor } \\
\text { sugerido }\end{array}$ \\
\hline$\alpha$ & Número de solicitações assíncronas simultâneas por nó & 3 \\
B & Tamanho da chave de identificação em bits & 160 \\
$k$ & Capacidade de armazenamento de um k-bucket & 20 \\
tExpire & Tempo de expiração de um par (chave,valor) & $86400 \mathrm{~s}$ \\
tRefresh & $\begin{array}{l}\text { Intervalo de tempo ao final do qual um k-bucket não acessado deve } \\
\text { tReplicate }\end{array}$ & $\begin{array}{l}\text { intervalo de tempo ao fim do qual cada nó deve republicar o conteúdo } \\
\text { de seu banco de dados }\end{array}$ \\
& $\begin{array}{l}\text { Intervalo de tempo ao fim do qual cada servidor original deve republicar } \\
\text { tRepublish }\end{array}$ & $3600 \mathrm{~s}$ \\
& a informação inicial & $86400 \mathrm{~s}$ \\
\hline
\end{tabular}

Insere-se em cada mensagem enviada um código hash que deve ser retornado ao remetente para constatação do recebimento pelo destinatário. Sempre que esta constatação ocorre, o nó remetente atualiza o conteúdo de seu $k$-bucket adequado com o endereço do nó destinatário, que se acaba de descobrir estar ativo. Desta maneira, a troca de mensagens entre nós é o mecanismo básico para a construção das tabelas de roteamento em cada nó.

As descrições das mensagens e rotinas apresentadas a seguir, têm como referência os trabalhos de (MAYMOUNKOV; MAZIĖRES, 2002b; THE XLATTICE PROJECT, 2010; SPORI, 2006). 


\subsubsection{Mensagem PING}

O objetivo desta mensagem é verificar se outro nó encontra-se ativo. Ao receber uma resposta positiva, o nó remetente atualiza seu $k$-bucket adequado com os dados do destinatário.

\subsubsection{Mensagem STORE}

Esta mensagem, não iterativa, envia um par (chave, valor) a outro nó para que este o armazene para posterior recuperação.

\subsubsection{Mensagem FIND_NODE}

Nesta mensagem, envia-se ao nó destinatário a chave de um nó procurado. $\mathrm{O}$ recipiente, retorna uma lista com os $k$ nós mais próximos ao procurado (dentre seus nós conhecidos).

\subsubsection{Mensagem FIND_VALUE}

Envia-se uma chave ao nó destinatário. Caso este o possua em sua lista de dados armazenados, retorna o valor associado. Em caso contrário, retorna uma lista com os $k$ nós mais próximos, tal como ocorre com a mensagem FIND_NODE.

\subsubsection{Rotina Node_Lookup}

Esta rotina implementa o algoritmo utilizado para localizar os nós mais próximos a uma determinada chave. Executam-se os seguintes passos:

- Procuram-se no k-bucket local apropriado, $\alpha$ contatos mais próximos ao objetivo; se não houver esta quantidade disponível, a busca estende-se a outros k_buckets; retorna-se a lista obtida (ainda que com menos do que $\alpha$ contatos);

- Marca-se o nó mais próximo ao alvo; 
- Para cada nó da lista, enviam-se simultaneamente e de maneira assíncrona, mensagens FIND_NODE;

- Cada mensagem deve retornar uma relação de $k$ contatos que acrescentam-se à lista; se não houver resposta de uma ou mais FIND_NODEs, o nó respectivo é removido da lista;

- Verifica-se se algum dos nós está mais próximo ao alvo, marcando-o como tal;

- Novamente, selecionam-se na lista $\alpha$ contatos mais próximos ao objetivo;

- Enviam-se mensagens FIND_NODE a cada contato, caso ainda não tenham sido visitados;

- A sequência continua até que não se obtenha um nó mais próximo que o obtido na iteração anterior ou que a lista já acumule $k$ contatos ativos.

\subsubsection{Rotina Value_Lookup}

Implementa-se esta rotina de maneira análoga à Node_Lookup utilizando-se, porém, a mensagem FIND_VALUE no lugar da FIND_NODE. Desta maneira, chegase ao valor buscado ou a uma lista contendo os $k$ nós mais próximos ao objetivo. Quando a rotina obtém o valor desejado, envia-se uma mensagem STORE_VALUE ao nó mais próximo do objetivo que não tenha retornado o valor.

\subsubsection{Rotina Iterative_Store}

Realiza-se a rotina Node_Lookup, enviando-se a cada um dos $k$ nós retornados uma mensagem STORE_RPC com o valor a ser armazenado.

\subsubsection{Conexão à rede}

A conexão de um nó à rede obedece à seguinte sequência:

- Atribui-se uma chave de identificação ao nó; pode-se utilizar um valor 
pseudoaleatório obtido no espaço de 160 bits;

- Qualquer lista de contatos válidos que tenha sido previamente armazenada pode ser utilizada;

- Insere-se no(s) k-buckets adequado(s) uma ou mais chaves de outros nós já conhecidos;

- Realiza-se um Node_Lookup da própria chave, procedimento que preenche os primeiros valores na tabela de roteamento.

\subsubsection{Procedimentos}

Maymounkov e Mazières especificam a realização dos procedimentos abaixo em intervalos regulares de tempo. Encontram-se na Tabela 5 a definição dos intervalos de tempo citados a seguir:

- Todos os pares (chave, valor) devem expirar findo o prazo tExpire;

- Passado um intervalo de tempo igual a tRefresh, um k-bucket não consultado deve atualizar seu conteúdo através de um Node_Lookup a um nó com valor pseudoaleatório em sua faixa de chaves válidos;

- Cada nó gerador de um par (chave,valor) deve republicá-lo a cada intervalo tRepublish;

- Cada nó deve republicar o conteúdo de seu banco de dados a cada intervalo tReplicate.

\subsection{Melhorias no protocolo Kademlia}

Maymounkov e Mazières (2002) propõem a adoção de k-buckets relacionados a um número maior de bits do espaço amostral. Desta maneira, aumenta-se sua capacidade de armazenamento por meio de uma maior cobertura do espaço amostral.

Neste caso, considerados $B$ bits cobertos em cada $k$-bucket, o tempo de recuperação de uma informação é da ordem de:

$$
T_{n} \in O\left(\log _{B}(n)\right)
$$




\subsection{Segurança}

Douceur (2002) apresenta uma vulnerabilidade da rede Kademlia a ataques na qual um ou mais nós atacantes apresentam chaves de identificação falsas, porém de valores adequados para o isolamento de determinados nós da rede. Desta maneira, pedidos de inserção de pares (chave,valor) podem ser aceitos e não efetuados, ou adulterados.

A solução proposta por Douceur para este ataque, por ele denominado como Sybil, é a autenticação rigorosa dos nós participantes da rede, como sugerido em (AIELLO et al., 2008; KOHNEN; GERBECKS; RATHGEB, 2011; MACCARI et al., 2009).

De uma maneira geral, as redes $\mathrm{P} 2 \mathrm{P}$ apresentam vulnerabilidade a ataques deste tipo (LUA et al., 2005).

\subsection{Outras arquiteturas P2P DHT}

Apresentam-se, a seguir, outros modelos frequentemente empregados para a implantação de redes P2P DHT.

\subsubsection{Tapestry}

Proposta por Zhao et. al (2004), a rede Tapestry utiliza pares (chave,valor) com chaves de identificação de 160 bits (nodeID). A arquitetura permite a utilização de mais de um nó por servidor, o que leva a um segundo identificador (GUID) anexado como sufixo a nodeID. Sua arquitetura básica baseia-se na proposta de Plaxton et al. (1999), (chave,valor) que apresenta em seu trabalho uma estrutura para distribuição de dados conhecida como Plaxton mesh. Nela, os objetos contendo dados são conectados a um nó raiz (root). A busca ao nó raiz leva a sequência de dados buscados.

Na rede Tapestry a existência de múltiplos nós raiz garante a não existência de pontos únicos de falha. As tabelas de roteamento local dos nós são estruturadas em níveis, cada um responsável pelo sufixo da chave de identificação até uma determinada posição. Desta forma, o nó de ordem $n$ compartilha um sufixo de pelo 
menos $n$ dígitos com a chave do alvo. Na sequência do roteamento, procura-se no mapa do nível $(n+1)$ o nó que compartilha o próximo dígito de sua chave com a chave do alvo.

O método garante a convergência em um máximo de $\log _{B}(n)$ saltos, onde $B$ representa a base das chaves de identificação, sendo que usualmente $B=2^{4}=16$ para caracteres hexadecimais.

\subsubsection{Chord}

Proposta por Stoica et al. (2001) os nós de uma rede Chord possuem chaves de identificação de $n$ bits distribuídos em um círculo. Desta maneira, cada nó possui um único sucessor e antecessor. Para se evitar a queda da rede com a eventual saída de algum nó, mantém-se uma relação com um determinado número de nós sucessores e antecessores, de maneira a garantir uma elevada probabilidade de manutenção do serviço.

A busca de uma chave a partir de um nó por visitação ao sucessor leva a um tempo da ordem de $O(n)$. Para uma melhor performance, cada nó mantém uma tabela de roteamento, denominada finger table, contendo uma relação de endereços de até $n$ nós, onde a entrada de ordem $i$ na tabela leva ao endereço do nó sucessor de ordem $2^{i}$, o que leva a um tempo de busca da ordem de $O(\log (n))$.

Observe-se que na rede Chord o roteamento ocorre sempre em um único sentido, a partir de um nó para seus sucessores.

\subsubsection{Pastry}

Proposta por Rowstron e Druschel (2001), a rede Pastry mantém chaves de identificação de 128 bits em uma distribuição circular dos nós, como a rede Chord. Assim como a Tapestry, a arquitetura básica da rede baseia-se na Plaxton mesh utilizando, no entanto, o prefixo das chaves, como elemento.

$O$ roteamento ocorre em até $\log _{B}(n)$ saltos, onde $B$ é a base das chaves de identificação, sendo que usualmente $B=2^{4}=16$ para caracteres hexadecimais.

Em cada salto, a rede leva ao nó cuja chave seja numericamente mais 
próxima à chave do alvo. Para isto, procura em sua tabela de roteamento um nó que possua pelo menos um dígito a mais do que o prefixo já compartilhado pelo nó corrente e a chave do alvo.

\subsection{Comparação entre arquiteturas}

A título de comparação entre as diversas arquiteturas apresentadas, apresentam-se na Tabela 6 características compiladas por (LUA et al., 2005).

Tabela 6 - Comparação entre redes P2P DHT

\begin{tabular}{|c|c|c|c|c|}
\hline & Tapestry & Pastry & Chord & Kademlia \\
\hline Número de nós & $\mathrm{n}$ & $\mathrm{n}$ & $\mathrm{n}$ & $\mathrm{n}$ \\
\hline Performance & $\mathrm{O}\left(\log _{B}(\mathrm{n})\right)$ & $\mathrm{O}(\log (n))$ & $O(\log (n))$ & $\mathrm{O}\left(\log _{\mathrm{B}}(\mathrm{n})\right)$ \\
\hline Arquitetura básica & $\begin{array}{l}\text { Plaxton } \\
\text { mesh }\end{array}$ & $\begin{array}{l}\text { Plaxton } \\
\text { mesh }\end{array}$ & $\begin{array}{l}\text { NodelD } \\
\text { unidirecional e } \\
\text { circular }\end{array}$ & $\begin{array}{l}\text { Métrica XOR } \\
\text { para distância } \\
\text { entre nós }\end{array}$ \\
\hline Protocolo de busca & $\begin{array}{l}\text { Busca de sufixo } \\
\text { no NodelD }\end{array}$ & $\begin{array}{l}\text { Igualdade de } \\
\text { chave e prefixo } \\
\text { de NodelD }\end{array}$ & $\begin{array}{l}\text { Igualdade de } \\
\text { chave e NodelD }\end{array}$ & $\begin{array}{l}\text { Igualdade de } \\
\text { chave e NodelD }\end{array}$ \\
\hline $\begin{array}{l}\text { Pode armazenar } \\
\text { diversas rotas para } \\
\text { cada nó }\end{array}$ & $\operatorname{sim}$ & $\operatorname{sim}$ & não & não \\
\hline $\begin{array}{l}\text { Nova tentativa de } \\
\text { leitura após falha }\end{array}$ & não & não & $\operatorname{sim}$ & não \\
\hline $\begin{array}{c}\text { Múltiplos nós } \\
\text { armazenam a } \\
\text { mesma informação }\end{array}$ & $\operatorname{sim}$ & $\operatorname{sim}$ & $\operatorname{sim}$ & $\operatorname{sim}$ \\
\hline $\begin{array}{c}\text { Falha de nós } \\
\text { individuais afetam a } \\
\text { rede }\end{array}$ & não & não & não & não \\
\hline $\begin{array}{c}\text { Susceptibilidade a } \\
\text { ataques }\end{array}$ & $\operatorname{sim}$ & $\operatorname{sim}$ & $\operatorname{sim}$ & $\operatorname{sim}$ \\
\hline
\end{tabular}

Pela análise da tabela, observa-se a similaridade de características entre as várias arquiteturas, que compartilham tanto boas qualidades (bom desempenho e ausência de pontos únicos de falha) como características indesejáveis (susceptibilidade a ataques). 
Comentando as características da rede Kademlia em relação às demais, pode se destacar:

- Mensagens em número reduzido, rotinas e algoritmos simples aliados à baixa demanda de recursos computacionais proporcionam uma implantação (programação) mais simples, quando comparada às demais, informação que é tratada superficialmente na literatura, até por sua difícil medição, porém constatada pelo autor durante a pesquisa;

- O reenvio de mensagens no caso de falhas, presente na Chord, pode ser implantado facilmente e sem prejuízo do desempenho, dada a característica assíncrona das mensagens; a melhoria na eficácia proporcionada pela Kademlia com a implementação deste reenvio pode ser objeto para nova pesquisa;

- A característica de poder armazenar diversas rotas para um mesmo nó, presente na Tapestry, em uma primeira análise não se faz necessária na Kademlia, onde a busca é orientada a nós próximos a um objetivo e não uma chave específica; novamente, outra pesquisa pode trazer informações sobre esta questão;

- A métrica para busca de nós, baseada na operação XOR, computacionalmente é extremamente simples;

- A saída de nós na rede ocorre de forma localizada, qualquer nó remove outro peer de sua tabela de roteamento ao perceber que este não se encontra mais disponível; não é necessário o envio de nenhuma mensagem a outros nós, seja o que se retira, ou o que percebe a reconfiguração;

- A entrada de nós na rede também ocorre de maneira simples; durante a conexão à rede, o nó faz uma auto busca à própria chave, o que começa a preencher sua tabela de roteamento, ao mesmo tempo que vai informando sua presença a outros nós, processo que se acentua à medida em que novas mensagens forem sendo trocadas. 


\section{SOLUÇÃO PROPOSTA}

Ao longo da revisão bibliográfica, com o entendimento dos fundamentos da arquitetura EPCglobal, observou-se o número significativo de artigos científicos envolvendo propostas para a criação de Sistemas de Resolução de Objetos EPC, motivados pela falta de especificação deste componente pelo GS1, o que levou o autor a apresentar a presente proposta.

A partir da análise dos trabalhos de outros pesquisadores, e das observações registradas no item 5.7, optou-se pela utilização de uma rede $\mathrm{P} 2 \mathrm{P}$ baseada na arquitetura Kademlia, com uma variante do algoritmo interno de busca de nós, além da modificação de alguns comportamentos previstos para os nós da rede, com o objetivo de maximizar a eficácia no caso da presença de um grande número de informações sobre cada EPC, condição que ocorre na prática.

É importante ressaltar o significado do grifo acima: maximizar a eficácia significa, neste caso, a obtenção da maior lista de nós contendo informações sobre a chave pesquisada. No entanto, tanto Kademlia quanto os demais modelos de rede P2P apresentados, não podem garantir uma eficácia de $100 \%$, pois a informação registrada em um nó indisponível não poderá ser obtida enquanto esta situação perdurar. Outras situações transientes de adaptação dinâmica da rede poderão causar uma breve indisponibilidade de certos nós.

\subsection{Problema não resolvido no algoritmo Kademlia}

Nas redes Kademlia, segundo a proposta de Maymounkov e Mazières (2002), o algoritmo de busca por uma chave cessa a busca tão logo um nó consultado possua sua localização.

Este comportamento não é desejável para a implantação de um EPCDS, pois informações de um determinado EPC estão, usualmente, em diversos sistemas EPCIS por onde a passagem do item houver sido registrada.

llustra-se na Figura 20, um exemplo deste problema. Em uma rede P2P Kademlia com 16 nós, a chave epc apresenta dados registrados em 4 servidores: 1 , 7, 12 e 14. Ao requisitar informações sobre a chave epc, um EPCIS ou aplicativo cliente externo envia a mensagem iterativeFindValue(epc) à rede. $\mathrm{O}$ algoritmo 
Kademlia leva a apenas um nó contendo este valor. No exemplo, o nó encontrado é o número 12. Ao ser encontrado, encerra-se a busca. Nenhuma informação sobre a existência de outros nós é obtida.

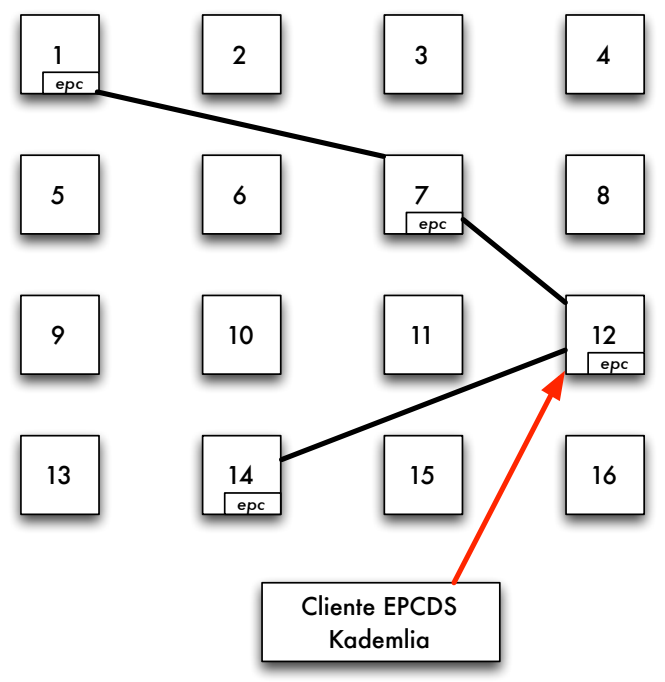

Figura 20 - Cliente de uma EPCIS baseado na rede P2P Kademlia original.

Vale ressaltar que a determinação do nó encontrado é função da tabela de roteamento do nó que inicia a requisição; portanto diferentes resultados poderão ser retornados em diferentes momentos e/ou quando solicitados por diferentes nós.

Outro possível tentativa, a obtenção de um desempenho mais elevado da rede não é promissora, pois dada a característica de tempos de resposta da ordem $c+O(\log (n))$ do algoritmo original, a procura por melhor desempenho poderia levar a alguma melhoria no valor da constante $c$, pouco expressiva.

\subsection{Proposta do autor}

A partir destas peculiaridades, buscaram-se alterações do algoritmo original e de certos comportamentos especificados para os nós da rede que levassem à maximização de eficácia na busca por informações diversas espalhadas na rede. Mais objetivamente, que se aumentasse a probabilidade de obtenção de todos os nós da rede que contenham informações sobre a chave buscada.

A primeira alteração efetuada foi na alteração do algoritmo do processamento iterativeFindValue(). Na proposta inicial, tem-se a seguinte sequência apresentada 
nos itens 5.3.3.5 e 5.3.3.6.

Ao receber a (única) resposta positiva obtida com a aplicação do algoritmo original, que leva a um dos nós que contém um ponteiro para o servidor onde a informação buscada reside, envia-se a este nó nova mensagem iterativeFindValue(). Repete-se este processo até que não se obtenham novos nós. Ilustra-se este processo na Figura 21, que apresenta uma rede composta pelos nós $A, B, C, D, E$ e $F$. Os nós $E, F$ e $G$ contém informações sobre a chave epc. A informação que leva a estes nós está armazenada nos nós B, C e D. A busca, conforme a proposta do autor ocorre em uma sequência de quatro fases:

- Nó A envia iterativeFindValue(key) a rede (não ilustrado) e recebe B;

- Nó A envia iterativeFindValue(key) a B e recebe C (a);

- Nó A envia iterativeFindValue(key) a C e recebe D (b);

- Nó A envia iterativeFindValue(key) e D e recebe resposta negativa (c);

Obtém-se, desta maneira, a lista dos servidores que contém as informações sobre epc composta pelos nós B, C e D (que levam aos servidores F, G e H).

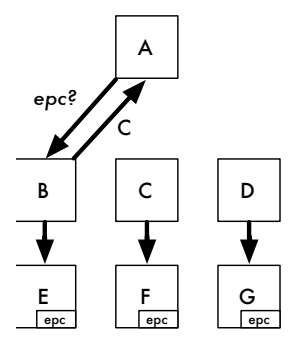

(a)

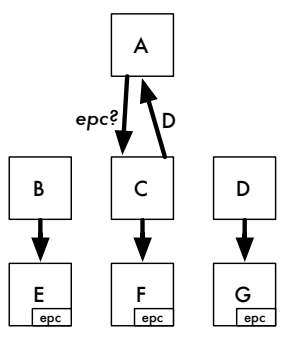

(b)

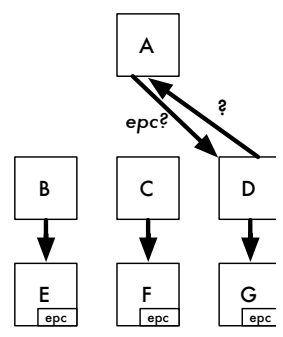

(c)

Figura 21 - Exemplo de fluxo para a busca proposta.

Descartam-se soluções que envolvam nós visitados.

\subsection{Simulação}

Uma vez definida a solução a ser proposta, desenvolveu-se um software composto por quatro módulos, destinado a emular o funcionamento de um nó em uma rede Kademlia, alterada conforme descrição no item anterior. 


\subsubsection{Gateway coordenador}

O primeiro módulo atua como gateway "coordenador" da rede, atribuindo os contatos iniciais a cada nó, durante sua conexão à rede, o que foi útil na simulação. Em uma implementação prática, este módulo não seria necessário. Bastariam a existência de alguns endereços iniciais de referência. Efetua-se a conexão a este módulo por meio de datagramas UDP em endereços IP e porta fixos.

\subsubsection{Emulador de nó}

O segundo modo emula um nó da rede $\mathrm{P} 2 \mathrm{P}$, com o protocolo Kademlia modificado implementado; cada nó possui chave de identificação distinta, bem como IP e porta para comunicação entre os demais módulos.

Este é o módulo mais complexo. Apresenta-se na Figura 22 o diagrama funcional deste módulo.

\subsubsection{Inicializador da rede}

O terceiro módulo, inicializa o gateway e a rede formada por um número de nós determinado pelo usuário, atribuindo a cada nó seu número de porta e chave de identificação.

Ao final, gera um número de códigos EPC (pseudoaleatórios), também definido pelo usuário, bem como o número de nós da rede que deverão receber a informação. 


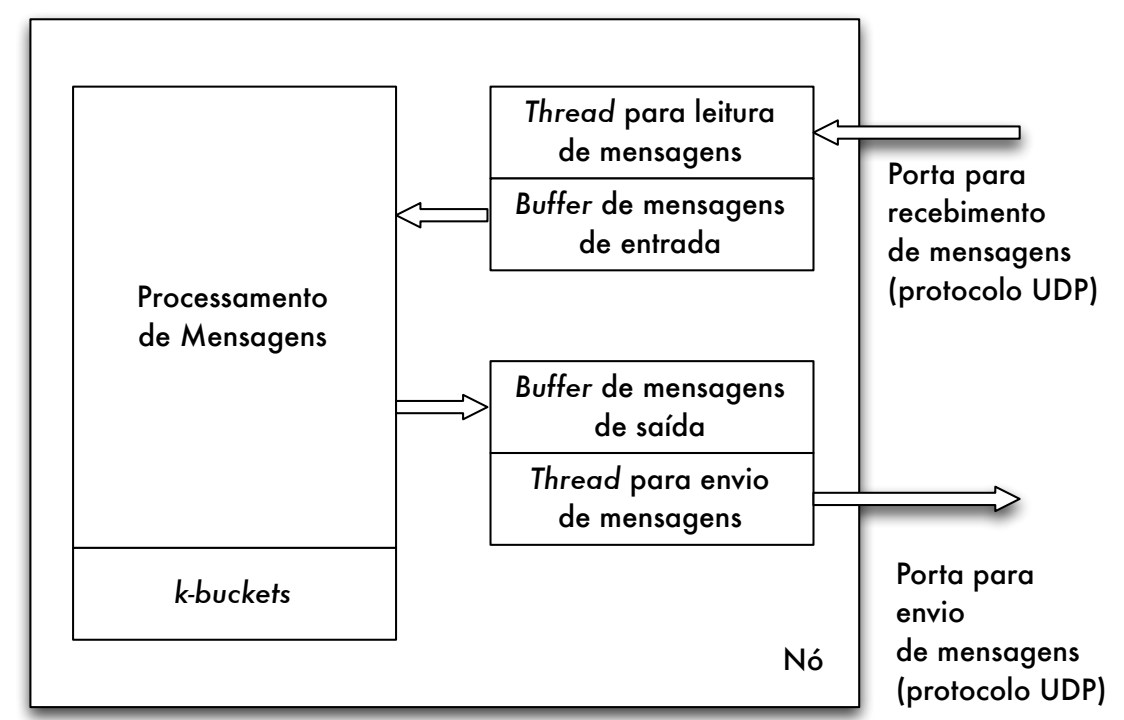

Figura 22 - Diagrama funcional do emulador de nó P2P Kademlia modificado.

\subsubsection{Alimentador de dados}

O quarto módulo "popula" a rede com os códigos EPC gerados pelo módulo anterior. A requisição de armazenamento é enviada a nós diferentes a cada iteração.

\subsubsection{Módulo de consulta}

O quinto e último módulo realiza, em intervalos periódicos, a consulta a nós aleatórios sobre a existência de códigos EPC; podem-se definir o intervalo de tempo e a utilização ou não de códigos não existentes na rede. Este módulo permite a verificação da eficácia da solução, identificando os resultados e tempos de resposta de cada consulta e armazenando esta informação no banco de dados. O módulo direciona a consulta a diferentes nós em cada iteração. Apresenta-se na Figura 23, o diagrama funcional dos módulos encarregados da simulação. 


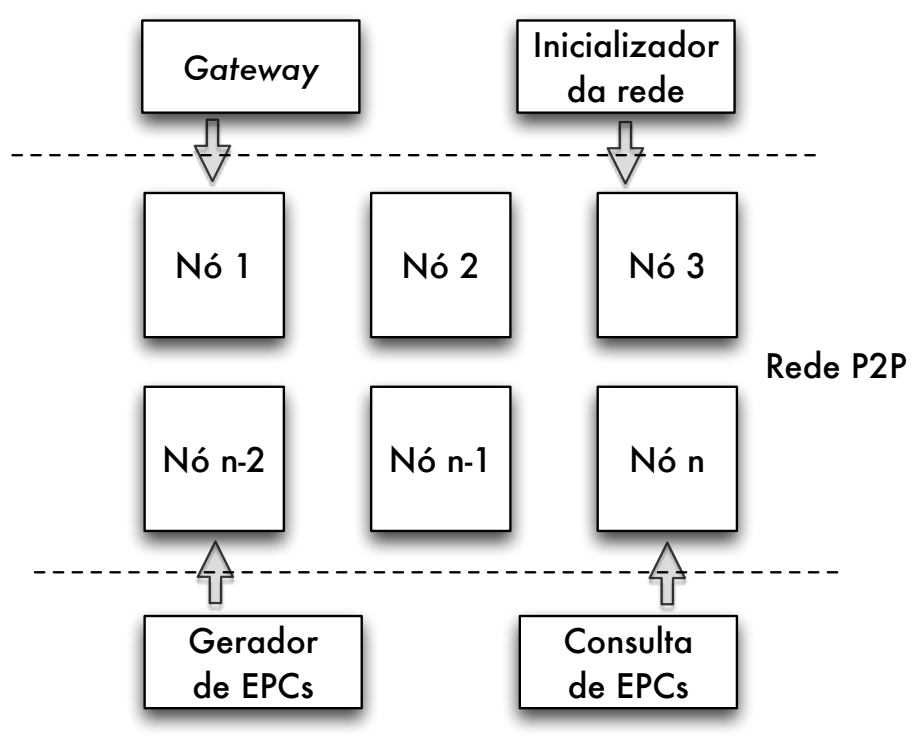

Figura 23 - Diagrama funcional do software de simulação.

A Figura 24 - Tela do computador realizando a simulação apresenta a tela do computador, capturada em um momento da execução de uma das simulações iniciais de testes com uma rede de 8 nós.

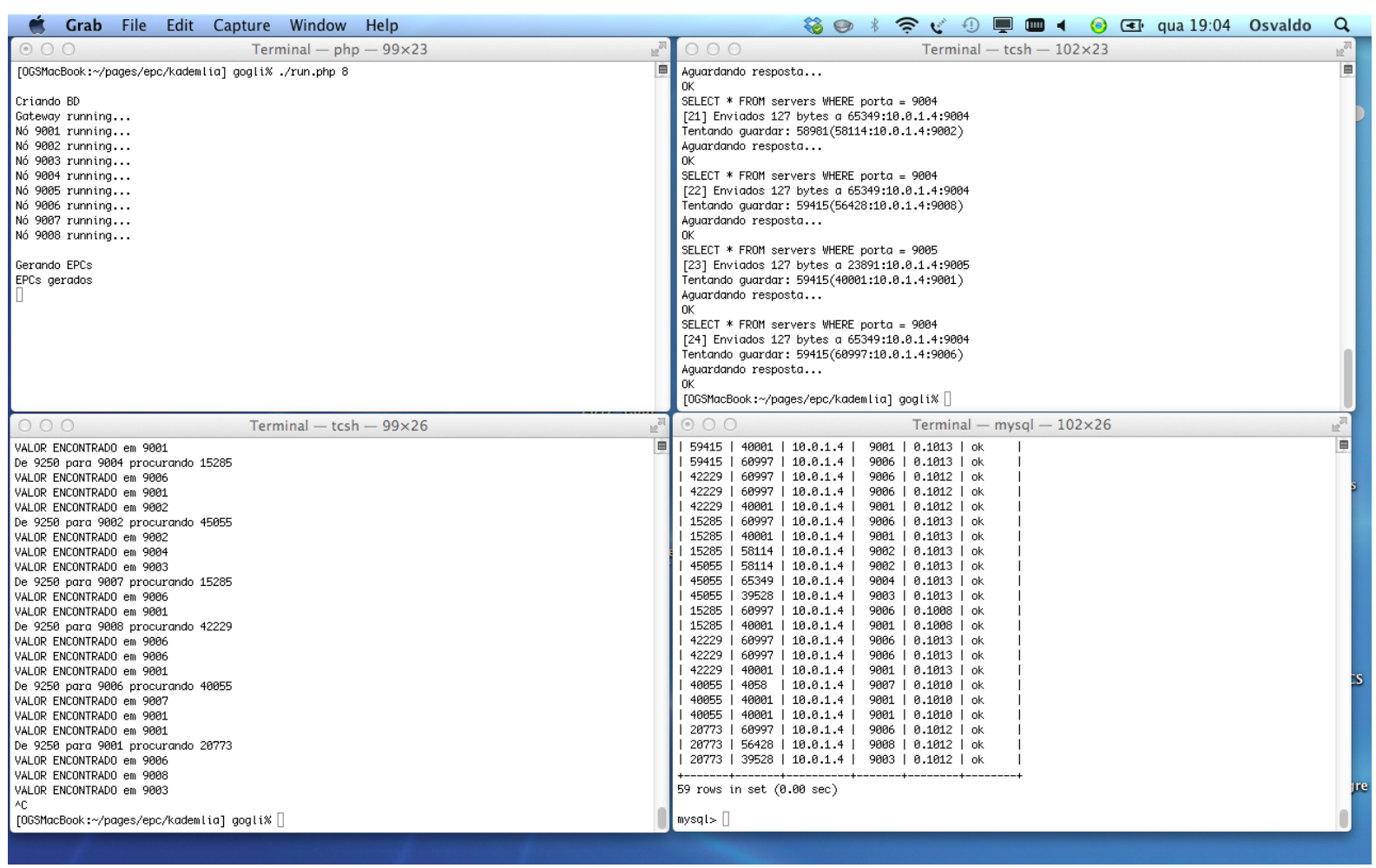

Figura 24 - Tela do computador realizando a simulação. 


\subsubsection{Equipamento utilizado}

A simplicidade do protocolo Kademlia, já comentada no item 5.7, levou a uma solução com diminuto tamanho e baixa exigência de recursos computacionais do software, permitindo a simulação, em apenas um computador, de uma rede composta por até 64 servidores com execução simultânea em um único microcomputador MacBook, com sistema operacional MacOs V. 10.7.5, com 4 gigabytes de memória RAM. Observe-se que o sistema operacional MacOs é baseado no FreeBSD Unix.

\subsubsection{Ferramentas e linguagem utilizadas}

Descartou-se, a priori, a utilização de uma ferramenta de simulação computacional para redes. Fundamenta-se esta decisão, no tempo necessário à implementação do modelo da rede Kademlia na ferramenta, comparado ao tempo de desenvolvimento de um software dedicado à simulação. Favorecem esta opção a larga experiência do autor com desenvolvimento de software, a consideração exclusiva de fatores pertinentes à simulação em estudo (o que não é normalmente possível quando se emprega uma ferramenta tradicional) e a simplicidade do protocolo Kademlia.

Desenvolveu-se o software com a linguagem PHP V 5.3.15 (THE PHP GROUP, 2007). A escolha da linguagem de programação fundamentou-se unicamente na experiência prévia do autor com sua utilização. Diversas outras linguagens poderiam ser utilizadas. No entanto as seguintes características do PHP foram fundamentais para a agilidade do desenvolvimento:

- Linguagem interpretada de alto desempenho, evitando o ciclo programação, compilação, teste, edição;

- Possibilidade de execução em computadores com praticamente quaisquer sistemas operacionais em uso;

- Possibilidade de programação com a utilização de threads, por meio de uma biblioteca externa (BARBU, 2009), que contribuíram para o desempenho adequado.

Para registro dos dados da simulação empregou-se a ferramenta MySQL 
versão 5.5.15 (ORACLE, 2007).

\subsection{Código fonte do software empregado.}

Para maior transparência do trabalho realizado, possibilidade de repetição das simulações realizadas e para que sirva como guia para interessados em futuras implementações, os códigos fontes dos cinco módulos utilizados encontram-se disponíveis para download no endereço Internet :

http:www.abili.com.br/kademlia/kademlia.zip.

\subsection{Pontos não abordados na solução proposta}

Não se consideraram na pesquisa as questões indicadas a seguir. Embora todas elas sejam relevantes para uma implementação bem sucedida de um serviço EPCDS, delimitou-se o escopo da pesquisa ao problema apresentado. É importante ressaltar, contudo, que nenhum destes pontos afeta a eficácia da solução proposta.

- Identificação e autorização: não se consideraram requisitos de identificação e autorização de usuários;

- Adequação do vocabulário de dados: a compatibilidade com o padrão EPCglobal deverá ser respeitada; na simulação realizada empregaram-se estruturas de dados simplificadas;

- Adequação da interface com outros nós e sistemas: a compatibilidade com o padrão EPCglobal deverá ser respeitada; na simulação realizada empregaram-se interfaces IP simples, por meio de datagramas UDP;

- Adequação dos protocolos de comunicação: os protocolos de comunicação também necessitam conformidade com o EPCglobal; particularmente, o uso de web services necessita ser implementado. 


\section{RESULTADOS E CONCLUSÕES}

\subsection{Resultados obtidos}

Segue uma análise dos resultados obtidos, tanto do ponto de vista do atendimento a requisitos não funcionais quanto a funcionais.

\subsubsection{Requisitos não funcionais}

Verifica-se a obtenção dos seguintes resultados, com relação aos requisitos fundamentais apresentados por Evdomimov (2010):

1) Suporte a esquemas de identificação de códigos flexíveis: previsto para a criação futura de esquemas de codificação diversos.

A utilização da função $S H A-1$ para a geração de chaves de identificação permite o emprego de chaves de quaisquer tamanhos.

2) Permissão de publicação: um provedor de informações deve poder fornecer ao EPCDS informações sobre os EPCs para os quais esteja autorizado a fazê-lo, incluindo endereços de EPCIS.

Este requisito não foi considerado nesta pesquisa. Sua implementação é possível e não invalida os resultados obtidos.

3) Publicação múltipla: diversos participantes independentes da cadeia (porém autorizados), devem ser capazes de fornecer dados.

Quanto à autorização, este requisito não foi considerado nesta pesquisa. Sua possível implementação não invalida os resultados obtidos. Na solução proposta qualquer nó pode fornecer dados.

4) Consulta a EPC: após consulta sobre determinado EPC, o serviço deve fornecer, a clientes autorizados, uma lista com os EPCIS contendo dados relativos ao código consultado.

Quanto à autorização, este requisito não foi considerado nesta pesquisa. A solução proposta entrega a lista dos EPCIS solicitados.

5) Atualização: participantes da cadeia autorizados devem poder atualizar informações previamente gravadas no serviço.

Este requisito leva à republicação de mensagens, possível (e desejável) nas 
redes Kademlia.

6) Cancelamento: participantes da cadeia autorizados devem poder cancelar informações previamente gravadas no serviço. Documentos gravados devem possuir indicação de tempo de validade (time-to-live - TTL), com o objetivo de automatizar o trabalho de deleção e reduzir o espaço de armazenamento.

Não se consideraram as questões de tempo de validade nesta pesquisa. Sua implantação, embora simples, deve ser cuidadosa devido aos requisitos legais para a manutenção destas informações.

7) Endereços em nível de referência: se o EPC estiver estruturado como número de referência do item e número de série, o serviço deve ser capaz de aceitar consultas contendo apenas a informação de referência do item.

Este requisito não é atendido na solução proposta. Sua implementação é possível, mas levaria a uma dupla rede, contendo adicionalmente somente os códigos de referência do item. O custo benefício deste requisito é discutível.

8) Endereços contendo número de série: se o EPC estiver estruturado como número de referência do item e número de série, o serviço deve ser capaz de aceitar consultas contendo a informação total, incluindo o número de referência do item e seu número de série.

A solução proposta atende a este requisito.

Desta maneira, verifica-se que com exceção de um (sétimo requisito), atendem-se a todos os requisitos em maior ou menor grau. Nos demais requisitos, onde verificam-se atendimentos parciais, a adoção de critérios de segurança possibilita o atendimento total. Novamente, é importante observar que a eficácia da solução não é afetada por estas questões.

Com relação ao sexto requisito que impõe um limite de tempo para validade das informações armazenadas, vale ressaltar que embora de fácil implementação, o atendimento a este requisito tem implicações que podem afetar as exigências legais sobre a manutenção de informações sobre a rastreabilidade das cadeias produtivas.

\subsubsection{Requisitos funcionais}

Por meio do software descrito no Capítulo 6, efetuou-se uma simulação de 
rede P2P, com a proposta do autor. Utilizaram-se os seguintes parâmetros:

Tabela 7 - Parâmetros da simulação

\begin{tabular}{lc}
\hline Característica & Valor \\
\hline Número de nós & 64 \\
Número de bits das chaves & 16 \\
$k$ & 4 \\
$\alpha$ & 1 \\
Números de EPCs alimentados & 483 \\
Média de EPCs registrados por nó & 3 \\
Resultados obtidos & 403 \\
\hline
\end{tabular}

Observe-se que o número de 16 bits por chave, embora inferior ao usual (160 bits) em nada interfere na eficácia da solução permitindo, porém, um emulador de nó de menor tamanho. Valem as mesmas observações para o parâmetro $k$. O valor reduzido de $\alpha$ afeta somente o desempenho da simulação e não a eficácia da proposta.

Obtiveram-se os seguintes resultados:

Tabela 8 - Resultados obtidos

\begin{tabular}{lc}
\hline Métrica & Valor \\
\hline Eficácia (retorno de todos os nós existentes) & $100 \%$ \\
Tempo máximo de resposta & $10,0910 \mathrm{~s}$ \\
Tempo mínimo de resposta & $0,1002 \mathrm{~s}$ \\
Tempo médio de resposta & $1,1730 \mathrm{~s}$ \\
Números de EPCs alimentados & 483 \\
Média de EPCs registrados por nó & 3 \\
Buscas positivas obtidas & 403 \\
\hline
\end{tabular}

Apresentam-se os resultados das medições individuais nos Anexo A e B deste trabalho.

\subsection{Conclusões}

Verifica-se que a proposta apresentada corresponde ao objetivo de 
proporcionar uma arquitetura básica de rede $\mathrm{P} 2 \mathrm{P}$, capaz de dar suporte a um serviço EPCDS.

A futura definição do modelo a ser adotado pelo GS1 para os serviços de busca de códigos EPC dentro da arquitetura EPCglobal será de grande importância para a adoção desta arquitetura de referência, pois as funcionalidades a serem agregadas por este serviço serão significativas.

Espera-se que este estudo possa contribuir para a análise do modelo a ser definido como padrão para a arquitetura.

\subsection{Sugestões para pesquisas futuras}

Os aspectos apresentados a seguir podem contribuir para um maior aprofundamento da proposta apresentada.

- O estudo do impacto na eficácia da solução com o possível reenvio de mensagens em caso de falhas.

- O efeito do armazenamento de diversas rotas para um mesmo nó.

- Os efeitos de uma eventual substituição do protocolo UDP pelo TCP/IP; trata-se de uma questão envolvendo maior robustez da solução contra menor desempenho.

- Os efeitos causados pela retirada de nós da rede durante a simulação.

- O estudo de limites de tempo para armazenamento de informações (TTL), considerando-se tanto aspectos legais como questões ligadas ao volume de dados armazenados.

- O estudo do efeito da implementação dos aspectos não abordados na pesquisa, descritos no item 6.5.

- O efeito da realização desta simulação por meio de uma ferramenta de simulação computacional tradicional. 


\section{REFERÊNCIAS}

ABU-AMARA, M. et al. Dynamic peer-to-peer (P2P) solution to counter malicious higher Domain Name System (DNS) nameservers. In: Conference on Electrical and Computer Engineering (CCECE), 2011 24th Canadian, 2011, Anais... IEEE, 2011. p. 001014-001018.

ACCENTURE. Pilot RFID/EPC Brasil: A Cadeia de Suprimento do Futuro. 2005.

Disponível em: <http://www.pg.com/pt_BR/downloads/pdf/revista_RFID_23-0805.pdf>. Acesso em: 20 Set 2012.

AIELLO, L. M. et al. Tempering Kademlia with a Robust Identity Based System. In: P2P '08. Eighth International Conference on Peer-to-Peer Computing, 2008., 2008, Anais... 2008. p. 30-39.

ANDROUTSELLIS-THEOTOKIS, S. A survey of peer-to-peer file sharing technologies. Athens: 2002. Disponível em: <http://citeseerx.ist.psu.edu/ viewdoc/summary?doi=10.1.1.12.8524>. Acesso em: 03 Nov 2012.

ASHTON, K. That 'Internet of Things' Thing. RFiD Journal, v. 22, p. 97-114, 2009.

ASSOCIAÇÃO BRASILEIRA DE NORMAS TÉCNICAS. NBR ISO 22000: Sistemas de gestão da segurança de alimentos - Requisitos para qualquer organização na cadeia produtiva de alimentos. Rio de Janeiro, 2006, 35 p.

ATZORI, L.; IERA, A.; MORABITO, G. The internet of things: A survey. Computer Networks, v. 54, n. 15, p. 2787-2805, 2010.

BAKER, M.; BUYYA, R.; LAFORENZA, D. Grids and Grid technologies for wide-area distributed computing. Software: Practice and Experience Softw: Pract. Exper., v. 32, n. 15, p. 1437-1466, 2002.

BARBU, T. Multithreading in PHP. 2009. Disponível em: <http://blog.motane.lu/ 2009/01/02/multithreading-in-php/>. Acesso em: 10 Jan. 2013.

BARCHETTI, U. et al. Implementation and testing of an EPCglobal-aware Discovery Service for item-level traceability. In: Ultra Modern Telecommunications \& Workshops, 2009. ICUMT '09. International Conference on Ultra Modern Telecommunications \& Workshops, 2009, Anais... 2009. p. 1-8.

BERNARD, A. et al. The Belgian PCB/Dioxin Incident: Analysis of the Food Chain Contamination and Health Risk Evaluation. Environmental Research, Amsterdam, v. 88, n. 1, p. 1-18, 2002. 
BOWERSOX, D. J.; CLOSS, D. J.; COOPER, M. B. Gestão Logística de Cadeias de Suprimentos Gestão Logística de Cadeias de Suprimentos. Porto Alegre: Bookman, 2006, 528 p.

BRASIL. Instituto Nacional da Propriedade Industrial. Define as condições para a concessão de indicações geográficas no Brasil. Resolução INPI n 075/2000. 28 de Novembro de 2000.

BRASIL. Portaria No 368 de 04 de Setembro de 1997, 1997. Ministério da Agricultura, Pecuária e Abastecimento.

—. Lei 12.097 de 24 de Novembro de 2009, 2009. Diário Oficial da União. 25 de Novembro de 2009.

BROCK, D. The Compact Electronic Product Code A 64-bit Representation of the Electronic Product Code. Boston: 2001. Disponível em: <http://www.autoidlabs.org/uploads/media/MIT-AUTOID-WH-008.pdf>. Acesso em: 12 Jul. 2012.

BROCK, D.; CUMMINS, C. EPC TM Tag Specification. Boston: 2003. Disponível em: <http://forum.autoidlabs.org/uploads/media/MIT-AUTOID-WH025.pdf>. Acesso em: 29 Mai. 2012.

BUREAU INTERNATIONAL DE POIDS ET MESURES. International vocabulary of metrology - Basic and general concepts and associated terms (VIM). 2008. Disponível em: <http://www.bipm.org/utils/common/documents/jcgm/ JCGM_200_2012.pdf>. Acesso em: 13 Jun. 2012.

CAI, M. et al. MAAN: a multi-attribute addressable network for grid information services. In: Grid Computing, 2003. Anais. Fourth International Workshop on Grid Computing, 2003. Anais. Fourth International Workshop on, 2003, Anais... 2003. p. 184-191.

CANTERO, J. J. et al. Traceability applications based on discovery services. In: Emerging Technologies and Factory Automation, 2008. ETFA 2008. IEEE International Conference on, 2008, Anais... IEEE, 2008. p. 1332-1337.

CASPIAN. Boycott Benetoon - No RFID tracking chips in clothing. 2012a. Disponível em: <http://www.boycottbenetton.com>. Acesso em: 12 Set 2012.

. Consumers Against Supermarket Privacy Invasion and Numbering.

2012b. Disponível em: <http://www.nocards.org>. Acesso em: 12 Set 2012.

CHOPRA, D. et al. Peer-to-peer overlays for real-time communication: security issues and solutions. Communications Surveys \& Tutorials, IEEE, v. 11, n. 
1, p. 4-12, 2009.

CREEDON, E. et al. Gnutella. 2003. Disponível em: <http://ntrg.cs.tcd.ie/undergrad/ 4ba2.02-03/p5.html>. Acesso em: 03 Nov. 2012.

CROSSE, S. et al. Napster. 2003. Disponível em: <http://ntrg.cs.tcd.ie/undergrad/ 4ba2.02-03/p4.html>. Acesso em: 03 Nov. 2013.

DALFOVO, O.; HOSTINS, C. A. Delineamento para aplicação do RFID na logística de supermercado como inteligência competitiva: supermercado Hostins. Revista Interdisciplinar Científica Aplicada, Blumenau, v. 4, n. 1, p. 23-48, 2010.

DAUGHERTY, P. J.; PITTMAN, P. H. Utilization of time-based strategies: creating distribution flexibility/responsiveness. International Journal of Operations 1\& Production Management, v. 15, n. 2, p. 54-60, 1995.

DIMARA, E.; SKURAS, D. Consumer Evaluations of Product Certification, Geographic Association and Traceability in Greece. European Journal of Marketing, Bingley, v. 37, n. 5/6, p. 690-705, 2003.

DOUCEUR, J. The Sybil AttackIn: Druschel, P.; Kaashoek, F.; Rowstron, A. (eds.), 2429. Springer Berlin Heidelberg, 2002.

EPCGLOBAL INC. EPC Information Services (EPCIS) Version 1.0.1

Specification. 2007. Disponível em: <http://www.gs1.org/gsmp/kc/epcglobal/ epcis/epcis_1_0_1-standard-20070921.pdf>. Acesso em: 01 Mai. 2012.

ERL, T. Service-Oriented Architecture. Upper Saddle River: Prentice Hall, 2004.

EVDOKIMOV, S. et al. Comparison of discovery service architectures for the internet of things. In: Sensor Networks, Ubiquitous, and Trustworthy Computing (SUTC), 2010 IEEE International Conference on, 2010, Anais... IEEE, 2010. p. 237-244.

FABIAN, B. Implementing Secure P2P-ONS. In: ICEEE International Conference on Communications, 2009, Anais... IEEE Computer Society, 2009. p. 1-5.

FABIAN, B.; GUNTHER, O. Distributed ONS and its Impact on Privacy. In: Communications, 2007. ICC'07. IEEE International Conference on, 2007, Anais... IEEE, 2007. p. 1223-1228.

FABIAN, B.; GÜNTHER, O. Security challenges of the EPCglobal Network. Communications of the ACM, v. 52, n. 7, p. 121-125, 2009.

FABIAN, B.; GÜNTHER, O.; SPIEKERMANN, S. Security Analysis of the Object Name Service. 2010. Disponível em: <http://citeseerx.ist.psu.edu/viewdoc/ 
summary?doi=10.1.1.152.7711>. Acesso em: 01 Mai. 2012.

GAO, J. Z.; PRAKASH, L.; JAGATESAN, R. Understanding 2D-BarCode Technology and Applications in M-Commerce - Design and Implementation of A 2D Barcode Processing Solution. In: Computer Software and Applications Conference, 2007. COMPSAC 2007. 31st Annual International Computer Software and Applications Conference, 2007. COMPSAC 2007. 31st Annual International, 2007, Anais... 2007. p. 49-56.

GLOBAL COMMERCE INITIATIVE. EPC: A Shared Vision for Transforming Business Processes. 2005. Disponível em: <http://www935.ibm.com/services/uk/igs/pdf/epc-a-shared-vision.pdf>. Acesso em: 13 Jul. 2012.

GOLAN, E. et al. Traceability in the U.S. Food Supply: Economic Theory and Industry Studies. Washington: United States Department of Agriculture, 2004. $48 \mathrm{p}$.

GOMES DE CASTRO, A. M.; LIMA, S. M. V.; CRISTO, C. M. P. N. Cadeia Produtiva: Marco Conceitual para Apoiar a Prospecc ão Tecnológica. In: XXII Simpósio de Gestão da Inovação Tecnológica, 2002, Salvador. Anais... Salvador: 2002. p. 14.

GROVER, A.; BERGHEL, H. A Survey of RFID Deployment and Security Issues. Journal of Information Processing Systems, v. 7, n. 4, p. 561-580, 2011.

GS1. The EPCglobal Architecture Framework Version 1.4. Brussels: 2010a. Disponível em: <http://www.gs1.org/gsmp/kc/epcglobal/architecture/architecture_1_4framework-20101215.pdf>. Acesso em: 29 Mai. 2012. - The Value and Benefits of the GS1 System of Standards. Bruxelas: 2012. Disponível em: <http://www.gs1.org/docs/GS1_System_of_Standards.pdf>. Acesso em: 30 jul. 2012.

—. GS1 EPC Tag Data Standard 1.6. Brussels: 2011. Disponível em: <http://www.gs1.org/gsmp/kc/epcglobal/tds/tds_1_6-RatifiedStd20110922.pdf>. Acesso em: 29 Mai. 2012.

GS1 General Specifications V13. 2013. Disponível em: <http://www.gs1us.org/DesktopModules/DNNCorp/DocumentLibrary/Componen ts/FileDownloader/FileDownloaderPage .aspx tabid=111\&did=1180\&pid=0\&lrf=/ DesktopModules/DNNCorp/DocumentLibrary/App_LocalResources/DocumentLi 
brary\&cl=en-

US\&mcs=\%2fDesktopModules\%2fDNNCorp\%2fDocumentLibrary\%2f\&uarn=Ad ministrators\&cd=false\&tmid=115\&ift=1>. Acesso em: 13 Fev. 2013.

GS1 BRASIL. Código de Barras. São Paulo: 2012. Disponível em: <http://www.gs1br.org/main.jsp?lumChannelld=402881762BA79A24012BAAB3 69F20C5D>. Acesso em: 01 Dez. 2012.

GS1. EPC Radio-Frequency Identity Protocols Class-1 Generation-2 UHF RFID Protocol for Communications at 860 MHz - 960 MHz Version 1.2.0. 2008a. Disponível em: <http://www.gs1.org/gsmp/kc/epcglobal/ uhfc1g2/uhfc1g2_1_2_0-standard-20080511.pdf>. Acesso em: 23 Out. 2008.

- EPCglobal Object Name Service (ONS) 1.0.1. Brussels: 2008b. Disponível em: $<$ http://www.gs1.org/gsmp/kc/epcglobal/ ons/ons_1_0_1-standard-20080529.pdf>. Acesso em: 29 Mai. 2012.

—. GS1 Standards Document GS1 Global Traceability Standard. 2010b. Disponível em: <http://www.gs1.org/sites/default/files/docs/gsmp/ traceability/Global_Traceability_Standard.pdf>. Acesso em: 13 Jun. 2012.

URDANETA, G.; PIERRE, G.; STEEN, M. V. A survey of DHT security techniques. ACM Comput. Surv., v. 43, n. 2, p. 1-49, 2011.

GIESBRECHT, H. O. Indicações Geográficas Brasileiras Indicações Geográficas Brasileiras. Brasília: INPI, SEBRAE., 2011, 164 p.

IDTECHEX. RFID Market Reaches \$7.67 Billion in 2012 - up 17\% from 2011. 2012. Disponível em: <http://www.idtechex.com/research/articles/rfid-marketreaches-7-67-billion-in-2012-up-17-from-2011-00004585.asp>. Acesso em: 12 Set 2012.

INTERNATIONAL ORGANIZATION FOR STANDARDIZATION. ISO 9000:2005. Quality management systems - Fundamentals and vocabulary. 2005, 30 p. INTERNET ENGINEERING TASK FORCE. HTTP Over TLS. 2000. Disponível em: <https://tools.ietf.org/html/rfc2818>. Acesso em: 15 Jan. 2007.

RFC 3174 - US Secure Hash Algorithm 1 (SHA1). 2001. Disponível em: <http://www.apps.ietf.org/rfc/rfc3174.html>. Acesso em: 15 Jul. 2009.

. MIME-Based Secure Peer-to-Peer Business Data Interchange Using HTTP, Applicability Statement 2 (AS2). 2005. Disponível em: <http://tools.ietf.org/html/rfc4130>. Acesso em: 10 Jan. 2013.

—. The Internet Engineering Task Force. 2013. Disponível em: 
<http://www.ietf.org>. Acesso em: 16 Mar. 2013.

STOICA, I. et al. Chord: A scalable peer-to-peer lookup service for internet applications. SIGCOMM Comput. Commun. Rev., v. 31, n. 4, p. 149-160, 2001.

JAKKHUPAN, W.; ARCHINT, S.; Y., L. I. Business process analysis and simulation for the RFID and EPCglobal Network enabled supply chain: A proof-of-concept approach. Journal of Network and Computer Applications, v. 34, n. 3, p. 949-957, 2011.

KOHNEN, M.; GERBECKS, J.; RATHGEB, E. P. Applying Certificate-Based Routing to a Kademlia-Based Distributed Hash Table. In: AP2PS 2011, The Third International Conference on Advances in P2P Systems, 2011, Anais... 2011. p. 85-89.

KÜRSCHNER, C. et al. Discovery Service Design in the EPCglobal Network

The Internet of Things. In: Floerkemeier, C.; Langheinrich, M.; Fleisch, E.; Mattern, F.; Sarma, S. (eds.), 4952. Springer Berlin / Heidelberg, 2008.

KYWE, S. M. et al. Evaluation of Different Electronic Product Code Discovery Service Models. Advances in Internet of Things, v. 2, n. 2, p. 37 - 46, 2012.

LANDT, J. The history of RFID. Potentials, IEEE Potentials, IEEE, v. Potentials, IEEE, n. 4, p. 8-11, 2005.

LATOUCHE, K.; RAINELLI, P.; VERMERSCH, D. Food Safety Issues and the BSE Scare: Some Lessons from the French Case. Food Policy, Amsterdam, v. 23, n. 5, p. 347-356, 1998.

LIU, Y.; WANG, D.; HU, Y. A scheme of integrating DNS into P2P service network. In: 2011 4th IEEE International Conference on roadband Network and Multimedia Technology (IC-BNMT), 2011, Anais... IEEE, 2011. p. 8-11.

LORENZ, M. et al. A Distributed EPC Discovery Service based on Peer-to-peer Technology. RFID SysTech 2011: 7th European Workshop on Smart Objects: Systems, Technologies and Applications, p. 1-7, 2011.

LUA, E. K. et al. A survey and comparison of peer-to-peer overlay network schemes. IEEE Communications Surveys and Tutorials, v. 7, n. 2, p. 72-93, 2005.

MACCARI, L. et al. Avoiding eclipse attacks on Kad/Kademlia: an identity based approach. In: ICC 2009 Communication and Information Systems Security Symposium, 2009, Dresden. Anais... Dresden: 2009.

MACHADO, R. T. M. Rastreabilidade, Teoria da Informação e Coordenação de 
Sistemas Agroindustriais. 2000. 224 p. Tese (doutorado) - Faculdade de Economia, Administração e Contabilidade. São Paulo, 2000.

MAYMOUNKOV, P.; MAZIĖRES, D. Kademlia: A Peer-to-Peer Information System

Based on the XOR Metric

Peer-to-Peer SystemsIn: Druschel, P.; Kaashoek, F.; Rowstron, A. (eds.), Lecture

Notes in Computer Science 2429. Springer Berlin / Heidelberg, 2002b.

MCFARLANE, D.; SHEFFI, Y. The Impact of Automatic Identification on Supply

Chain Operations. International Journal of Logistics Management, v. 4, n. 1 , p. 1-17, 2003.

MERCOSUL. Resoluc ão MERCOSUL GMC, № 80/96, 1996.

MULLER, J. et al. An Aggregating Discovery Service for the EPCglobal Network. In: 43rd Hawaii International Conference on System Sciences (HICSS), 2010, Anais... 2010. p. 1-9.

NATIONAL INTELLIGENCE COUNCIL. Disruptive Civil Technologies. 2008.

Disponível em: <http://www.dni.gov/files/documents/2008\%20Conference\%20 Report_Disruptive\%20Civil\%20Technologies.pdf>. Acesso em: 12 Set 2012.

ORACLE. MySQL AB :: The world's most popular open source database. Uppsala: 2007. Site Internet oficial do MySQL, popular sistema gerenciador de banco de dados. Disponível em: <http://www.mysql.com>. Acesso em: 01 Ago. 2007.

PARLAMENTO EUROPEU E CONSELHO DA UNIÃO EUROPÉIA. Regulamento (CE) $N^{\circ} \mathbf{1 7 8 / 2 0 0 2 , 2 0 0 2}$. Determina os princípios e normas gerais da legislação alimentar, cria a Autoridade Europeia para a Segurança dos Alimentos e estabelece procedimentos em matéria de segurança dos gêneros alimentícios. Jornal Oficial das Comunidades Européias. 1 de Fevereiro de 2002.

ROBERTS, C. M. Radio frequency identification (RFID). Computers \&amp; Security, v. 25, n. 1, p. 18-26, 2006.

RODUNER, C.; FLOERKEMEIER, C. Fosstrak - Open Source RFID Platform. 2012. Disponível em: <http://code.google.com/p/fosstrak/>. Acesso em: 13 Jul. 2012.

ROWSTRON, A.; DRUSCHEL, P. Pastry: Scalable, Decentralized Object Location, and Routing for Large-Scale Peer-to-Peer Systems Middleware.In: Guerraoui, R. (ed.), Peer-to-Peer Systems Middleware, 2218. Springer Berlin / Heidelberg, 2001. 
SEIDEMAN, T. Barcodes Sweep the World. 2011. Disponível em: <http://www.barcoding.com/information/barcode_history.shtml>. Acesso em: 13 Fev. 2013.

SHRESTHA, S. et al. A peer-to-peer RFID resolution framework for supply chain network. In: Second International Conference on Future Networks, 2010. ICFN'10., 2010, Anais... IEEE, 2010. p. 318-322.

SIMCHI-LEVI, D.; KAMINSKY, P.; SIMCHI-LEVI, E. Cadeia de Suprimentos: Projeto e Gestão Cadeia de Suprimentos: Projeto e Gestão. Porto Alegre: Bookman, 2003, $584 \mathrm{p}$.

SMIERS, L.; GRIFFIOEN, W. Oracle EPCIS and Discovery Service - First Implementation $\quad$ Experiences. Disponível em: <http://www.capgemini.com/m/en/tl/tl_Oracle_EPCIS_and_Discovery_Service__First_Implementation_Experiences.pdf>. Acesso em: 13 Jul. 2012.

SPORI, B. Implementation of the Kademlia Distributed Hash Table. 2006. Semester thesis - Zurich,

SPYCHIPS. How RFID will compromise privacy, security, freedom. 2012. Disponível em: <http://www.spychips.com>. Acesso em: 12 Set 2012.

STOICA, I. et al. Chord: a scalable peer-to-peer lookup protocol for Internet applications. Networking, IEEE/ACM Transactions on Networking, IEEE/ACM Transactions on, v. Networking, IEEE/ACM Transactions on, n. 1, p. 17-32, 2003.

THAKUR, M. et al. Managing food traceability information using EPCIS framework. Journal of Food Engineering, v. 103, n. 4, p. 417-433, 2011.

THE EUROPEAN PARLIAMENT AND THE COUNCIL OF THE EUROPEAN UNION. Regulation (EC) $N^{\circ} 178 / 2002$ of The European Parliament and of The Council, 2002. Laying down the general principles and requirements of food law, establishing the European Food Safety Authority and laying down procedures in matters of food safety. Official Journal of the European Communities. 2002.

THE PHP GROUP. PHP: Hypertext Preprocessor. 2007. Site oficial da linguagem PHP e sua especificação, mantido pelo The PHP Group. Disponível em: <http://www.php.net>. Acesso em: 01 Ago. 2007.

THE XLATTICE PROJECT. Kademlia - A Design Implementation. 2010. Disponível em: <http://xlattice.sourceforge.net/components/protocol/kademlia/ 
specs.html>. Acesso em: 02 Jan 2013.

THIESSE, F. et al. Technology, Standards, and Real-World Deployments of the EPC

Network. Internet Computing, IEEE Internet Computing, IEEE, v. Internet Computing, IEEE, n. 2, p. 36-43, 2009.

THIESSE, F.; MICHAHELLES, F. An overview of EPC technology. Sensor Review, v. 26, n. 2, p. 101-105, 2006.

TROCCHIA, P. J.; AINSCOUGH, T. L. Consumer Attitudes Toward RFID Tracking In

The Retail Environment. Review of Business Information Systems (RBIS), v. 16, n. 2, p. 67-72, 2012.

WEBER, R. H. Internet of Things - New security and privacy challenges. Computer Law \& Security Review, v. 26, n. 1, p. 23-30, 2010.

WHITE, G. et al. A comparison of barcoding and RFID technologies in practice. Journal of Information, Information Technology and Organizations, v. 2, p. 119-132, 2007.

WORLD WIDE WEB CONSORTIUM. Hypertext Transfer Protocol - HTTP/1.1. 1999. Disponível em: <http://www.w3.org/Protocols/rfc2616/rfc2616.html>. Acesso em: 01 Mar 2009.

URIs, URLs, and URNs: Clarifications and Recommendations 1.0. 2001. Disponível em: <http://www.w3.org/TR/uri-clarification/>. Acesso em: 01 Mar 2009.

. Extensible Markup Language (XML). Cambridge: 2007a. Site Internet da especificação da Extensible Markup Language (XML), mantido pelo W3C. Disponível em: <http://www.w3.org/XML/>. Acesso em: 01 Ago. 2007.

SOAP Specifications. Cambridge: 2007b. Site Internet da especificação do protocolo SOAP, mantido pelo W3C. Disponível em: <http://www.w3.org/TR/soap/>. Acesso em: 01 Ago. 2007.

WU, H.; LIN, F.; ZHANG, H. A novel Data-Oriented Name Service for next generation internet. In: ICCTA'09. IEEE International Conference on Communications Technology and Applications, 2009., 2009, Anais... IEEE, 2009. p. 790-795.

WU, Y. B. et al. RFID enabled traceability networks: a survey. Distrib Parallel Dat, Univ Adelaide, Adelaide, SA 5005, Australia yanbo.wu@adelaide.edu.au, v. 29, n. 5-6, p. 397-443, 2011.

ZHAO, B. Y. et al. Tapestry: a resilient global-scale overlay for service deployment. Selected Areas in Communications, IEEE Journal on Selected Areas in 
Communications, IEEE Journal on, v. 22, n. 1, p. 41-53, 2004.

ZHU, X.; MUKHOPADHYAY, S. K.; KURATA, H. A review of RFID technology and its managerial applications in different industries. Journal of Engineering and Technology Management, v. 29, n. 1, p. 152-167, 2012. 


\section{ANEXO A. Valores correspondentes aos EPCs gerados durante a simulação e sua distribuição pela rede}

Apresentam-se no Quadro 1 a distribuição dos EPCs pela rede. As três primeiras colunas contém os dados de cada EPC. A chave de busca, o ID do EPCIS que mantém a informação e qual sua porta. As duas últimas colunas fornecem o ID do nó onde a informação foi gravada e sua porta.

$\mathrm{Na}$ simulação, cada EPC gerado teve informações armazenadas em três EPCIS distintos e esta informação, por sua vez, foi armazenada em três nós distintos da rede. Por exemplo, o EPC com chave 25805 aparece nas 9 primeiras linhas da tabela. Existem informações armazenadas nos EPCIS 52560 (porta 9036), 41503 (porta 9021) e 16983 (porta 9057). A existência destas informações aparecem nos nós 29845 (porta 9006), 24685 (porta 9051) e 32335 (porta (9027).

$\mathrm{Na}$ simulação, todos os nós possuem o mesmo IP, portanto informou-se apenas o número da porta UDP.

Quadro 1 - Valores correspondentes aos EPCs gerados durante a simulação e sua distribuição pela rede

\begin{tabular}{|c|c|c|c|c|}
\hline \multicolumn{3}{|c|}{ EPC a Ser Buscado } & Nó que armazena a informação \\
\hline Chave & EPCIS & Porta & ID & Porta \\
\hline 25805 & 52560 & 9036 & 29845 & 9006 \\
\hline 25805 & 52560 & 9036 & 24685 & 9051 \\
\hline 25805 & 52560 & 9036 & 32335 & 9027 \\
\hline 25805 & 41503 & 9021 & 29845 & 9006 \\
\hline 25805 & 41503 & 9021 & 24685 & 9051 \\
\hline 25805 & 41503 & 9021 & 32335 & 9027 \\
\hline 25805 & 16983 & 9057 & 29845 & 9006 \\
\hline 25805 & 16983 & 9057 & 24685 & 9051 \\
\hline 25805 & 16983 & 9057 & 32335 & 9027 \\
\hline 14505 & 51725 & 9026 & 4483 & 9011 \\
\hline 14505 & 51725 & 9026 & 15788 & 9039 \\
\hline 14505 & 51725 & 9026 & 11159 & 9049 \\
\hline 14505 & 39936 & 9009 & 7054 & 9005 \\
\hline 14505 & 39936 & 9009 & 15788 & 9039 \\
\hline 14505 & 39936 & 9009 & 11159 & 9049 \\
\hline
\end{tabular}




\begin{tabular}{|c|c|c|c|c|}
\hline 14505 & 38345 & 9001 & 12347 & 9014 \\
\hline 14505 & 38345 & 9001 & 14592 & 9045 \\
\hline 14505 & 38345 & 9001 & 11860 & 9041 \\
\hline 55068 & 38600 & 9047 & 54448 & 9024 \\
\hline 55068 & 38600 & 9047 & 54687 & 9053 \\
\hline 55068 & 38600 & 9047 & 55816 & 9032 \\
\hline 55068 & 7054 & 9005 & 38718 & 9003 \\
\hline 55068 & 7054 & 9005 & 54448 & 9024 \\
\hline 55068 & 7054 & 9005 & 55816 & 9032 \\
\hline 55068 & 43642 & 9062 & 54687 & 9053 \\
\hline 55068 & 43642 & 9062 & 54749 & 9048 \\
\hline 55068 & 43642 & 9062 & 55816 & 9032 \\
\hline 60571 & 28854 & 9013 & 60724 & 9008 \\
\hline 60571 & 28854 & 9013 & 59713 & 9030 \\
\hline 60571 & 28854 & 9013 & 51725 & 9026 \\
\hline 60571 & 4405 & 9061 & 50496 & 9018 \\
\hline 60571 & 4405 & 9061 & 60724 & 9008 \\
\hline 60571 & 4405 & 9061 & 51725 & 9026 \\
\hline 60571 & 50288 & 9040 & 60724 & 9008 \\
\hline 60571 & 50288 & 9040 & 64119 & 9004 \\
\hline 60571 & 50288 & 9040 & 51725 & 9026 \\
\hline 50635 & 24685 & 9051 & 64119 & 9004 \\
\hline 50635 & 24685 & 9051 & 50496 & 9018 \\
\hline 50635 & 24685 & 9051 & 52560 & 9036 \\
\hline 50635 & 946 & 9019 & 64119 & 9004 \\
\hline 50635 & 946 & 9019 & 50496 & 9018 \\
\hline 50635 & 946 & 9019 & 52560 & 9036 \\
\hline 50635 & 45778 & 9016 & 64119 & 9004 \\
\hline 50635 & 45778 & 9016 & 50496 & 9018 \\
\hline 50635 & 45778 & 9016 & 52560 & 9036 \\
\hline 15524 & 19411 & 9038 & 12347 & 9014 \\
\hline 15524 & 19411 & 9038 & 15788 & 9039 \\
\hline 15524 & 19411 & 9038 & 11860 & 9041 \\
\hline 15524 & 21114 & 9054 & 11940 & 9015 \\
\hline 15524 & 21114 & 9054 & 15788 & 9039 \\
\hline 15524 & 21114 & 9054 & 11860 & 9041 \\
\hline 15524 & 7856 & 9025 & 9248 & 9034 \\
\hline 15524 & 7856 & 9025 & 15788 & 9039 \\
\hline 15524 & 7856 & 9025 & 11860 & 9041 \\
\hline
\end{tabular}




\begin{tabular}{|c|c|c|c|c|}
\hline 41898 & 38345 & 9001 & 60724 & 9008 \\
\hline 41898 & 38345 & 9001 & 47516 & 9002 \\
\hline 41898 & 38345 & 9001 & 45778 & 9016 \\
\hline 41898 & 44329 & 9022 & 47516 & 9002 \\
\hline 41898 & 44329 & 9022 & 41614 & 9052 \\
\hline 41898 & 44329 & 9022 & 43642 & 9062 \\
\hline 41898 & 29845 & 9006 & 49013 & 9058 \\
\hline 41898 & 29845 & 9006 & 41167 & 9028 \\
\hline 41898 & 29845 & 9006 & 44329 & 9022 \\
\hline 56102 & 17099 & 9043 & 54448 & 9024 \\
\hline 56102 & 17099 & 9043 & 56304 & 9056 \\
\hline 56102 & 17099 & 9043 & 54749 & 9048 \\
\hline 56102 & 38345 & 9001 & 56304 & 9056 \\
\hline 56102 & 38345 & 9001 & 54687 & 9053 \\
\hline 56102 & 38345 & 9001 & 54448 & 9024 \\
\hline 56102 & 59713 & 9030 & 60724 & 9008 \\
\hline 56102 & 59713 & 9030 & 55816 & 9032 \\
\hline 56102 & 59713 & 9030 & 54749 & 9048 \\
\hline 23944 & 279 & 9023 & 32216 & 9010 \\
\hline 23944 & 279 & 9023 & 23391 & 9029 \\
\hline 23944 & 279 & 9023 & 17099 & 9043 \\
\hline 23944 & 55816 & 9032 & 17987 & 9020 \\
\hline 23944 & 55816 & 9032 & 16538 & 9017 \\
\hline 23944 & 55816 & 9032 & 16983 & 9057 \\
\hline 23944 & 48217 & 9037 & 4483 & 9011 \\
\hline 23944 & 48217 & 9037 & 22315 & 9035 \\
\hline 23944 & 48217 & 9037 & 23391 & 9029 \\
\hline 53710 & 50496 & 9018 & 54448 & 9024 \\
\hline 53710 & 50496 & 9018 & 54749 & 9048 \\
\hline 53710 & 50496 & 9018 & 55816 & 9032 \\
\hline 53710 & 54687 & 9053 & 54749 & 9048 \\
\hline 53710 & 54687 & 9053 & 54687 & 9053 \\
\hline 53710 & 54687 & 9053 & 55816 & 9032 \\
\hline 53710 & 21114 & 9054 & 54749 & 9048 \\
\hline 53710 & 21114 & 9054 & 54687 & 9053 \\
\hline 53710 & 21114 & 9054 & 55816 & 9032 \\
\hline 51511 & 34167 & 9063 & 50496 & 9018 \\
\hline 51511 & 34167 & 9063 & 51725 & 9026 \\
\hline 51511 & 34167 & 9063 & 50288 & 9040 \\
\hline
\end{tabular}




\begin{tabular}{|c|c|c|c|c|}
\hline 51511 & 61592 & 9042 & 52560 & 9036 \\
\hline 51511 & 61592 & 9042 & 49180 & 9060 \\
\hline 51511 & 61592 & 9042 & 50288 & 9040 \\
\hline 51511 & 14592 & 9045 & 60724 & 9008 \\
\hline 51511 & 14592 & 9045 & 51725 & 9026 \\
\hline 51511 & 14592 & 9045 & 50288 & 9040 \\
\hline 57545 & 49180 & 9060 & 64119 & 9004 \\
\hline 57545 & 49180 & 9060 & 59713 & 9030 \\
\hline 57545 & 49180 & 9060 & 50496 & 9018 \\
\hline 57545 & 21114 & 9054 & 64119 & 9004 \\
\hline 57545 & 21114 & 9054 & 59713 & 9030 \\
\hline 57545 & 21114 & 9054 & 50496 & 9018 \\
\hline 57545 & 59713 & 9030 & 60724 & 9008 \\
\hline 57545 & 59713 & 9030 & 59713 & 9030 \\
\hline 57545 & 59713 & 9030 & 50288 & 9040 \\
\hline 31440 & 4483 & 9011 & 32216 & 9010 \\
\hline 31440 & 4483 & 9011 & 32335 & 9027 \\
\hline 31440 & 4483 & 9011 & 24685 & 9051 \\
\hline 31440 & 46389 & 9046 & 32216 & 9010 \\
\hline 31440 & 46389 & 9046 & 32335 & 9027 \\
\hline 31440 & 46389 & 9046 & 24685 & 9051 \\
\hline 31440 & 34305 & 9033 & 28854 & 9013 \\
\hline 31440 & 34305 & 9033 & 32335 & 9027 \\
\hline 31440 & 34305 & 9033 & 24685 & 9051 \\
\hline 37699 & 4405 & 9061 & 48217 & 9037 \\
\hline 37699 & 45778 & 9016 & 38729 & 9012 \\
\hline 37699 & 4405 & 9061 & 38600 & 9047 \\
\hline 37699 & 45778 & 9016 & 38718 & 9003 \\
\hline 37699 & 45778 & 9016 & 34305 & 9033 \\
\hline 37699 & 4405 & 9061 & 39936 & 9009 \\
\hline 37699 & 7856 & 9025 & 38718 & 9003 \\
\hline 37699 & 7856 & 9025 & 38729 & 9012 \\
\hline 37699 & 7856 & 9025 & 45778 & 9016 \\
\hline 40617 & 54749 & 9048 & 39936 & 9009 \\
\hline 40617 & 54749 & 9048 & 38718 & 9003 \\
\hline 40617 & 54749 & 9048 & 34305 & 9033 \\
\hline 40617 & 21114 & 9054 & 39936 & 9009 \\
\hline 40617 & 21114 & 9054 & 38718 & 9003 \\
\hline 40617 & 21114 & 9054 & 34305 & 9033 \\
\hline
\end{tabular}




\begin{tabular}{|c|c|c|c|c|}
\hline 50550 & 17987 & 9020 & 50496 & 9018 \\
\hline 50550 & 17987 & 9020 & 50288 & 9040 \\
\hline 50550 & 17987 & 9020 & 51725 & 9026 \\
\hline 50550 & 11860 & 9041 & 60724 & 9008 \\
\hline 40617 & 49013 & 9058 & 38718 & 9003 \\
\hline 40617 & 49013 & 9058 & 39936 & 9009 \\
\hline 40617 & 49013 & 9058 & 34305 & 9033 \\
\hline 50550 & 24685 & 9051 & 64119 & 9004 \\
\hline 50550 & 24685 & 9051 & 50496 & 9018 \\
\hline 50550 & 24685 & 9051 & 52560 & 9036 \\
\hline 30468 & 41614 & 9052 & 29845 & 9006 \\
\hline 30468 & 41614 & 9052 & 28854 & 9013 \\
\hline 30468 & 41614 & 9052 & 24685 & 9051 \\
\hline 30468 & 15788 & 9039 & 17987 & 9020 \\
\hline 30468 & 15788 & 9039 & 29845 & 9006 \\
\hline 30468 & 15788 & 9039 & 24685 & 9051 \\
\hline 30468 & 54448 & 9024 & 29845 & 9006 \\
\hline 30468 & 54448 & 9024 & 28854 & 9013 \\
\hline 30468 & 54448 & 9024 & 24685 & 9051 \\
\hline 39477 & 946 & 9019 & 39936 & 9009 \\
\hline 39477 & 946 & 9019 & 38718 & 9003 \\
\hline 39477 & 946 & 9019 & 34305 & 9033 \\
\hline 39477 & 64119 & 9004 & 38345 & 9001 \\
\hline 39477 & 64119 & 9004 & 39936 & 9009 \\
\hline 39477 & 64119 & 9004 & 48217 & 9037 \\
\hline 39477 & 60724 & 9008 & 38729 & 9012 \\
\hline 39477 & 60724 & 9008 & 39936 & 9009 \\
\hline 39477 & 60724 & 9008 & 38600 & 9047 \\
\hline 17277 & 14592 & 9045 & 16538 & 9017 \\
\hline 17277 & 14592 & 9045 & 16983 & 9057 \\
\hline 17277 & 14592 & 9045 & 19411 & 9038 \\
\hline 17277 & 49180 & 9060 & 16538 & 9017 \\
\hline 17277 & 49180 & 9060 & 16983 & 9057 \\
\hline 17277 & 49180 & 9060 & 19411 & 9038 \\
\hline 17277 & 24685 & 9051 & 28854 & 9013 \\
\hline 17277 & 24685 & 9051 & 16538 & 9017 \\
\hline 17277 & 24685 & 9051 & 19411 & 9038 \\
\hline 61935 & 34167 & 9063 & 64119 & 9004 \\
\hline 61935 & 34167 & 9063 & 61592 & 9042 \\
\hline
\end{tabular}




\begin{tabular}{|c|c|c|c|c|}
\hline 61935 & 34167 & 9063 & 54448 & 9024 \\
\hline 61935 & 6736 & 9044 & 61592 & 9042 \\
\hline 61935 & 6736 & 9044 & 64119 & 9004 \\
\hline 61935 & 6736 & 9044 & 54448 & 9024 \\
\hline 61935 & 34305 & 9033 & 54448 & 9024 \\
\hline 61935 & 34305 & 9033 & 61592 & 9042 \\
\hline 61935 & 34305 & 9033 & 60724 & 9008 \\
\hline 8233 & 11940 & 9015 & 9248 & 9034 \\
\hline 8233 & 11940 & 9015 & 11860 & 9041 \\
\hline 8233 & 11940 & 9015 & 14592 & 9045 \\
\hline 8233 & 22315 & 9035 & 11860 & 9041 \\
\hline 8233 & 22315 & 9035 & 9178 & 9064 \\
\hline 8233 & 22315 & 9035 & 14592 & 9045 \\
\hline 63318 & 47516 & 9002 & 64119 & 9004 \\
\hline 63318 & 47516 & 9002 & 61592 & 9042 \\
\hline 63318 & 47516 & 9002 & 54448 & 9024 \\
\hline 63318 & 14592 & 9045 & 60724 & 9008 \\
\hline 63318 & 14592 & 9045 & 61592 & 9042 \\
\hline 63318 & 14592 & 9045 & 54448 & 9024 \\
\hline 59375 & 21114 & 9054 & 50496 & 9018 \\
\hline 59375 & 21114 & 9054 & 60724 & 9008 \\
\hline 59375 & 21114 & 9054 & 64119 & 9004 \\
\hline 63318 & 34305 & 9033 & 59713 & 9030 \\
\hline 63318 & 34305 & 9033 & 54448 & 9024 \\
\hline 59375 & 46351 & 9031 & 41167 & 9028 \\
\hline 59375 & 46351 & 9031 & 60724 & 9008 \\
\hline 59375 & 46351 & 9031 & 61592 & 9042 \\
\hline 59375 & 16538 & 9017 & 60724 & 9008 \\
\hline 59375 & 16538 & 9017 & 59713 & 9030 \\
\hline 59375 & 16538 & 9017 & 50496 & 9018 \\
\hline 60480 & 41614 & 9052 & 44329 & 9022 \\
\hline 60480 & 41614 & 9052 & 54448 & 9024 \\
\hline 60480 & 41614 & 9052 & 61592 & 9042 \\
\hline 60480 & 38718 & 9003 & 60724 & 9008 \\
\hline 60480 & 38718 & 9003 & 59713 & 9030 \\
\hline 60480 & 38718 & 9003 & 51725 & 9026 \\
\hline 60480 & 45778 & 9016 & 50496 & 9018 \\
\hline 60480 & 45778 & 9016 & 60724 & 9008 \\
\hline 49299 & 946 & 9019 & 38600 & 9047 \\
\hline
\end{tabular}




\begin{tabular}{|c|c|c|c|c|}
\hline 49299 & 946 & 9019 & 54687 & 9053 \\
\hline 49299 & 946 & 9019 & 54749 & 9048 \\
\hline 49299 & 21114 & 9054 & 38345 & 9001 \\
\hline 49299 & 21114 & 9054 & 50496 & 9018 \\
\hline 49299 & 21114 & 9054 & 52560 & 9036 \\
\hline 49299 & 14592 & 9045 & 46351 & 9031 \\
\hline 49299 & 14592 & 9045 & 50288 & 9040 \\
\hline 49299 & 14592 & 9045 & 52560 & 9036 \\
\hline 18704 & 29845 & 9006 & 22315 & 9035 \\
\hline 18704 & 29845 & 9006 & 17987 & 9020 \\
\hline 18704 & 7856 & 9025 & 16538 & 9017 \\
\hline 18704 & 7856 & 9025 & 17987 & 9020 \\
\hline 18704 & 946 & 9019 & 32216 & 9010 \\
\hline 18704 & 946 & 9019 & 16538 & 9017 \\
\hline 18704 & 946 & 9019 & 17099 & 9043 \\
\hline 57840 & 49013 & 9058 & 60724 & 9008 \\
\hline 57840 & 49013 & 9058 & 59713 & 9030 \\
\hline 57840 & 49013 & 9058 & 64119 & 9004 \\
\hline 57840 & 64119 & 9004 & 64119 & 9004 \\
\hline 57840 & 64119 & 9004 & 59713 & 9030 \\
\hline 57840 & 64119 & 9004 & 50496 & 9018 \\
\hline 57840 & 43642 & 9062 & 50496 & 9018 \\
\hline 57840 & 43642 & 9062 & 59713 & 9030 \\
\hline 57840 & 43642 & 9062 & 64119 & 9004 \\
\hline 56968 & 1335 & 9007 & 55816 & 9032 \\
\hline 56968 & 1335 & 9007 & 56304 & 9056 \\
\hline 56968 & 1335 & 9007 & 54749 & 9048 \\
\hline 56968 & 46389 & 9046 & 54448 & 9024 \\
\hline 56968 & 46389 & 9046 & 55816 & 9032 \\
\hline 56968 & 46389 & 9046 & 54749 & 9048 \\
\hline 56968 & 43642 & 9062 & 64119 & 9004 \\
\hline 56968 & 43642 & 9062 & 54749 & 9048 \\
\hline 5807 & 38729 & 9012 & 21114 & 9054 \\
\hline 5807 & 38729 & 9012 & 4483 & 9011 \\
\hline 5807 & 38729 & 9012 & 6736 & 9044 \\
\hline 3477 & 46389 & 9046 & 11159 & 9049 \\
\hline 3477 & 46389 & 9046 & 1413 & 9059 \\
\hline 3477 & 46389 & 9046 & 946 & 9019 \\
\hline 3477 & 51725 & 9026 & 1413 & 9059 \\
\hline
\end{tabular}




\begin{tabular}{|c|c|c|c|c|}
\hline 3477 & 51725 & 9026 & 2590 & 9050 \\
\hline 3477 & 51725 & 9026 & 946 & 9019 \\
\hline 48513 & 55816 & 9032 & 45778 & 9016 \\
\hline 48513 & 55816 & 9032 & 46351 & 9031 \\
\hline 48513 & 41614 & 9052 & 47516 & 9002 \\
\hline 48513 & 41614 & 9052 & 48217 & 9037 \\
\hline 48513 & 41614 & 9052 & 45778 & 9016 \\
\hline 48513 & 34305 & 9033 & 45778 & 9016 \\
\hline 48513 & 34305 & 9033 & 48217 & 9037 \\
\hline 48188 & 29845 & 9006 & 48217 & 9037 \\
\hline 48188 & 29845 & 9006 & 49013 & 9058 \\
\hline 48513 & 34305 & 9033 & 46351 & 9031 \\
\hline 48188 & 29845 & 9006 & 46351 & 9031 \\
\hline 48188 & 41167 & 9028 & 48217 & 9037 \\
\hline 48188 & 41167 & 9028 & 49013 & 9058 \\
\hline 48188 & 41167 & 9028 & 46351 & 9031 \\
\hline 48188 & 51725 & 9026 & 47516 & 9002 \\
\hline 48188 & 51725 & 9026 & 48217 & 9037 \\
\hline 48188 & 51725 & 9026 & 45778 & 9016 \\
\hline 34315 & 46389 & 9046 & 38600 & 9047 \\
\hline 34315 & 46389 & 9046 & 33862 & 9055 \\
\hline 34315 & 46389 & 9046 & 34167 & 9063 \\
\hline 34315 & 46389 & 9046 & 38718 & 9003 \\
\hline 34315 & 46389 & 9046 & 34305 & 9033 \\
\hline 34315 & 46389 & 9046 & 38729 & 9012 \\
\hline 34315 & 56304 & 9056 & 38718 & 9003 \\
\hline 34315 & 56304 & 9056 & 34305 & 9033 \\
\hline 34315 & 56304 & 9056 & 38729 & 9012 \\
\hline 61654 & 17099 & 9043 & 50288 & 9040 \\
\hline 61654 & 17099 & 9043 & 61592 & 9042 \\
\hline 61654 & 17099 & 9043 & 60724 & 9008 \\
\hline 61654 & 6736 & 9044 & 64119 & 9004 \\
\hline 61654 & 6736 & 9044 & 61592 & 9042 \\
\hline 61654 & 6736 & 9044 & 54448 & 9024 \\
\hline 61654 & 41503 & 9021 & 54448 & 9024 \\
\hline 61654 & 41503 & 9021 & 61592 & 9042 \\
\hline 61654 & 41503 & 9021 & 60724 & 9008 \\
\hline 24032 & 54687 & 9053 & 1413 & 9059 \\
\hline 24032 & 54687 & 9053 & 22315 & 9035 \\
\hline
\end{tabular}




\begin{tabular}{|c|c|c|c|c|}
\hline 24032 & 54687 & 9053 & 17099 & 9043 \\
\hline 24032 & 7054 & 9005 & 17987 & 9020 \\
\hline 24032 & 7054 & 9005 & 21114 & 9054 \\
\hline 23959 & 55816 & 9032 & 17987 & 9020 \\
\hline 23959 & 55816 & 9032 & 21114 & 9054 \\
\hline 23959 & 21114 & 9054 & 29845 & 9006 \\
\hline 23959 & 21114 & 9054 & 22315 & 9035 \\
\hline 23959 & 21114 & 9054 & 17099 & 9043 \\
\hline 43291 & 946 & 9019 & 48217 & 9037 \\
\hline 43291 & 946 & 9019 & 44329 & 9022 \\
\hline 43291 & 946 & 9019 & 41614 & 9052 \\
\hline 43291 & 17987 & 9020 & 43642 & 9062 \\
\hline 43291 & 17987 & 9020 & 44329 & 9022 \\
\hline 43291 & 17987 & 9020 & 41614 & 9052 \\
\hline 43291 & 64119 & 9004 & 43642 & 9062 \\
\hline 43291 & 64119 & 9004 & 44329 & 9022 \\
\hline 43291 & 64119 & 9004 & 41614 & 9052 \\
\hline 13704 & 1335 & 9007 & 11940 & 9015 \\
\hline 13704 & 1335 & 9007 & 9248 & 9034 \\
\hline 54574 & 41614 & 9052 & 54448 & 9024 \\
\hline 54574 & 41614 & 9052 & 54687 & 9053 \\
\hline 54574 & 41614 & 9052 & 55816 & 9032 \\
\hline 23959 & 19411 & 9038 & 23391 & 9029 \\
\hline 23959 & 19411 & 9038 & 17987 & 9020 \\
\hline 23959 & 19411 & 9038 & 16983 & 9057 \\
\hline 54574 & 4483 & 9011 & 50288 & 9040 \\
\hline 13704 & 1335 & 9007 & 32216 & 9010 \\
\hline 54574 & 4483 & 9011 & 54687 & 9053 \\
\hline 13704 & 1335 & 9007 & 7054 & 9005 \\
\hline 54574 & 4483 & 9011 & 55816 & 9032 \\
\hline 54574 & 17987 & 9020 & 54687 & 9053 \\
\hline 24032 & 28854 & 9013 & 23391 & 9029 \\
\hline 24032 & 28854 & 9013 & 16983 & 9057 \\
\hline 54574 & 17987 & 9020 & 55816 & 9032 \\
\hline 28451 & 64119 & 9004 & 29845 & 9006 \\
\hline 28451 & 64119 & 9004 & 24685 & 9051 \\
\hline 45702 & 56304 & 9056 & 47516 & 9002 \\
\hline 45702 & 56304 & 9056 & 45778 & 9016 \\
\hline 28451 & 12347 & 9014 & 22315 & 9035 \\
\hline
\end{tabular}




\begin{tabular}{|c|c|c|c|c|}
\hline 45702 & 56304 & 9056 & 49013 & 9058 \\
\hline 28451 & 64119 & 9004 & 28854 & 9013 \\
\hline 28451 & 12347 & 9014 & 24685 & 9051 \\
\hline 28451 & 12347 & 9014 & 32216 & 9010 \\
\hline 45702 & 60724 & 9008 & 38729 & 9012 \\
\hline 45702 & 60724 & 9008 & 45778 & 9016 \\
\hline 45702 & 60724 & 9008 & 49013 & 9058 \\
\hline 6332 & 12347 & 9014 & 7054 & 9005 \\
\hline 6332 & 12347 & 9014 & 2590 & 9050 \\
\hline 6332 & 19411 & 9038 & 4483 & 9011 \\
\hline 6332 & 19411 & 9038 & 4405 & 9061 \\
\hline 6332 & 54448 & 9024 & 946 & 9019 \\
\hline 6332 & 54448 & 9024 & 4405 & 9061 \\
\hline 55511 & 16538 & 9017 & 55816 & 9032 \\
\hline 55511 & 16538 & 9017 & 56304 & 9056 \\
\hline 55511 & 16538 & 9017 & 54687 & 9053 \\
\hline 55511 & 41503 & 9021 & 60724 & 9008 \\
\hline 55511 & 41503 & 9021 & 55816 & 9032 \\
\hline 55511 & 41503 & 9021 & 54687 & 9053 \\
\hline 55511 & 1335 & 9007 & 55816 & 9032 \\
\hline 55511 & 1335 & 9007 & 56304 & 9056 \\
\hline 55511 & 1335 & 9007 & 54687 & 9053 \\
\hline 46118 & 4483 & 9011 & 45778 & 9016 \\
\hline 46118 & 4483 & 9011 & 46389 & 9046 \\
\hline 46118 & 4483 & 9011 & 47516 & 9002 \\
\hline 46118 & 22315 & 9035 & 46389 & 9046 \\
\hline 46118 & 22315 & 9035 & 46351 & 9031 \\
\hline 46118 & 22315 & 9035 & 47516 & 9002 \\
\hline 23174 & 16983 & 9057 & 23391 & 9029 \\
\hline 23174 & 16983 & 9057 & 17099 & 9043 \\
\hline 23174 & 16983 & 9057 & 17987 & 9020 \\
\hline 38081 & 54448 & 9024 & 38718 & 9003 \\
\hline 38081 & 54448 & 9024 & 38345 & 9001 \\
\hline 38081 & 54448 & 9024 & 46351 & 9031 \\
\hline 38081 & 22315 & 9035 & 38729 & 9012 \\
\hline 38081 & 22315 & 9035 & 38345 & 9001 \\
\hline 38081 & 22315 & 9035 & 38600 & 9047 \\
\hline 38081 & 54749 & 9048 & 38345 & 9001 \\
\hline 38081 & 54749 & 9048 & 38600 & 9047 \\
\hline
\end{tabular}




\begin{tabular}{|c|c|c|c|c|}
\hline 38081 & 54749 & 9048 & 39936 & 9009 \\
\hline 55363 & 946 & 9019 & 50288 & 9040 \\
\hline 55363 & 946 & 9019 & 55816 & 9032 \\
\hline 55363 & 946 & 9019 & 56304 & 9056 \\
\hline 55363 & 41167 & 9028 & 54448 & 9024 \\
\hline 55363 & 41167 & 9028 & 55816 & 9032 \\
\hline 55363 & 41167 & 9028 & 54687 & 9053 \\
\hline 55363 & 50496 & 9018 & 48217 & 9037 \\
\hline 55363 & 50496 & 9018 & 54687 & 9053 \\
\hline 55363 & 50496 & 9018 & 54749 & 9048 \\
\hline 24318 & 52560 & 9036 & 17099 & 9043 \\
\hline 24318 & 52560 & 9036 & 23391 & 9029 \\
\hline 54163 & 29845 & 9006 & 54687 & 9053 \\
\hline 54163 & 29845 & 9006 & 54749 & 9048 \\
\hline 54163 & 29845 & 9006 & 55816 & 9032 \\
\hline 24318 & 946 & 9019 & 29845 & 9006 \\
\hline 24318 & 946 & 9019 & 22315 & 9035 \\
\hline 24318 & 946 & 9019 & 16983 & 9057 \\
\hline 54163 & 39936 & 9009 & 54448 & 9024 \\
\hline 54163 & 39936 & 9009 & 54687 & 9053 \\
\hline 54163 & 39936 & 9009 & 55816 & 9032 \\
\hline 54163 & 17987 & 9020 & 50496 & 9018 \\
\hline 54163 & 17987 & 9020 & 54687 & 9053 \\
\hline 54163 & 17987 & 9020 & 56304 & 9056 \\
\hline 36771 & 21114 & 9054 & 38729 & 9012 \\
\hline 36771 & 21114 & 9054 & 34305 & 9033 \\
\hline 36771 & 21114 & 9054 & 38718 & 9003 \\
\hline 36771 & 38345 & 9001 & 44329 & 9022 \\
\hline 36771 & 38345 & 9001 & 39936 & 9009 \\
\hline 36771 & 38345 & 9001 & 33862 & 9055 \\
\hline 36771 & 54687 & 9053 & 38718 & 9003 \\
\hline 36771 & 54687 & 9053 & 34305 & 9033 \\
\hline 36771 & 54687 & 9053 & 39936 & 9009 \\
\hline 2097 & 12347 & 9014 & 11159 & 9049 \\
\hline 2097 & 12347 & 9014 & 946 & 9019 \\
\hline 2097 & 64119 & 9004 & 2590 & 9050 \\
\hline 2097 & 64119 & 9004 & 279 & 9023 \\
\hline 2097 & 64119 & 9004 & 1413 & 9059 \\
\hline 2097 & 1413 & 9059 & 11159 & 9049 \\
\hline
\end{tabular}




\begin{tabular}{|c|c|c|c|c|}
\hline 2097 & 1413 & 9059 & 946 & 9019 \\
\hline 24842 & 14592 & 9045 & 28854 & 9013 \\
\hline 24842 & 14592 & 9045 & 24685 & 9051 \\
\hline 24842 & 14592 & 9045 & 32335 & 9027 \\
\hline 24842 & 38718 & 9003 & 28854 & 9013 \\
\hline 24842 & 38718 & 9003 & 24685 & 9051 \\
\hline 24842 & 38718 & 9003 & 32335 & 9027 \\
\hline 4512 & 41614 & 9052 & 4483 & 9011 \\
\hline 4512 & 52560 & 9036 & 4483 & 9011 \\
\hline 4512 & 52560 & 9036 & 4405 & 9061 \\
\hline 4512 & 52560 & 9036 & 7856 & 9025 \\
\hline 4512 & 41614 & 9052 & 7856 & 9025 \\
\hline 32929 & 51725 & 9026 & 48217 & 9037 \\
\hline 32929 & 51725 & 9026 & 38345 & 9001 \\
\hline 32929 & 51725 & 9026 & 34305 & 9033 \\
\hline 32929 & 38729 & 9012 & 49013 & 9058 \\
\hline 32929 & 38729 & 9012 & 38345 & 9001 \\
\hline 32929 & 38729 & 9012 & 38600 & 9047 \\
\hline 18904 & 17099 & 9043 & 32216 & 9010 \\
\hline 18904 & 17099 & 9043 & 16538 & 9017 \\
\hline 18904 & 17099 & 9043 & 17099 & 9043 \\
\hline 18904 & 23391 & 9029 & 17099 & 9043 \\
\hline 18904 & 23391 & 9029 & 17987 & 9020 \\
\hline 18904 & 1413 & 9059 & 17987 & 9020 \\
\hline 18904 & 1413 & 9059 & 16538 & 9017 \\
\hline 38123 & 4405 & 9061 & 48217 & 9037 \\
\hline 38123 & 4405 & 9061 & 38345 & 9001 \\
\hline 38123 & 4405 & 9061 & 33862 & 9055 \\
\hline 18904 & 1413 & 9059 & 23391 & 9029 \\
\hline 38123 & 11159 & 9049 & 38345 & 9001 \\
\hline 38123 & 11159 & 9049 & 38600 & 9047 \\
\hline 38123 & 11159 & 9049 & 39936 & 9009 \\
\hline 38123 & 9248 & 9034 & 47516 & 9002 \\
\hline 38123 & 9248 & 9034 & 38345 & 9001 \\
\hline 38123 & 9248 & 9034 & 39936 & 9009 \\
\hline 26857 & 59713 & 9030 & 17099 & 9043 \\
\hline 26857 & 59713 & 9030 & 24685 & 9051 \\
\hline 26857 & 59713 & 9030 & 32216 & 9010 \\
\hline 26857 & 28854 & 9013 & 32216 & 9010 \\
\hline
\end{tabular}




\begin{tabular}{|c|c|c|c|c|}
\hline 26857 & 28854 & 9013 & 24685 & 9051 \\
\hline 26857 & 28854 & 9013 & 29845 & 9006 \\
\hline 50487 & 59713 & 9030 & 54448 & 9024 \\
\hline 50487 & 59713 & 9030 & 50496 & 9018 \\
\hline 50487 & 59713 & 9030 & 49180 & 9060 \\
\hline 37304 & 34305 & 9033 & 38718 & 9003 \\
\hline 37304 & 34305 & 9033 & 38345 & 9001 \\
\hline 37304 & 34305 & 9033 & 34167 & 9063 \\
\hline 50487 & 60724 & 9008 & 60724 & 9008 \\
\hline 50487 & 60724 & 9008 & 52560 & 9036 \\
\hline 37304 & 61592 & 9042 & 38718 & 9003 \\
\hline 37304 & 61592 & 9042 & 34167 & 9063 \\
\hline 47039 & 59713 & 9030 & 46389 & 9046 \\
\hline 47039 & 59713 & 9030 & 46351 & 9031 \\
\hline 47039 & 59713 & 9030 & 47516 & 9002 \\
\hline 47039 & 46351 & 9031 & 38718 & 9003 \\
\hline 47039 & 46351 & 9031 & 45778 & 9016 \\
\hline 47039 & 46351 & 9031 & 48217 & 9037 \\
\hline 47039 & 45778 & 9016 & 46351 & 9031 \\
\hline 47039 & 45778 & 9016 & 46389 & 9046 \\
\hline 47039 & 45778 & 9016 & 48217 & 9037 \\
\hline 46233 & 9178 & 9064 & 47516 & 9002 \\
\hline 46233 & 9178 & 9064 & 46351 & 9031 \\
\hline 46233 & 9178 & 9064 & 49013 & 9058 \\
\hline 46233 & 48217 & 9037 & 54448 & 9024 \\
\hline 46233 & 48217 & 9037 & 47516 & 9002 \\
\hline 46233 & 48217 & 9037 & 48217 & 9037 \\
\hline 30204 & 7054 & 9005 & 28854 & 9013 \\
\hline 30204 & 7054 & 9005 & 29845 & 9006 \\
\hline 30204 & 7054 & 9005 & 24685 & 9051 \\
\hline 30204 & 41503 & 9021 & 29845 & 9006 \\
\hline 30204 & 41503 & 9021 & 28854 & 9013 \\
\hline 30204 & 41503 & 9021 & 24685 & 9051 \\
\hline 41673 & 1335 & 9007 & 41614 & 9052 \\
\hline 41673 & 1335 & 9007 & 44329 & 9022 \\
\hline 1618 & 11159 & 9049 & 11860 & 9041 \\
\hline 1618 & 11159 & 9049 & 2590 & 9050 \\
\hline 1618 & 28854 & 9013 & 1413 & 9059 \\
\hline 1618 & 28854 & 9013 & 2590 & 9050 \\
\hline
\end{tabular}




\section{ANEXO B. Resultados das buscas efetuadas durante a simulação.}

Apresentam-se no Quadro 2 os tempos de busca obtidos durante a simulação para cada EPC (primeira coluna). Os dados sobre os EPCIS resultantes e o tempo de busca encontram-se nas colunas 2 a 4 .

Quadro 2 - Resultados das buscas efetuadas durante a simulação

\begin{tabular}{|c|c|c|c|}
\hline \multirow{2}{*}{ EPC } & \multicolumn{3}{|c|}{ Endereço do EPCIS } \\
\hline & ID & Porta & Resposta (s) \\
\hline 13704 & 1335 & 9007 & 3.5331 \\
\hline 13704 & 1335 & 9007 & 3.7340 \\
\hline 14505 & 39936 & 9009 & 0.1014 \\
\hline 14505 & 39936 & 9009 & 1.9196 \\
\hline 14505 & 39936 & 9009 & 0.1012 \\
\hline 14505 & 39936 & 9009 & 0.7064 \\
\hline 14505 & 51725 & 9026 & 0.1014 \\
\hline 14505 & 51725 & 9026 & 1.9196 \\
\hline 14505 & 51725 & 9026 & 0.1012 \\
\hline 15524 & 19411 & 9038 & 0.1005 \\
\hline 15524 & 19411 & 9038 & 2.5223 \\
\hline 15524 & 19411 & 9038 & 0.1014 \\
\hline 15524 & 19411 & 9038 & 0.1013 \\
\hline 15524 & 21114 & 9054 & 0.1005 \\
\hline 15524 & 21114 & 9054 & 2.5223 \\
\hline 15524 & 21114 & 9054 & 0.1014 \\
\hline 15524 & 21114 & 9054 & 0.1013 \\
\hline 15524 & 7856 & 9025 & 0.1014 \\
\hline 15524 & 7856 & 9025 & 0.1013 \\
\hline 15524 & 7856 & 9025 & 0.1005 \\
\hline 15524 & 7856 & 9025 & 2.5223 \\
\hline 1618 & 11159 & 9049 & 0.2015 \\
\hline 1618 & 28854 & 9013 & 1.7161 \\
\hline 1618 & 28854 & 9013 & 1.8166 \\
\hline 1618 & 28854 & 9013 & 0.1013 \\
\hline 1618 & 28854 & 9013 & 0.2015 \\
\hline 17277 & 14592 & 9045 & 1.9164 \\
\hline
\end{tabular}




\begin{tabular}{|c|c|c|c|}
\hline 17277 & 14592 & 9045 & 1.8155 \\
\hline 17277 & 24685 & 9051 & 1.8155 \\
\hline 17277 & 24685 & 9051 & 1.9164 \\
\hline 17277 & 24685 & 9051 & 0.1005 \\
\hline 17277 & 49180 & 9060 & 1.9164 \\
\hline 17277 & 49180 & 9060 & 1.8155 \\
\hline 18704 & 29845 & 9006 & 0.1007 \\
\hline 18704 & 7856 & 9025 & 0.1010 \\
\hline 18704 & 946 & 9019 & 0.1006 \\
\hline 18704 & 946 & 9019 & 0.1010 \\
\hline 18904 & 1413 & 9059 & 0.1013 \\
\hline 18904 & 1413 & 9059 & 0.1013 \\
\hline 18904 & 17099 & 9043 & 0.2016 \\
\hline 18904 & 23391 & 9029 & 0.1013 \\
\hline 18904 & 23391 & 9029 & 0.1013 \\
\hline 18904 & 23391 & 9029 & 0.2016 \\
\hline 2097 & 64119 & 9004 & 0.1011 \\
\hline 23174 & 16983 & 9057 & 0.1012 \\
\hline 23174 & 16983 & 9057 & 0.3027 \\
\hline 23174 & 16983 & 9057 & 0.1012 \\
\hline 23174 & 16983 & 9057 & 0.1008 \\
\hline 23944 & 279 & 9023 & 0.1004 \\
\hline 23944 & 48217 & 9037 & 0.1013 \\
\hline 23944 & 48217 & 9037 & 0.1007 \\
\hline 23944 & 48217 & 9037 & 0.1004 \\
\hline 23944 & 48217 & 9037 & 0.1006 \\
\hline 23944 & 55816 & 9032 & 0.1005 \\
\hline 23959 & 19411 & 9038 & 1.8211 \\
\hline 23959 & 19411 & 9038 & 0.1009 \\
\hline 23959 & 21114 & 9054 & 0.1011 \\
\hline 23959 & 55816 & 9032 & 1.8211 \\
\hline 24032 & 28854 & 9013 & 0.1013 \\
\hline 24032 & 28854 & 9013 & 0.5029 \\
\hline 24032 & 28854 & 9013 & 0.5042 \\
\hline 24032 & 54687 & 9053 & 0.1013 \\
\hline 24318 & 52560 & 9036 & 0.4035 \\
\hline 24318 & 946 & 9019 & 0.4032 \\
\hline 24318 & 946 & 9019 & 0.1013 \\
\hline
\end{tabular}




\begin{tabular}{|c|c|c|c|}
\hline 24842 & 14592 & 9045 & 0.3030 \\
\hline 24842 & 14592 & 9045 & 0.1013 \\
\hline 24842 & 14592 & 9045 & 0.1015 \\
\hline 24842 & 14592 & 9045 & 0.1005 \\
\hline 24842 & 14592 & 9045 & 0.1011 \\
\hline 24842 & 38718 & 9003 & 0.1015 \\
\hline 24842 & 38718 & 9003 & 0.1013 \\
\hline 24842 & 38718 & 9003 & 0.3030 \\
\hline 24842 & 38718 & 9003 & 0.1011 \\
\hline 24842 & 38718 & 9003 & 0.1005 \\
\hline 25805 & 16983 & 9057 & 0.2008 \\
\hline 25805 & 16983 & 9057 & 0.1008 \\
\hline 25805 & 41503 & 9021 & 0.2008 \\
\hline 25805 & 41503 & 9021 & 0.1008 \\
\hline 25805 & 52560 & 9036 & 0.1008 \\
\hline 25805 & 52560 & 9036 & 0.2008 \\
\hline 26857 & 28854 & 9013 & 0.2019 \\
\hline 26857 & 28854 & 9013 & 0.1013 \\
\hline 26857 & 28854 & 9013 & 0.1002 \\
\hline 26857 & 28854 & 9013 & 0.3025 \\
\hline 26857 & 59713 & 9030 & 0.1002 \\
\hline 26857 & 59713 & 9030 & 0.1013 \\
\hline 26857 & 59713 & 9030 & 0.3025 \\
\hline 26857 & 59713 & 9030 & 0.2019 \\
\hline 28451 & 12347 & 9014 & 0.1012 \\
\hline 28451 & 64119 & 9004 & 0.1009 \\
\hline 28451 & 64119 & 9004 & 0.1010 \\
\hline 28451 & 64119 & 9004 & 0.1012 \\
\hline 30204 & 41503 & 9021 & 0.3031 \\
\hline 30204 & 41503 & 9021 & 0.2023 \\
\hline 30204 & 41503 & 9021 & 2.0172 \\
\hline 30204 & 41503 & 9021 & 0.1006 \\
\hline 30204 & 41503 & 9021 & 0.1012 \\
\hline 30204 & 7054 & 9005 & 0.1006 \\
\hline 30204 & 7054 & 9005 & 0.1012 \\
\hline 30204 & 7054 & 9005 & 0.2023 \\
\hline 30204 & 7054 & 9005 & 0.3031 \\
\hline 30204 & 7054 & 9005 & 2.0172 \\
\hline
\end{tabular}




\begin{tabular}{|c|c|c|c|}
\hline 30468 & 15788 & 9039 & 0.1011 \\
\hline 30468 & 15788 & 9039 & 0.4023 \\
\hline 30468 & 41614 & 9052 & 0.1011 \\
\hline 30468 & 41614 & 9052 & 0.4023 \\
\hline 30468 & 54448 & 9024 & 0.4023 \\
\hline 30468 & 54448 & 9024 & 0.1011 \\
\hline 31440 & 34305 & 9033 & 0.1009 \\
\hline 31440 & 34305 & 9033 & 0.1012 \\
\hline 31440 & 34305 & 9033 & 0.1005 \\
\hline 31440 & 34305 & 9033 & 0.1006 \\
\hline 31440 & 4483 & 9011 & 0.1005 \\
\hline 31440 & 46389 & 9046 & 0.1005 \\
\hline 32929 & 38729 & 9012 & 0.1013 \\
\hline 32929 & 38729 & 9012 & 1.8182 \\
\hline 32929 & 51725 & 9026 & 1.8182 \\
\hline 34315 & 46389 & 9046 & 0.1012 \\
\hline 34315 & 46389 & 9046 & 0.1012 \\
\hline 34315 & 46389 & 9046 & 0.3029 \\
\hline 34315 & 56304 & 9056 & 0.1012 \\
\hline 34315 & 56304 & 9056 & 0.3029 \\
\hline 34315 & 56304 & 9056 & 0.1012 \\
\hline 3477 & 46389 & 9046 & 0.1008 \\
\hline 3477 & 51725 & 9026 & 0.1008 \\
\hline 3477 & 51725 & 9026 & 0.3030 \\
\hline 36771 & 21114 & 9054 & 0.3031 \\
\hline 36771 & 21114 & 9054 & 0.1010 \\
\hline 36771 & 38345 & 9001 & 0.1008 \\
\hline 36771 & 38345 & 9001 & 0.1008 \\
\hline 36771 & 54687 & 9053 & 0.1010 \\
\hline 36771 & 54687 & 9053 & 0.3031 \\
\hline 37304 & 34305 & 9033 & 0.3027 \\
\hline 37304 & 34305 & 9033 & 0.2025 \\
\hline 37304 & 34305 & 9033 & 0.2018 \\
\hline 37304 & 34305 & 9033 & 0.4040 \\
\hline 37304 & 61592 & 9042 & 0.4040 \\
\hline 37699 & 45778 & 9016 & 0.3036 \\
\hline 37699 & 45778 & 9016 & 0.2023 \\
\hline 37699 & 45778 & 9016 & 0.2022 \\
\hline
\end{tabular}




\begin{tabular}{|c|c|c|c|}
\hline 37699 & 45778 & 9016 & 0.1011 \\
\hline 37699 & 7856 & 9025 & 0.2022 \\
\hline 37699 & 7856 & 9025 & 0.3036 \\
\hline 37699 & 7856 & 9025 & 0.2023 \\
\hline 37699 & 7856 & 9025 & 0.1011 \\
\hline 38081 & 22315 & 9035 & 0.1010 \\
\hline 38081 & 22315 & 9035 & 0.2024 \\
\hline 38081 & 22315 & 9035 & 0.1013 \\
\hline 38081 & 54448 & 9024 & 0.1010 \\
\hline 38081 & 54448 & 9024 & 0.1013 \\
\hline 38081 & 54448 & 9024 & 0.2024 \\
\hline 38081 & 54749 & 9048 & 0.1010 \\
\hline 38081 & 54749 & 9048 & 0.2024 \\
\hline 38081 & 54749 & 9048 & 0.1013 \\
\hline 38123 & 11159 & 9049 & 0.2014 \\
\hline 38123 & 11159 & 9049 & 0.2024 \\
\hline 38123 & 11159 & 9049 & 0.1007 \\
\hline 38123 & 11159 & 9049 & 0.1008 \\
\hline 38123 & 4405 & 9061 & 0.2024 \\
\hline 38123 & 4405 & 9061 & 0.2014 \\
\hline 38123 & 4405 & 9061 & 0.1008 \\
\hline 38123 & 4405 & 9061 & 0.1007 \\
\hline 38123 & 9248 & 9034 & 0.1008 \\
\hline 38123 & 9248 & 9034 & 0.1007 \\
\hline 38123 & 9248 & 9034 & 0.2014 \\
\hline 38123 & 9248 & 9034 & 0.2024 \\
\hline 39477 & 60724 & 9008 & 0.1010 \\
\hline 39477 & 60724 & 9008 & 0.1013 \\
\hline 39477 & 64119 & 9004 & 0.1013 \\
\hline 39477 & 64119 & 9004 & 0.1010 \\
\hline 39477 & 64119 & 9004 & 0.2022 \\
\hline 39477 & 946 & 9019 & 0.1013 \\
\hline 39477 & 946 & 9019 & 0.1010 \\
\hline 40617 & 21114 & 9054 & 0.2024 \\
\hline 40617 & 21114 & 9054 & 0.1011 \\
\hline 40617 & 21114 & 9054 & 0.2014 \\
\hline 40617 & 21114 & 9054 & 0.2020 \\
\hline 40617 & 21114 & 9054 & 0.1015 \\
\hline
\end{tabular}




\begin{tabular}{|c|c|c|c|}
\hline 40617 & 49013 & 9058 & 0.1015 \\
\hline 40617 & 49013 & 9058 & 0.1011 \\
\hline 40617 & 49013 & 9058 & 0.2024 \\
\hline 40617 & 49013 & 9058 & 0.2020 \\
\hline 40617 & 49013 & 9058 & 0.2014 \\
\hline 40617 & 54749 & 9048 & 0.2020 \\
\hline 40617 & 54749 & 9048 & 0.1011 \\
\hline 40617 & 54749 & 9048 & 0.2014 \\
\hline 40617 & 54749 & 9048 & 0.2024 \\
\hline 40617 & 54749 & 9048 & 0.1015 \\
\hline 41673 & 1335 & 9007 & 0.5030 \\
\hline 41673 & 1335 & 9007 & 0.4040 \\
\hline 41673 & 1335 & 9007 & 0.5036 \\
\hline 41673 & 1335 & 9007 & 0.2020 \\
\hline 41673 & 1335 & 9007 & 0.3019 \\
\hline 41898 & 29845 & 9006 & 3.3308 \\
\hline 41898 & 29845 & 9006 & 1.7126 \\
\hline 41898 & 44329 & 9022 & 0.1012 \\
\hline 41898 & 44329 & 9022 & 0.4021 \\
\hline 43291 & 17987 & 9020 & 0.3031 \\
\hline 43291 & 17987 & 9020 & 0.1013 \\
\hline 43291 & 17987 & 9020 & 0.4034 \\
\hline 43291 & 64119 & 9004 & 0.3031 \\
\hline 43291 & 64119 & 9004 & 0.1013 \\
\hline 43291 & 64119 & 9004 & 0.4034 \\
\hline 43291 & 946 & 9019 & 0.1013 \\
\hline 43291 & 946 & 9019 & 0.3031 \\
\hline 43291 & 946 & 9019 & 0.4034 \\
\hline 4512 & 41614 & 9052 & 1.9197 \\
\hline 4512 & 52560 & 9036 & 1.8180 \\
\hline 4512 & 52560 & 9036 & 1.9197 \\
\hline 45702 & 56304 & 9056 & 0.1012 \\
\hline 45702 & 56304 & 9056 & 0.2018 \\
\hline 45702 & 56304 & 9056 & 0.1013 \\
\hline 45702 & 56304 & 9056 & 0.2019 \\
\hline 45702 & 56304 & 9056 & 0.1012 \\
\hline 45702 & 60724 & 9008 & 0.1012 \\
\hline 45702 & 60724 & 9008 & 0.1013 \\
\hline
\end{tabular}




\begin{tabular}{|c|c|c|c|}
\hline 45702 & 60724 & 9008 & 0.2019 \\
\hline 46118 & 22315 & 9035 & 0.1012 \\
\hline 46118 & 22315 & 9035 & 0.1011 \\
\hline 46118 & 4483 & 9011 & 0.1012 \\
\hline 46118 & 4483 & 9011 & 0.1011 \\
\hline 46233 & 48217 & 9037 & 0.2013 \\
\hline 46233 & 9178 & 9064 & 0.1013 \\
\hline 46233 & 9178 & 9064 & 0.1012 \\
\hline 47039 & 45778 & 9016 & 0.1013 \\
\hline 47039 & 45778 & 9016 & 0.1009 \\
\hline 47039 & 46351 & 9031 & 0.2020 \\
\hline 47039 & 46351 & 9031 & 0.1008 \\
\hline 47039 & 59713 & 9030 & 0.1013 \\
\hline 47039 & 59713 & 9030 & 0.1009 \\
\hline 48188 & 29845 & 9006 & 0.2022 \\
\hline 48188 & 29845 & 9006 & 0.1012 \\
\hline 48188 & 29845 & 9006 & 0.1006 \\
\hline 48188 & 41167 & 9028 & 0.2022 \\
\hline 48188 & 41167 & 9028 & 0.1012 \\
\hline 48188 & 41167 & 9028 & 0.1006 \\
\hline 48188 & 51725 & 9026 & 0.3028 \\
\hline 48188 & 51725 & 9026 & 0.2022 \\
\hline 48188 & 51725 & 9026 & 0.1012 \\
\hline 48513 & 34305 & 9033 & 0.6061 \\
\hline 48513 & 34305 & 9033 & 0.1012 \\
\hline 48513 & 41614 & 9052 & 0.6061 \\
\hline 48513 & 41614 & 9052 & 0.3030 \\
\hline 48513 & 41614 & 9052 & 0.3030 \\
\hline 48513 & 41614 & 9052 & 0.1012 \\
\hline 49299 & 14592 & 9045 & 0.4035 \\
\hline 49299 & 14592 & 9045 & 0.1008 \\
\hline 49299 & 21114 & 9054 & 0.3036 \\
\hline 50487 & 59713 & 9030 & 0.2022 \\
\hline 50487 & 59713 & 9030 & 1.9168 \\
\hline 50487 & 60724 & 9008 & 0.1013 \\
\hline 50550 & 17987 & 9020 & 0.1012 \\
\hline 50550 & 17987 & 9020 & 0.2023 \\
\hline 50550 & 17987 & 9020 & 0.2016 \\
\hline
\end{tabular}




\begin{tabular}{|c|c|c|c|}
\hline 50550 & 17987 & 9020 & 0.1013 \\
\hline 50550 & 17987 & 9020 & 0.3033 \\
\hline 50550 & 24685 & 9051 & 0.1012 \\
\hline 50550 & 24685 & 9051 & 0.3033 \\
\hline 50550 & 24685 & 9051 & 0.1013 \\
\hline 50550 & 24685 & 9051 & 0.2023 \\
\hline 50550 & 24685 & 9051 & 0.2016 \\
\hline 50635 & 24685 & 9051 & 0.1007 \\
\hline 50635 & 24685 & 9051 & 0.1013 \\
\hline 50635 & 24685 & 9051 & 0.1011 \\
\hline 50635 & 24685 & 9051 & 0.4031 \\
\hline 50635 & 24685 & 9051 & 0.4027 \\
\hline 50635 & 45778 & 9016 & 0.1011 \\
\hline 50635 & 45778 & 9016 & 0.1007 \\
\hline 50635 & 45778 & 9016 & 0.1013 \\
\hline 50635 & 45778 & 9016 & 0.4027 \\
\hline 50635 & 45778 & 9016 & 0.4031 \\
\hline 50635 & 946 & 9019 & 0.4027 \\
\hline 50635 & 946 & 9019 & 0.4031 \\
\hline 50635 & 946 & 9019 & 0.1013 \\
\hline 50635 & 946 & 9019 & 0.1011 \\
\hline 50635 & 946 & 9019 & 0.1007 \\
\hline 51511 & 14592 & 9045 & 0.2021 \\
\hline 51511 & 14592 & 9045 & 0.2018 \\
\hline 51511 & 34167 & 9063 & 0.2021 \\
\hline 51511 & 34167 & 9063 & 0.2018 \\
\hline 51511 & 34167 & 9063 & 0.2014 \\
\hline 51511 & 61592 & 9042 & 0.2021 \\
\hline 51511 & 61592 & 9042 & 0.1010 \\
\hline 51511 & 61592 & 9042 & 0.2014 \\
\hline 53710 & 21114 & 9054 & 0.2109 \\
\hline 53710 & 21114 & 9054 & 0.1010 \\
\hline 53710 & 21114 & 9054 & 0.3028 \\
\hline 53710 & 50496 & 9018 & 0.1005 \\
\hline 53710 & 50496 & 9018 & 0.3028 \\
\hline 53710 & 50496 & 9018 & 0.1006 \\
\hline 53710 & 50496 & 9018 & 0.2109 \\
\hline 53710 & 54687 & 9053 & 0.3028 \\
\hline
\end{tabular}




\begin{tabular}{|c|c|c|c|}
\hline 53710 & 54687 & 9053 & 0.1010 \\
\hline 53710 & 54687 & 9053 & 0.2109 \\
\hline 54163 & 17987 & 9020 & 2.0205 \\
\hline 54163 & 39936 & 9009 & 0.1008 \\
\hline 54574 & 41614 & 9052 & 0.3021 \\
\hline 54574 & 41614 & 9052 & 2.0161 \\
\hline 54574 & 41614 & 9052 & 0.7064 \\
\hline 54574 & 4483 & 9011 & 0.1007 \\
\hline 55068 & 38600 & 9047 & 0.1007 \\
\hline 55068 & 38600 & 9047 & 0.2019 \\
\hline 55068 & 38600 & 9047 & 0.1011 \\
\hline 55068 & 38600 & 9047 & 0.1009 \\
\hline 55068 & 43642 & 9062 & 0.1007 \\
\hline 55068 & 43642 & 9062 & 0.2019 \\
\hline 55068 & 43642 & 9062 & 0.1009 \\
\hline 55068 & 7054 & 9005 & 0.1011 \\
\hline 55363 & 41167 & 9028 & 0.1013 \\
\hline 55363 & 41167 & 9028 & 0.1008 \\
\hline 55363 & 41167 & 9028 & 0.1005 \\
\hline 55363 & 41167 & 9028 & 0.2015 \\
\hline 55363 & 946 & 9019 & 0.2015 \\
\hline 55363 & 946 & 9019 & 0.1013 \\
\hline 55511 & 1335 & 9007 & 1.8150 \\
\hline 55511 & 1335 & 9007 & 0.1009 \\
\hline 55511 & 1335 & 9007 & 0.3029 \\
\hline 55511 & 1335 & 9007 & 0.1009 \\
\hline 55511 & 16538 & 9017 & 1.8150 \\
\hline 55511 & 16538 & 9017 & 0.1009 \\
\hline 55511 & 16538 & 9017 & 0.1009 \\
\hline 55511 & 16538 & 9017 & 0.3029 \\
\hline 55511 & 41503 & 9021 & 0.1009 \\
\hline 55511 & 41503 & 9021 & 0.1009 \\
\hline 55511 & 41503 & 9021 & 0.3029 \\
\hline 55511 & 41503 & 9021 & 1.8150 \\
\hline 56102 & 17099 & 9043 & 0.1005 \\
\hline 56102 & 17099 & 9043 & 0.1013 \\
\hline 56102 & 38345 & 9001 & 0.1005 \\
\hline 56102 & 38345 & 9001 & 0.1013 \\
\hline
\end{tabular}




\begin{tabular}{|c|c|c|c|}
\hline 56102 & 59713 & 9030 & 0.7055 \\
\hline 56968 & 1335 & 9007 & 0.1010 \\
\hline 56968 & 1335 & 9007 & 0.1013 \\
\hline 56968 & 46389 & 9046 & 0.1006 \\
\hline 56968 & 46389 & 9046 & 0.1010 \\
\hline 56968 & 46389 & 9046 & 0.1013 \\
\hline 56968 & 46389 & 9046 & 0.2015 \\
\hline 56968 & 46389 & 9046 & 0.1013 \\
\hline 57545 & 59713 & 9030 & 0.9081 \\
\hline 57545 & 59713 & 9030 & 0.1006 \\
\hline 57840 & 43642 & 9062 & 0.2030 \\
\hline 57840 & 43642 & 9062 & 0.2021 \\
\hline 57840 & 43642 & 9062 & 0.1006 \\
\hline 57840 & 49013 & 9058 & 0.2030 \\
\hline 57840 & 49013 & 9058 & 0.2021 \\
\hline 57840 & 64119 & 9004 & 0.1006 \\
\hline 57840 & 64119 & 9004 & 0.2030 \\
\hline 57840 & 64119 & 9004 & 0.2021 \\
\hline 59375 & 16538 & 9017 & 0.1009 \\
\hline 59375 & 16538 & 9017 & 0.1008 \\
\hline 59375 & 21114 & 9054 & 0.1009 \\
\hline 59375 & 21114 & 9054 & 0.1008 \\
\hline 59375 & 21114 & 9054 & 0.1012 \\
\hline 59375 & 46351 & 9031 & 0.1008 \\
\hline 59375 & 46351 & 9031 & 0.1009 \\
\hline 60480 & 38718 & 9003 & 1.8182 \\
\hline 60480 & 38718 & 9003 & 0.2014 \\
\hline 60480 & 41614 & 9052 & 0.4032 \\
\hline 60480 & 41614 & 9052 & 0.1013 \\
\hline 60480 & 41614 & 9052 & 0.4026 \\
\hline 60480 & 45778 & 9016 & 0.2014 \\
\hline 60571 & 28854 & 9013 & 0.7069 \\
\hline 60571 & 28854 & 9013 & 0.1013 \\
\hline 60571 & 28854 & 9013 & 0.1011 \\
\hline 60571 & 4405 & 9061 & 0.1011 \\
\hline 60571 & 4405 & 9061 & 0.7069 \\
\hline 60571 & 50288 & 9040 & 0.7069 \\
\hline 60571 & 50288 & 9040 & 0.1011 \\
\hline
\end{tabular}




\begin{tabular}{|c|c|c|c|}
\hline 61654 & 17099 & 9043 & 0.1007 \\
\hline 61654 & 17099 & 9043 & 0.1013 \\
\hline 61654 & 17099 & 9043 & 0.3026 \\
\hline 61654 & 17099 & 9043 & 0.1010 \\
\hline 61654 & 41503 & 9021 & 0.1013 \\
\hline 61654 & 41503 & 9021 & 0.3026 \\
\hline 61654 & 41503 & 9021 & 0.1010 \\
\hline 61654 & 41503 & 9021 & 0.1007 \\
\hline 61654 & 6736 & 9044 & 0.1007 \\
\hline 61654 & 6736 & 9044 & 0.3026 \\
\hline 61654 & 6736 & 9044 & 0.1013 \\
\hline 61935 & 34167 & 9063 & 0.1013 \\
\hline 61935 & 34167 & 9063 & 0.1008 \\
\hline 61935 & 34167 & 9063 & 0.1011 \\
\hline 61935 & 34305 & 9033 & 0.1011 \\
\hline 61935 & 34305 & 9033 & 0.1013 \\
\hline 61935 & 6736 & 9044 & 0.1011 \\
\hline 61935 & 6736 & 9044 & 0.1008 \\
\hline 61935 & 6736 & 9044 & 0.1013 \\
\hline 63318 & 14592 & 9045 & 0.1011 \\
\hline 63318 & 14592 & 9045 & 0.1012 \\
\hline 63318 & 14592 & 9045 & 0.1004 \\
\hline 63318 & 14592 & 9045 & 0.1006 \\
\hline 63318 & 14592 & 9045 & 0.3030 \\
\hline 63318 & 47516 & 9002 & 0.3030 \\
\hline 63318 & 47516 & 9002 & 0.1004 \\
\hline 6332 & 12347 & 9014 & 0.3024 \\
\hline 6332 & 12347 & 9014 & 0.2018 \\
\hline 6332 & 12347 & 9014 & 0.1010 \\
\hline 6332 & 12347 & 9014 & 0.3030 \\
\hline 8233 & 11940 & 9015 & 0.3025 \\
\hline 8233 & 11940 & 9015 & 4.9455 \\
\hline 8233 & 11940 & 9015 & 0.2021 \\
\hline 8233 & 11940 & 9015 & 0.2018 \\
\hline
\end{tabular}

